\title{
WestVirginiaUniversity
}

THE RESEARCH REPOSITORY @ WVU

Graduate Theses, Dissertations, and Problem Reports

2010

\section{Phospholipid enhanced separation with capillary electrophoresis}

Ruijuan Luo

West Virginia University

Follow this and additional works at: https://researchrepository.wvu.edu/etd

\section{Recommended Citation}

Luo, Ruijuan, "Phospholipid enhanced separation with capillary electrophoresis" (2010). Graduate Theses, Dissertations, and Problem Reports. 4628.

https://researchrepository.wvu.edu/etd/4628

This Dissertation is protected by copyright and/or related rights. It has been brought to you by the The Research Repository @ WVU with permission from the rights-holder(s). You are free to use this Dissertation in any way that is permitted by the copyright and related rights legislation that applies to your use. For other uses you must obtain permission from the rights-holder(s) directly, unless additional rights are indicated by a Creative Commons license in the record and/ or on the work itself. This Dissertation has been accepted for inclusion in WVU Graduate Theses, Dissertations, and Problem Reports collection by an authorized administrator of The Research Repository @ WVU.

For more information, please contact researchrepository@mail.wvu.edu. 


\title{
PHOSPHOLIPID ENHANCED SEPARATION WITH CAPILLARY ELECTROPHORESIS
}

\author{
by \\ Ruijuan Luo \\ Dissertation Submitted to the Eberly College of Arts and Sciences \\ at West Virginia University \\ in Partial Fulfillment of The Requirements \\ for the Degree of \\ Doctor of Philosophy \\ in \\ Chemistry
}

\author{
Approved by \\ Lisa A. Holland, Ph.D., Committee chair \\ Harry O. Finklea, Ph.D. \\ Fred King, Ph.D. \\ Xiaodong Michael Shi, Ph.D. \\ Jorge A. Flores, Ph.D.
}

\author{
Chemistry Department \\ Morgantown, West Virginia \\ 2010
}

Key words: Phospholipids, oligosaccharides, DNA, capillary electrophoresis

Copyright (C) 2010 Ruijuan Luo 


\section{ABSTRACT \\ Phospholipid Enhanced Separation with Capillary Electrophoresis \\ Ruijuan Luo}

Phospholipids were used as an additive in capillary electrophoresis to enhance the separation of glycans derived from $\alpha 1$-acid glycoprotein, fetuin, and ribonuclease B. The properties of phospholipid preparations were dependent upon composition, hydration, and temperature. Separation performance was evaluated as a function of these variables. A preparation of 1,2-dimyristoyl-sn-glycero-3-phosphocholine (DMPC) and 1,2-dihexanoyl-snglycero-3-phosphocholine (DHPC), with $[\mathrm{DMPC}] /[\mathrm{DHPC}]=2.5$, in $10 \% \mathrm{lipid} /$ aqueous buffer at $25{ }^{\circ} \mathrm{C}$ provided the best separation efficiency at an electric field strength of 400 $\mathrm{V} / \mathrm{cm}$. Resolution was enhanced with the additive as well.

Phospholipids were also investigated as an additive for capillary electrophoresis separation of DNA molecules. Lipid preparations with $[\mathrm{DMPC}] /[\mathrm{DHPC}]=2.5$ at hydrations of $6 \%, 8 \%, 10 \%, 12 \%$ and $15 \%$ were used to separate a 50 base pair double stranded DNA ladder. The experiments demonstrated that separation of DNA in phospholipids occurred via a sieving process. Electric field as low as $100 \mathrm{~V} / \mathrm{cm}$ was suitable for the separation of DNA fragments larger than 450 base pairs. For double stranded DNA smaller than 450 base pairs the electric field strength ranging from 100 to $300 \mathrm{~V} / \mathrm{cm}$ is suitable. The best resolution of small DNA fragments was obtained at high phospholipid concentration, while dilute phospholipid solution was favorable for the separation of larger fragments. The pore size of phospholipid was estimated by plotting the absolute mobility into a standard equation obtained from a Ferguson plot. The calculated value was approximately $29 \mathrm{~nm}$, which is 
close to the pore size $(27 \mathrm{~nm})$ of the polymer solution employed for the separation of a similar DNA ladder. 


\section{DEDICATION}

To my parents (Yufeng Huo and Huanyi Luo), my husband (Yang Hu) and my son (Xiaomiao $\mathrm{Hu}$ ), I dedicate this dissertation with love. 


\section{ACKNOWLEDGEMENT}

First, I would like to acknowledge my academic advisor Dr Holland for her instruction since I joined in her group. Without her guidance and support, I would not finish my program on time.

I would also like to acknowledge my committee members, Dr Lisa A. Holland, Dr Harry O. Finklea, Dr Fred King, Dr Xiaodong Michael Shi, and Dr Jorge A. Flores for their support, instruction, and time.

I would like to thank faculties who taught me classes and staff who helped me for everything that I asked and not asked.

I would like to thank graduate program of Eberly college of arts and science for accepting me as a graduate student and offering me opportunities to present my work to other people.

I appreciate Dissertation scholarship organization and persons who donate money for this scholarship for offering me this scholarship.

I would like to acknowledge my lab mates, Dr Theron John Pappas, Dr Liliya Bykoya, Christian White, Ted Langan, Stephanie Archer-Hartmann and Xingwei Wu for helping me use the instrumental, all assistance and time we spent together. 


\section{Table of Contents}

Abstract ----------------------------------------------------------------------------------------------- ii

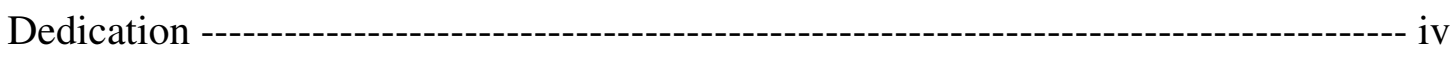

Acknowledgements ---------------------------------------------------------------------------------- V

Table of Contents ---------------------------------------------------------------------------------- vi

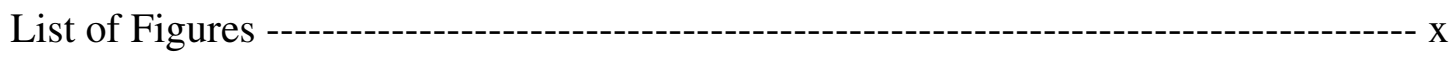

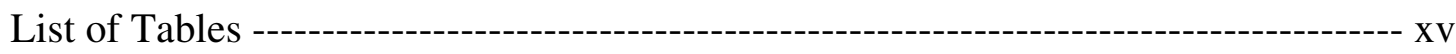

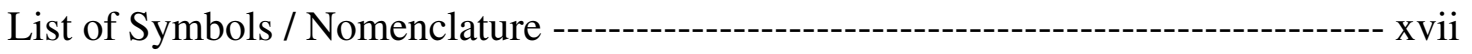

Chapter 1: Capillary Electrophoresis (CE) Fundamentals ---------------------------------- 1

1.1.0 Basics of Capillary Electrophoresis: Instrumentation and Fundamentals -------- 2

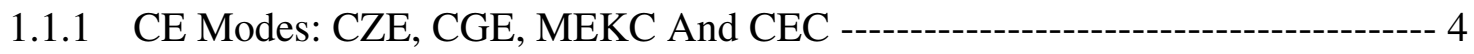

1.1.2 Detection ------------------------------------------------------------------------------------ 7

1.1.3 Sample Injection -----------------------------------------------------------------------------7

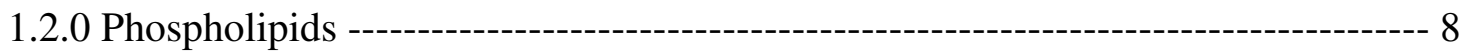

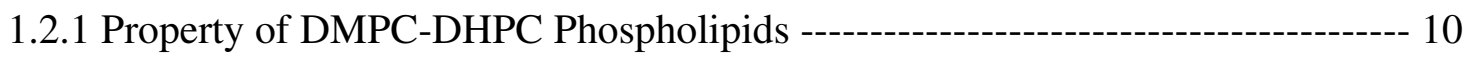

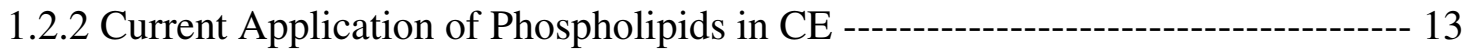

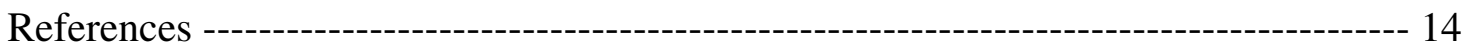

Chapter 2: Separation of Oligosaccharide by Capillary Electrophoresis Using

Phospholipid Additives --------------------------------------------------------------------------- 20

2.1.0 Introduction ----------------------------------------------------------------------------------- 21

2.1.1 Basics of Carbohydrate Structure ------------------------------------------------------- 21

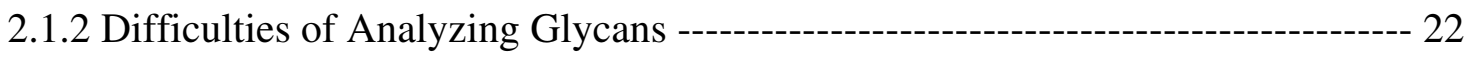

2.1.3 Biological Roles of Glycans ------------------------------------------------------------ 27 
2.1.4 Background of Glycan Analysis --------------------------------------------------------- 27

2.1.5 Chemical Labeling of Carbohydrates in CE Separation ----------------------------- 29

2.1.6 Separation of Oligosaccharides with Phospholipid Additives ----------------------- 31

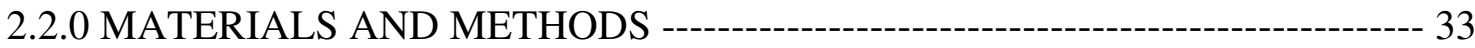

2.2.1 Chemicals ------------------------------------------------------------------------------------- 33

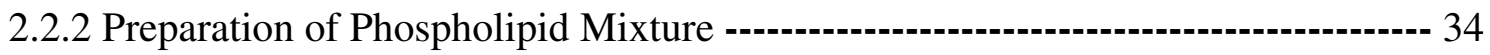

2.2.3 Sample Preparation and Derivatization ---------------------------------------------------35

2.2.4 Capillary Electrophoresis --------------------------------------------------------------------- 36

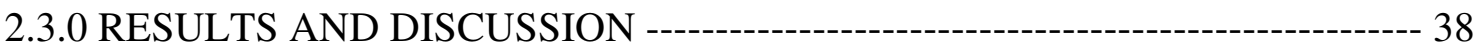

2.3.1 Preliminary Study with Linear Oligosaccharides ------------------------------------ 38

2.3.1.1 10 cm Effective Separation ------------------------------------------------------------ 38

2.3.1.2 Improvement of Separation Performance by Using $30 \mathrm{~cm}$ Effective Separation-

2.3.2 Separation of Complex Carbohydrates with Phospholipids -------------------------- 42

2.3.3 Enhancement of CE Separations of Glycans with Phospholipid Additives ------- 45

2.3.4 Sample Introduction for CE Separations That Incorporate Phospholipids -------- 52

2.3.5 Factors Relevant to Evaluate Separation Performance of Phospholipid

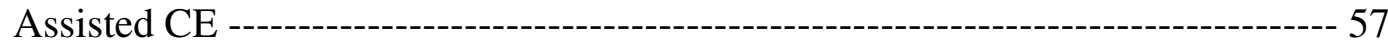

2.3.6 Effect of q Value on Separation Performance----------------------------------------------59

2.3.7 Effect of Hydration $(q=2.5)$ on Separation Performance -----------------------------59

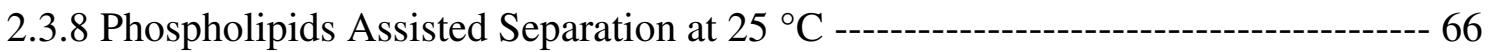

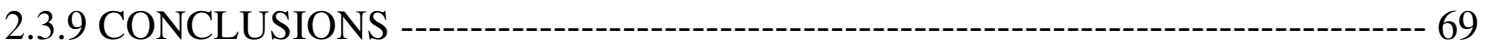

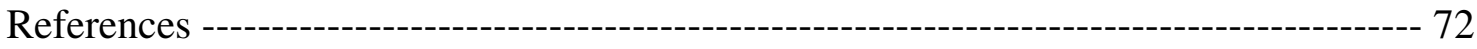


Chapter 3: DNA Separation Using Phospholipids as a New Matrix on Capillary

Electrophoresis ------------------------------------------------------------------------------------- 84

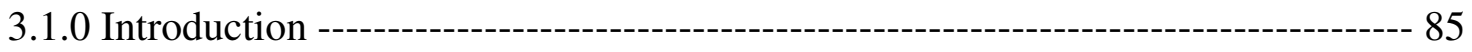

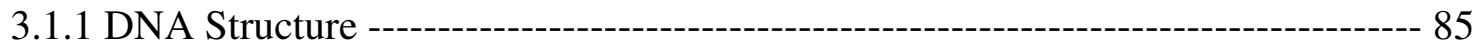

3.1.2 Slab Gel Electrophoresis on Separation of Nucleic Acids --------------------------- 89

3.1.3 DNA Separation with Capillary Electrophoresis --------------------------------------- 91

3.1.4 Polymers Used for DNA Separation by CE -------------------------------------------- 92

3.1.5 Other Materials or Methods Used for DNA Separation ----------------------------- 94

3.1.6 Phospholipid Mediated DNA Separation ------------------------------------------------- 95

3.2.0 Theory and Mechanisms for DNA Separation in CE --------------------------------- 96

3.2.1 Ogston Sieving ------------------------------------------------------------------------ 96

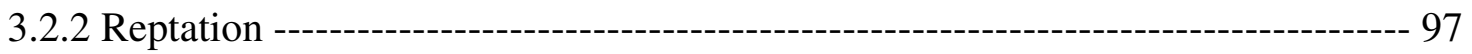

3.2.3 Other Observation with Microscope for DNA Separation -------------------------- 98

3.3.0 Materials and Methods ---------------------------------------------------------------------- 98

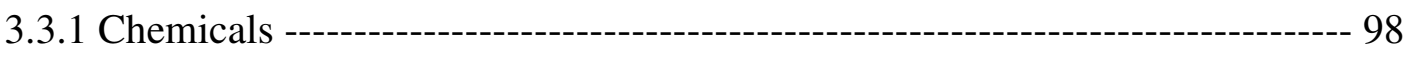

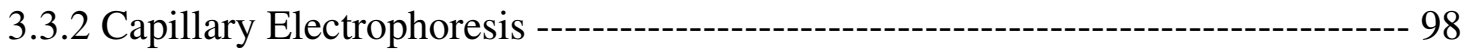

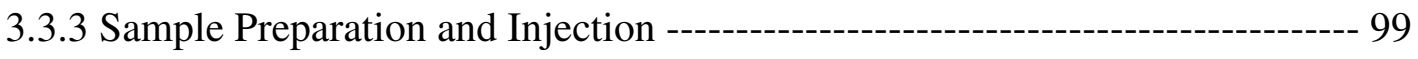

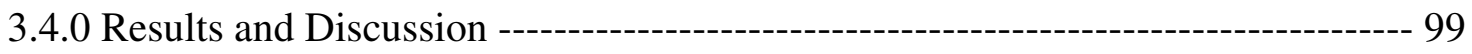

3.4.1 Effect of Lipid Hydration on DNA Separation ---------------------------------- 100

3.4.2 Effect Of Temperature On DNA Separation ------------------------------------ 107

3.4.3 Effect Of Electrical Field On DNA Separation ---------------------------------- 113

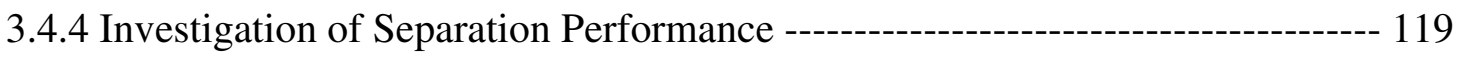

3.4.5. Discussion of Separation Mechanism ----------------------------------------------- 123 
3.5.0 Conclusion --------------------------------------------------------------------------------------- 126

References ------------------------------------------------------------------------------------------- 128

Chapter 4 Summary and Future Direction ------------------------------------------------- 139

4.1.0 Summary of Carbohydrate and DNA Separation in Chapter 2 and 3-1 --------- 140

4.2.0 Future Direction ---------------------------------------------------------------------------- 140

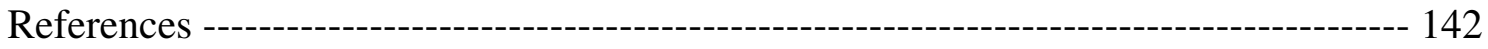

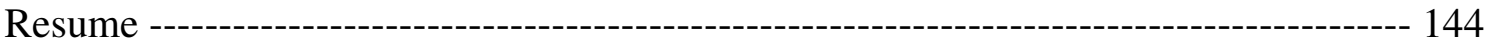




\section{LIST OF FIGURES}

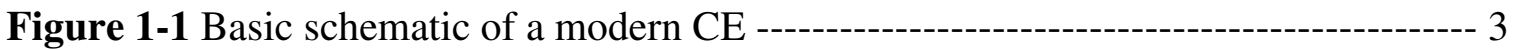

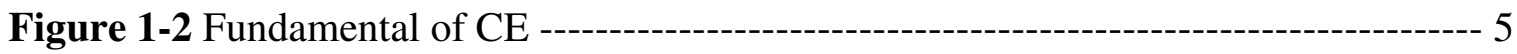

Figure1-3 Structure of DMPC and DHPC ------------------------------------------------- 9

Figure1-4 Schematic of bicelle (A), ribbon-like micelle (B), interconnected ribbons(C). and (D) cross-section for ideal bicelle adapted from the references [36] and [39]--------- 11

Figure 2-1 Haworth projection of common monosacharides found in $\mathrm{N}$-glycans derived from glycoproteins. Note: each sugar could exist as either $\alpha$ - or $\beta$-configuration ---------------- 23

Figure 2-2 Linkage between glycan residue and polypeptides in a typical glycoprotein - 24

Figure2-3 Typical structures of N-glycans. A is complex type, B is high mannose type and $\mathrm{C}$ is hybrid type which combines structure characters of A and B. Adapted from the references [4-5] --- 25

Figure 2-4 Potential disaccharides composed with two $\alpha$-D-glucose units (A) and (B) a peptide made of two asparagine amino acids ------------------------------------------ 26

Figure 2-5 Derivatizations of carbohydrates with APTS. Adapted from reference [63] -- 32

Figure 2-6 Schematic of capillary cartridge in the commercial CE instrumental from Beckman coulter. The picture was adapted from the manufacture web site ------------------ 37

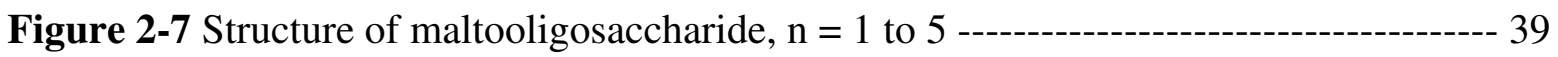

Figure 2-8 Demonstration of the advantage of using phospholipid additives to separate asialo-glycan isomers AII and FII derived from fetuin. The linkage to the galactose monomer labeled with the asterisk (*) is 1, 3 in FII and 1, 4 in AII. The separation in trace A was accomplished in a bare fused silica capillary under normal polarity. The separation in trace B was obtained using phospholipid additive and a phospholipid coated capillary under 
identical conditions, except that it was performed with reversed polarity at $-16 \mathrm{kV}$. The total length of capillary was $40 \mathrm{~cm}$ and effective separation length was $30 \mathrm{~cm}$. The injection condition was described in the related paragraph. Reprinted with permission from reference [64]. Copyright 2010 American Chemical Society 46

Figure 2-9 Electrophoregrams of $\mathrm{N}$-glycans separation derived from AGP. The injection was adjusted to make sure that similar amount of sample was introduced into capillary. The separation condition was same to that described in Figure 2-8 48

Figure 2-10 Electrophoregrams of glycans derived from RNase B. Separation conditions were identical to that in Figure 2-8, trace B. The structures of RNase B glycans were included. The symbols for glycan monomers were defined in Figure 2-8 ------------------- 51 Figure 2-11 Illustration of the need for the injection procedure used in trace B to evaluate separation performance of phospholipid media. As shown in the schematic to the left, the sample (solid gray) was introduced into the capillary with an electrokinetic injection directly into phospholipid (wavy lines) or with aqueous buffer plugs (dotted) introduced before and after the sample injection. The separation was achieved at $25{ }^{\circ} \mathrm{C}$, with $\mathrm{q} 2.5-10 \%$ phospholipid at $-16 \mathrm{kV}, 50 \mu \mathrm{m}$ inner diameter, effective capillary length $30.2 \mathrm{~cm}$, total capillary length $40 \mathrm{~cm}$. Reprinted with permission from reference [64]. Copyright 2010 American Chemical Society 53

Figure 2-12 The injection method described in figure 2-10 (B) was used here except that (A) was from pressure injection of $0.7 \mathrm{kPa}(0.1 \mathrm{psi}) 2 \mathrm{sec}$ and (B) was from EK injection (5 kV 6 sec) 56

Figure 2-13 Displays the change in migration time for AII derived from AGP $(n=3)$ with increasing temperature for a $5 \% \mathrm{q}=2.5(\quad), \mathrm{q}=2 \%(\%)$, and $\mathrm{q}=1.5($ () preparation. The separation conditions are identical to that described for Figure 2 trace B. For clarity, error bars in 
are included only for q 2.0, which had the least reproducible migration times of the three preparations. Reprinted with permission from reference [64]. Copyright 2010 American Chemical Society 60

Figure 2-14 Change in migration time for AII derived from AGP with increasing temperature for a $q 2.5-5 \%(\mathrm{x}), 10 \%(\Delta)$, and $15 \%(\bullet)$ preparation. The separation conditions were identical to that described for Figure 2, trace B. Reprinted with permission from reference [64]. Copyright 2010 American Chemical Society 61

Figure 2-15 Displays the process of peak identification for asialofetuin using standards. The electrophoregrams in traces A and B were spiked with a standard solution of AII (trace A) or AI (trace B). The electrophoregram of asialofetuin in trace $\mathrm{C}$ was obtained prior to adding standard. The separations were achieved with $q 2.510 \%$ phospholipid at $16 \mathrm{kV}$, reversed polarity, at $25^{\circ} \mathrm{C}$. Samples were injected for 6 seconds at $5 \mathrm{kV}$ at $25^{\circ} \mathrm{C}$ 64

Figure 2-16 shows standard identification of AGP. The sample was spiked with standard AII (A), AI (B), and without addition of standard (C). The spiked peak was labeled with an asterisk. The separation and injection were identical to that reported in Figure 2-15 ------- 65

Figure 2-17 Separation efficiency (AI) as a function of electric field -------------------------- 67

Figure 3-1 Chemical structure of bases and sugar in DNA ------------------------------------- 86

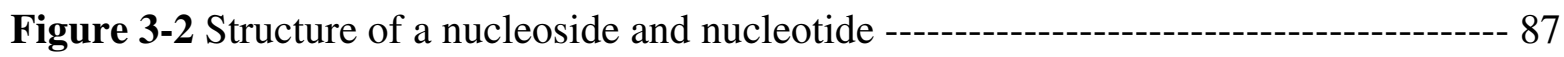

Figure 3-3 Complementary strands of DNA. Adapted from Voet, Donald and Voet, Judith G.

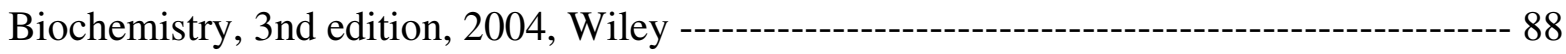

Figure 3-4 Chemical structure of most common polymers used in separation of DNA ---- 93

Figure 3-5 Electrophoregrams of 50 bp dsDNA separation with different lipid hydrations at $25{ }^{\circ} \mathrm{C}$ in the $100 \mathrm{~V} / \mathrm{cm}$ electric field 101 
Figure 3-6 Electrophoregrams of $50 \mathrm{bp}$ dsDNA separation with different lipid hydrations at $25{ }^{\circ} \mathrm{C}$ in the $300 \mathrm{~V} / \mathrm{cm}$ electric field 102

Figure 3-7 Electrophoregrams of $50 \mathrm{bp}$ dsDNA separation with different lipid hydrations at $33{ }^{\circ} \mathrm{C}$ in the $100 \mathrm{~V} / \mathrm{cm}$ electric field 103

Figure 3-8 Electrophoregrams of $50 \mathrm{bp}$ dsDNA separation with different lipid hydrations at $33{ }^{\circ} \mathrm{C}$ in the $300 \mathrm{~V} / \mathrm{cm}$ electric field 104

Figure 3-9. A Effect of hydration on migration time of 50bp dsDNA. The separation was carried out in the $100 \mathrm{~V} / \mathrm{cm}$ electric field at $25^{\circ} \mathrm{C}$ 105

Figure 3-9. B Effect of hydration on migration time of $50 \mathrm{bp}$ dsDNA. The separation was carried out in the $100 \mathrm{~V} / \mathrm{cm}$ electric field at $33{ }^{\circ} \mathrm{C}$ 106

Figure 3-10. A Effect of temperature on migration time of DNA fragments. The capillary was coated with a phospholipid and then filled with phospholipid additives for separation. The effective capillary length was $30.2 \mathrm{~cm}$ and total length was $40 \mathrm{~cm}$ 109

Figure 3-10. B Effect of temperature on migration time of DNA fragments. The capillary was coated with a phospholipid and then filled with phospholipid additives for separation. The effective capillary length was $30.2 \mathrm{~cm}$ and total length was $40 \mathrm{~cm}$ 110

Figure 3-11 Separation of $50 \mathrm{bp}$ dsDNA with q2.5 - 6\% lipids in the $100 \mathrm{~V} / \mathrm{cm}$ electric field at different temperatures 111

Figure 3-12 Separation of 50 bp dsDNA with q 2.5 - $6 \%$ lipids in the $250 \mathrm{~V} / \mathrm{cm}$ electric field at different temperatures 112

Figure 3-13 Effect of electric field on separation of 50 bp dsDNA 114

Figure 3-14 Separation of 50 bp dsDNA with q 2.5 - $6 \%$ lipids in the capillary under different electric fields. The separation temperature was $25^{\circ} \mathrm{C}$ 115 
Figure 3-15 Separation of 50 bp dsDNA with q 2.5 - $6 \%$ lipids in the capillary under different electric fields. The separation temperature was $33{ }^{\circ} \mathrm{C}$ 116

Figure 3-16 Separation of 50 bp dsDNA with q 2.5 - 15\% lipids in the capillary under different electric fields. The separation temperature was $25^{\circ} \mathrm{C}$ 117

Figure 3-17 Separation of 50 bp dsDNA with q 2.5 - $15 \%$ lipids in the capillary under different electric fields. The separation temperature was $33{ }^{\circ} \mathrm{C}$ 118

Figure 3-18 Comparison of resolutions (Rs) of 50bp and 100 bp pair. The separation was carried out with q 2.5 lipids at the $100 \mathrm{~V} / \mathrm{cm}$ electric field 120

Figure 3-19 Comparison of resolutions (Rs) of 916 and 1350 bp. The separation was carried out with q 2.5 lipids at the $100 \mathrm{~V} / \mathrm{cm}$ electric field

Figure 3-20 A typical Ferguson plot of $50 \mathrm{bp}$ dsDNA. The separation was carried out at 33 ${ }^{\circ} \mathrm{C}$ in the $100 \mathrm{~V} / \mathrm{cm}$ electric field. $\mathrm{N}$ is the number of base pair 124

Figure 3-21 Reptation plot for separation of $50 \mathrm{bp}$ dsDNA. The separation was carried out at $33{ }^{\circ} \mathrm{C}$ in the $100 \mathrm{~V} / \mathrm{cm}$ electric field. $\mathrm{N}$ is the number of base pair 125 


\section{LIST OF TABLES}

Table 2-1 Separation of glycans from AGP, fetuin and Rnase B glycoproeins with HPCE reported in the literatures

Table 2-2 Resolution of maltoses in 5\% lipids. The total length of capillary was $40 \mathrm{~cm}$ and effective separation length was $10 \mathrm{~cm}$. The injection condition was $3.5 \mathrm{kPa}(0.5 \mathrm{psi}) 5$ sec. The separation voltage was $16 \mathrm{kV}$

Table 2-3 Resolution of maltoses with different lipids. The total length of capillary was $40 \mathrm{~cm}$ and effective separation length was $30 \mathrm{~cm}$. The injection condition was $5 \mathrm{kV} 6 \mathrm{sec}$ with both front and behind mops plugs (explained in next section). The separation voltage was $-16 \mathrm{kV}$

Table 2-4 Compare resolution from 30cm effective separation $\left(\mathrm{R}_{30}\right)$ to $10 \mathrm{~cm}\left(\mathrm{R}_{10}\right)$ effective separation. The values included in this table were calculated by taking resolution values $\left(\mathrm{R}_{30}\right)$ in table 2-3 divided by the values $\left(\mathrm{R}_{10}\right)$ in Table $2-2$

Table 2-5 Theoretical plates (N) and resolution (R) for glycans derived from both fetiun and AGP. Reprinted with permission from reference [64]. Copyright 2010 American Chemical Society

Table 2-6 Efficiency (AI), $5 \%$ Hydration. Reprinted with permission from reference [64]. Copyright 2010 American Chemical Society 50

Table 2-7 Efficiency (AI), $q=2.5$. Reprinted with permission from reference [64]. Copyright 2010 American Chemical Society 50

Table 2-8 Comparison of pressure injection and EK injection performance. Two MOPS plugs described in figure 2-10. B was applied in both injection methods. The separation was obtained with q 2.5 - $10 \%$ lipids at $29{ }^{\circ} \mathrm{C}$ in the $400 \mathrm{~V} / \mathrm{cm}$ electric field 55 
Table 2-9 Injection variances contributing to band broadening. The calculation was based on triplet runs 58

Table 2-10 Reprinted with permission from reference [64]. Copyright 2010 American Chemical Society 62

Table 2-11 Resolution (FII/AII), $\mathrm{q}=2.5, n=3$. Reprinted with permission from reference [64]. Copyright 2010 American Chemical Society 63

Table 2-12 Efficiency (AII), q = 2.5. Reprinted with permission from reference [64]. Copyright 2010 American Chemical Society 63

Table 2-13 Slope log mobility vs. log MW. Reprinted with permission from reference [64]. Copyright 2010 American Chemical Society 70

Table 3-1 Molecular weight of possible base pairs in DNA 90

Table 3-2 Viscosity of polymer solutions commonly used to separate DNA in CE. Adapted from references [15] and [35] 94

Table 3-3 Comparison of resolutions (Rs) for two pairs of fragments. A was for $50 \mathrm{bp}$ and $100 \mathrm{bp}$; B is for 916 and $1350 \mathrm{bp}$. The separation was carried out with q 2.5 lipids at the 100 V/cm electric field. All data were based on triplet runs 122 


\section{LIST OF SYMBOLS / NOMENCLATURE}

1. AGP - $\alpha 1$ acid glycoprotein;

2. ANTS - aminonaphthalene- 1,3,6-trisulfonic acid;

3. bp - base pair;

4. C - concentration of each analyte;

5. CBQCA - 3-(4-carboxybenzoyl)-2-quinolinecarboxaldehyde;

6. CE - capillary electrophoresis;

7. CEC - capillary electrochromatography;

8. CGE - capillary gel electrophoresis;

9. CIEF - capillary isoelectric focusing;

10. CZE - capillary zone electrophoresis;

11. D - capillary internal diameter;

12. DHPC - 1, 2-dihexanoyl-sn-glycero-3-phosphocholine;

13. DMPC - 1, 2-dimyristoyl-sn-glycero-3-phosphocholine;

14. $\Delta \mathrm{P}$ - applied pressure;

15. DNA - Deoxyribonucleic acid;

16. E - electric field strength;

17. $E_{\text {inj }}$ - electric field strength during sample injection;

18. $\mathrm{E}_{\mathrm{sep}}$ - electric field strength during separation;

19. EK - electrokinetically;

20. EOF - electroosmotic flow;

21. HPLC - high performance liquid chromatography;

22. L - total length of the capillary (chapter 1); 
23. L - contour length of DNA (chapter 3);

24. 1- length of sample plug;

25. MEKC - micelle electrokinetic chromatography;

26. MS - mass spectrometry;

27. $\eta$ - viscosity;

28. NMR - nuclear magnetic resonance spectroscopy;

29. $p$ - persistence length of DNA;

30. Q - amount of analytes injected;

31. $q$ - charge of ions;

32. q - mole ratio of long-chain to short-chain lipid;

33. $\mathrm{r}$ - capillary radius;

34. $r$ - hydrodynamic radius;

35. RNA - Ribonucleic acid;

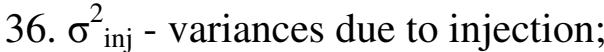

37. $\sigma_{\text {diff }}^{2}$ - variances due to diffusion;

38. t, tinj - time of injection;

39. $\mu, \mu_{\mathrm{ep}}$ - electrophoretic mobility;

40. $\mu_{\mathrm{eo}}-$ electroosmotic flow;

41. UV - ultraviolet visible;

42. $V_{t}$ - volume of injected sample;

43. $v_{\mathrm{eph}}$ - electrophoretic velocity of solute 
Chapter 1: Capillary Electrophoresis Fundamentals 


\subsubsection{Basics of capillary electrophoresis: instrumentation and fundamentals}

In this section, fundamentals of capillary electrophoresis (CE) that are required to understand chapter 2 and 3 are summarized. CE is a high performance analytical technique. CE was first reported in the 1980s [1-2]. Fundamental investigations and different applications have been extensively reported in following decades [3-4]. CE already is one of the major separation techniques applied widely in biomolecular-related research labs [5].

The typical CE instrument consists of three central pieces: a capillary, a power supply, and a detector. Figure1-1 is the basic schematic of modern CE instrument. The capillary is a hollow column made of fused silica. The internal diameter usually ranges from 20 to $100 \mu \mathrm{m}$. While performing an experiment, the two ends of the capillary are immersed in aqueous buffer. The inside of capillary is filled with buffer by using pressure, vacuum, or a pump. Two electrodes are also immersed in the buffer reservoirs, and connected to a high voltage power supply. One of reservoirs is switched between buffer and sample for separation and analyte injections, respectively.

When the electric field is turned on, analyte moves through the capillary. Cations migrate toward the cathode while anions migrate toward the anode. The mobility of ions depends on their charge - to - size ratio. A mathematical expression for the electrophoretic mobility is

$$
\mu=q /(6 \pi \eta r)
$$

where $q$ is the net charge of an analyte, $\eta$ is the viscosity of buffer, and $r$ is the ionic radius of an analyte $[1,6]$. Analytes will travel through the capillary with different velocities if the charge- to-size ratios are different. Therefore, separation among these solutes occurs. 


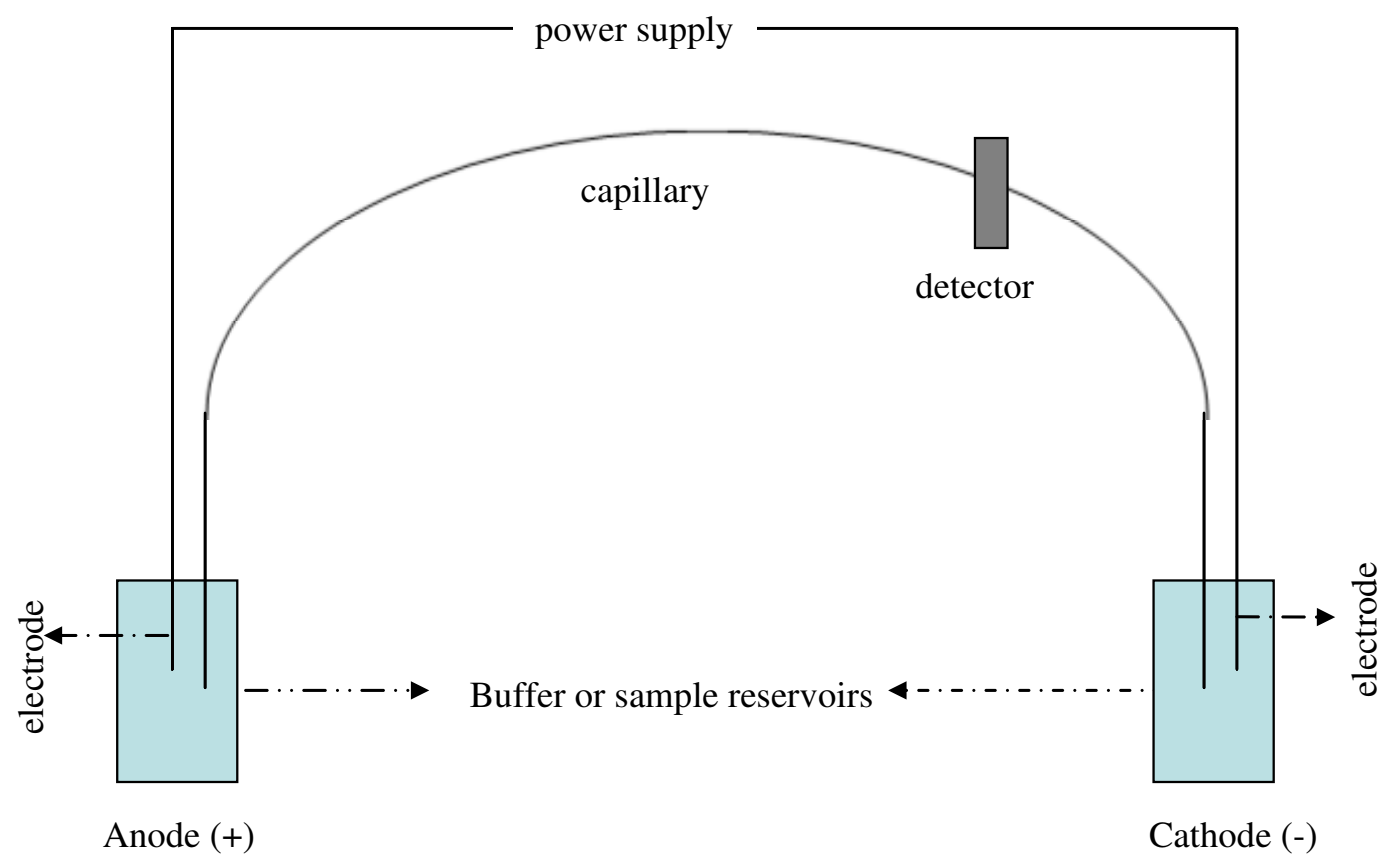

Figure 1-1 Basic schematic of a modern CE. 
In addition to electrophoretic movement of analytes, another process, electroosmotic flow (EOF) often exists during electrophoretic separations. Fused silica, the most common material for making a capillary, contains silanol groups at the surface. The silanol groups on the capillary surface are fully deprotonated when the $\mathrm{pH}$ is greater than 4 , which results in a negatively charged internal surface [1]. When the capillary is exposed to an electric field, solvent ions form a double layer on the inner surface of the capillary. This double layer attracts positively charged ions that move in the direction of cathode. This creates a bulk fluid flow called electroosmotic flow (EOF). EOF is like a pump driving analytes toward cathode regardless of charge [1]. Because of EOF, the apparent mobility of an analyte is the sum of both electrophoretic mobility and EOF as shown in figure 1-2. EOF is not always desirable in CE separation. In some cases, the separation is carried out in the absence of EOF.

\subsubsection{CE modes: CZE, CGE, MEKC, and CEC}

$\mathrm{CE}$ is a variable technique, embodying different separation modes. The common modes include capillary zone electrophoresis (CZE) [1], micelle electrokinetic chromatography (MEKC) [7], capillary gel electrophoresis (CGE) [8-10], capillary electrochromatography (CEC) and capillary isoelectric focusing (CIEF) [11-16]. Among these modes, only CZE, MEKC, and CGE will be described further since they are discussed in chapters two and three.

With CZE, the buffer is a homogeneous electrolyte, and separation is a consequence of the mobility difference of each analyte. CZE has been used to separate of a large variety of molecules from small ions such as metal ions to large biomolecules such as proteins. In MEKC, 


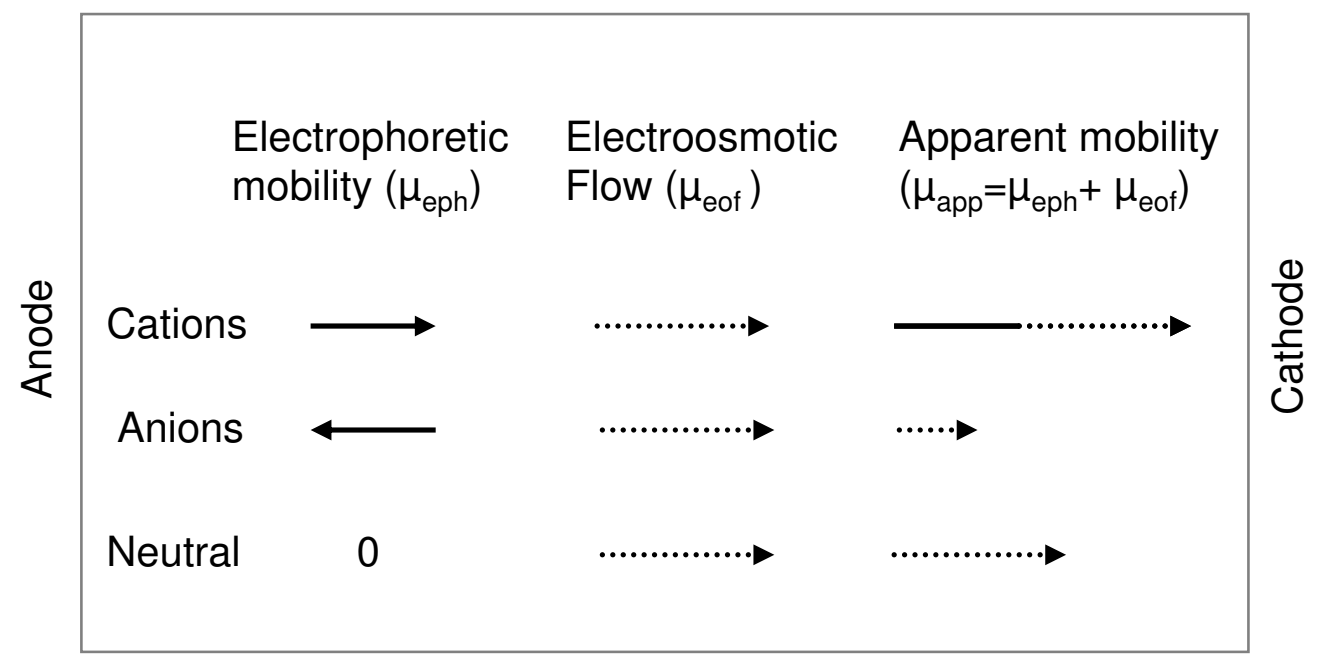

Figure 1-2 Fundamental of CE 
surfactants are added into buffer and form micelle aggregates above a critical concentration. Micelles have a hydrophobic core and hydrophilic outer layer. Hydrophobic groups of solutes partition into the hydrophobic core of the micelle and move at the speed of the micelle. Solute will incorporate into the micelle for different amount of time as a result of hydrophobicities. Therefore, the separation is based on both the electrophoretic mobility of the analyte and the distribution in the micelle. Neutral solutes with different hydrophobicity can be separated using MEKC. In addition to micelles, other molecules such as cyclodextrins and crown ethers are also used as additives. In CGE, gels or polymer solutions are employed as the separation medium. These materials are porous, and a size-dependant separation occurs when the analytes travel through the porous materials. The mechanism of size-dependant separation will be discussed further in the chapter three.

\subsubsection{Detection}

Two standard detectors used in capillary electrophoresis instruments are ultraviolet (UV)-visible absorption and fluorescence. For both detectors, the signal is collected when analyte passes through a detection window in the capillary. The benefits to using detectors directly coupled to the separation capillary are that they are simple to implement, there is no post-column band broadening, and there is no analyte dilution before detection. The DNA molecules analyzed in chapter three are monitored using UV-visible absorption because they absorb UV light well at approximately $250 \mathrm{~nm}$. For analytes lacking a chromophore or fluorophore, chemical labeling of analytes can be performed to improve optical detection. Carbohydrates studied in chapter two are chemically labeled to enable fluorescence detection. 


\subsubsection{Sample injection}

In CE, sample is introduced into the capillary either hydrodynamically or electrokinetically (EK). Hydrodynamic injection of a sample is accomplished by the application of pressure, vacuum or siphoning. The volume of injected sample can be calculated by Poiseuille equation

$$
\mathrm{V}_{\mathrm{t}}=\left(\Delta \mathrm{PD}^{4} \pi\right) /(128 \eta \mathrm{L})
$$

where $\Delta \mathrm{P}$ is the value of applied pressure, $\mathrm{D}$ is the capillary internal diameter, $\eta$ is the viscosity of buffer and L is the total length of the capillary [17-18].

EK injection is a process that electric field drives analytes to migrate into capillary from sample container. The amount of analytes injected is determined by following equation

$$
\mathrm{Q}=\left(\mu_{\mathrm{ep}}+\mu_{\mathrm{eo}}\right) \pi \mathrm{r}^{2} \mathrm{EC} \mathrm{t}
$$

where $\mathrm{r}$ is the capillary radius, $\mathrm{E}$ is the electric field, $\mathrm{C}$ is the concentration of each analyte and $t$ is the time of injection [18].

The capillaries used in CE have very small dimensions. For example, the total volume of a $40 \mathrm{~cm}$ long capillary with $50 \mathrm{um}$ ID is only $785 \mathrm{~nL}$. The sample plug must be small for an efficient separation. In chapter two, the injection method is optimized to improve separation performance.

\subsubsection{Capillary surface modification}

As mentioned earlier, the internal surface of capillary is often negatively charged. A consequence is that large biomolecules especially proteins might be adsorbed onto the surface electrostatically [19-21]. This type of adsorption is nonspecific, reduces separation efficiency, and leads to irreproducible separations. Adsorption of solutes can be eliminated by surface modification of capillary. 
There are two categories of methods used to passivate capillary surface: permanent (chemical) coating and dynamic (physical) coating. Permanent coating involves chemical reactions on the surface of capillary [22-23]. Covalent bonds are formed between coating material and silanol groups on capillary surface. In dynamic coating, physical interaction such as electrostatic interaction holds the coating material to the capillary surface. Dynamic coating is more convenient to perform than permanent coating [24-25]. The process of permanent coating often requires several steps of chemical reactions and the use of toxic organic solvents, while dynamic coating is performed by just flushing capillary with coating materials dissolved in an appropriate solvent [26]. Another benefit of using dynamic coating is that the modified surface can be refreshed after each run by flushing capillary with coating material, but this cannot be done with a permanent coated capillary. While capillary surface is passivated, EOF is also suppressed or modified [27]. In the following two chapters, dynamic coating is employed to suppress EOF mainly.

\subsubsection{Phospholipids.}

Phospholipids are amphiphilic molecules, possessing hydrophilic and hydrophobic regions. When phospholipids are dissolved in aqueous solution, the hydrophilic part of the molecule tends to associate with water while the hydrophobic part excludes water. As a result, phospholipids self-assemble and form unique morphology. In this section, structural properties and the application of binary mixtures of the phospholipids 1, 2-dimyristoyl-snglycero-3-phosphocholine (DMPC), and 1, 2-dihexanoyl-sn-glycero-3-phosphocholine (DHPC) are discussed. The structures of these two lipids are shown in figure 1-3. These phospholipids were explored as a separation medium in CE for carbohydrate 


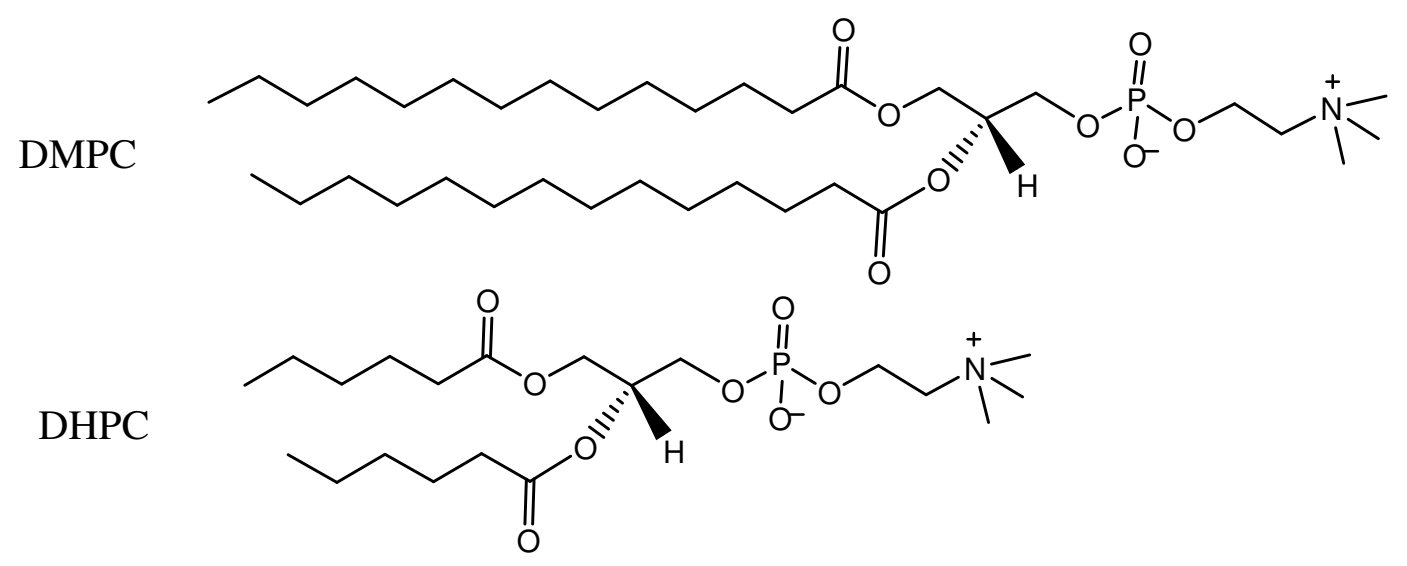

Figure1-3 Structure of DMPC and DHPC. 
analysis (chapter 2) and DNA separation (chapter 3). Phospholipid properties must be reviewed in order to understand how they benefit carbohydrate and DNA separation.

\subsubsection{Property of DMPC-DHPC Phospholipids}

Since Luzzati and Husson first demonstrated phospholipid self-assembly of lamellarstructures in aqueous solution [28], phospholipid morphology and corresponding physicochemical properties have been investigated. Three morphologies of interest for the use of DMPC and DHPC as additives for capillary electrophoresis are bilayered micelles (bicelles), ribbons-like micelles, and transient interconnected bilayer networks.

Bicelles are disk-like structures with a circular center made of DMPC and a rim occupied by DHPC. Figure 1-4 depicts the structure of bicelle. The thickness of the "disk" is dictated by a DMPC bilayer $(\sim 55 \AA)$. The disk radius is a function of DMPC temperature, hydration (total weight of lipid/ volume of water), and q, the mole ratio of long-chain to short-chain lipid $(q=[\mathrm{DMPC}] /[\mathrm{DHPC}])$. Theoretical calculations predict that the radius of the bilayered region for $1.5<\mathrm{q}<2.5$ ranges from 10-11 $\mathrm{nm}$ [29]. In a separate study dynamic light scattering measurements estimated the hydrodynamic radius of discs from $\mathrm{q}=$ $1.5-5 \%$ preparations ranging from $\sim 7 \mathrm{~nm}$ at $25{ }^{\circ} \mathrm{C}$ to $\sim 9 \mathrm{~nm}$ at $30{ }^{\circ} \mathrm{C}$ [30]. For $5 \%$ phospholipid preparations of $\mathrm{q} \leq 2$, even as temperature is increased up to $35^{\circ} \mathrm{C}$, the $\mathrm{q}=2$ 5\% preparation is described as bicelle [31-33]. Additionally, below the gel-to-fluid transition temperature of $24^{\circ} \mathrm{C}$, the morphology is isotropic and the viscosity of these preparations is close to water.

When the DMPC content is increased to $\mathrm{q} \geq 2.5$ and temperature is above the gel-tofluid transition point, the viscosity increases significantly. The change in viscosity is attributed to a transition from bicelles to ribbon-like micelle [33]. A q $=2.5-3 \%$ lipid 
A

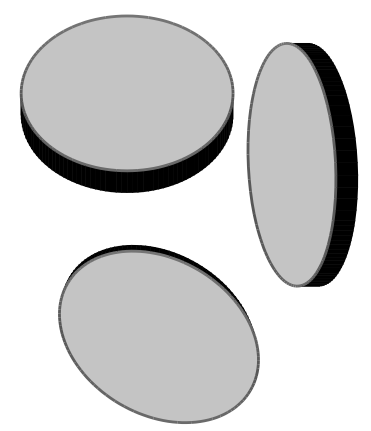

D
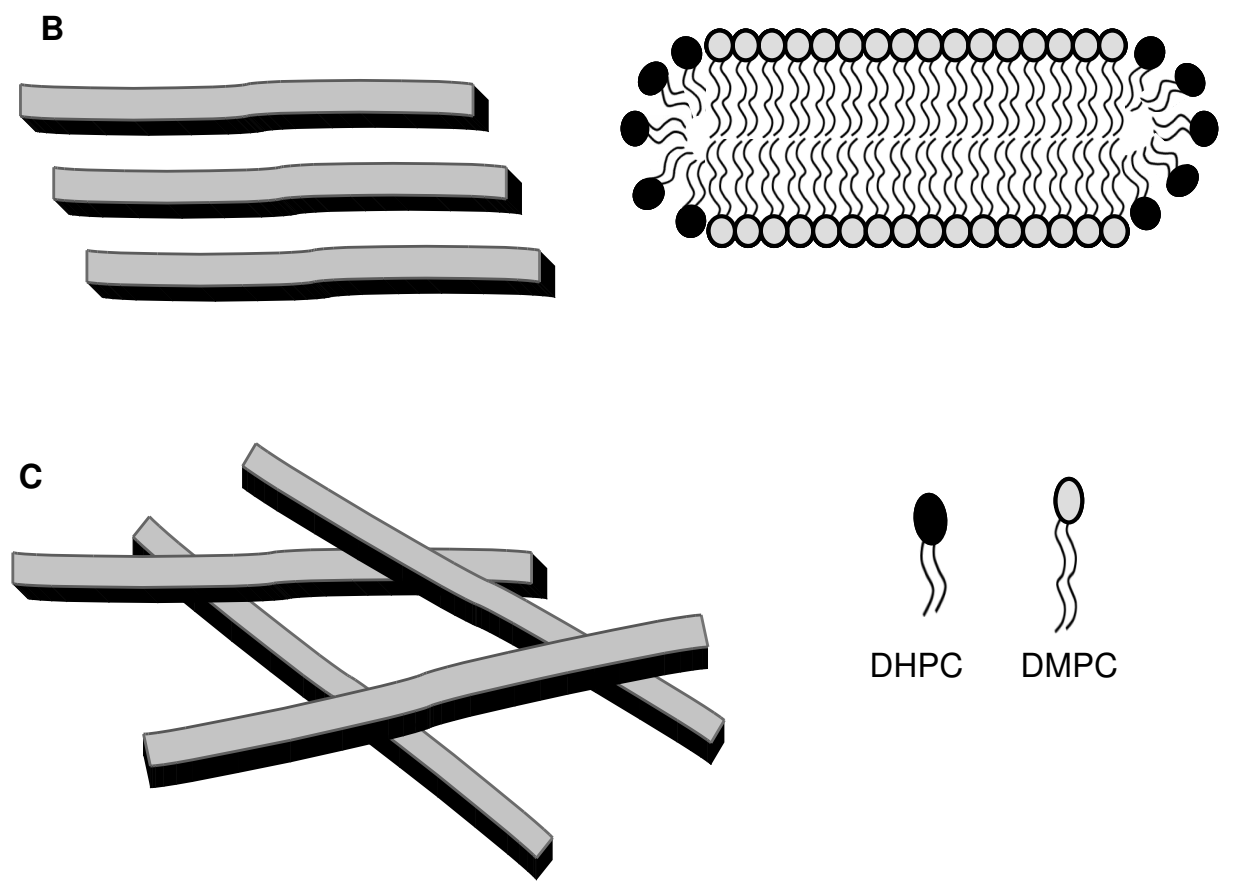

Figure1-4 Schematic of bicelle (A), ribbon-like micelle (B), interconnected ribbons $(\mathrm{C})$ and (D) cross-section for ideal bicelle adapted from references [36] and [39]. 
solution has ribbon-like micelles as long as several micrometer as dominant aggregates with small population of disks at $25^{\circ} \mathrm{C}$ [34]. A q $=3.2$ sample reportedly forms a chiral nematic phase described as helical structure with a 10 micrometer twist [32]. If the structure adopts a bilayer, the dimensions of the ribbons are $5 \mathrm{~nm}$ thick and $430 \mathrm{~nm}$ long for a $\mathrm{q}=3.2-25 \%$ preparation, and entanglement of these aggregates is presumed to produce a substantial increase in viscosity [32].

As temperature is further increased the ribbon-like morphology reportedly becomes more interconnected, increasing in turbidity and also decreasing in viscosity [30]. Prosser et al described the potential for DHPC lined holes in extended bilayer network [35]. Fluorescence resonance energy transfer measurements of $q=3.0-15 \%$ preparations doped with pyrene-labeled phospholipids support the premise of temperature induced reorganization of DHPC from disks into interconnected DMPC bilayers disrupted by DHPC pores, involving pore swelling that changes both the number of pores and the pore diameters [36]. A dynamic structure of high pore density subject to substantial membrane fusion and division has been suggested for $q=2.5-6$, such that the structure yields pore diameter $416 \AA$, with pore spacing of $170 \AA$ [33].

Spontaneous formation of supramolecular assemblies of DMPC-DHPC preparations causes the viscosity to vary with temperature in a non-Newtonian fashion. At temperatures below the gel phase transition the viscosity of an aqueous phospholipid preparation is similar to that of water. Above the gel phase transition, the viscosity increases dramatically to a maximum at $\sim 29^{\circ} \mathrm{C}$ [37]. The change in viscosity of aqueous phospholipid preparations is also a function of $\mathrm{q}$ - value as well as the percent hydration. The viscosity can increase with temperature as much as 370-fold for $\mathrm{q}=2.5-10 \%$ phospholipid preparations and even more 
so when comparing preparations of different $q$ values [37]. As an additive in capillary separations, an exciting consequence is that phospholipids, unlike highly viscous linear polymer additives, are easily introduced into the capillary at low temperature.

\subsubsection{Current application of phospholipids in CE}

Phospholipids are amenable to the study of membrane affinity of pharmaceuticals [38], and to separate drug molecules and antimicrobial peptides according to lipophilicity [39]. Because of biological compatibility, phospholipids have been decorated with proteins and immobilized either on a polydimethylsiloxane chip or a fused silica capillary to select affinity targets [40-41], and have been employed for surface passivation in capillary electrophoresis to reduce the nonspecific absorption of analytes onto the capillary wall, or to modify electroosmotic flow [38, 42-47]. Phospholipids have been employed as a pseudo-stationary phase for the study of liposome interaction [48], and as a phospholipid-nanoparticle pseudostationary phase for efficient and selective separation of proteins [49]. 


\section{References}

1. Jorgenson, J.W. and Lukacs, K.D., Zone electrophoresis in open-tubular glass capillaries. Analytical Chemistry, 1981. 53(8): p. 1298-1302.

2. Jorgenson, J.W. and Lukacs, K.D., Capillary zone electrophoresis. Science, 1983. 222(4621): p. 266-272.

3. $\quad$ Beale, S.C., Capillary electrophoresis. Analytical Chemistry, 1998. 70(12): p. 279300.

4. Huck, C.W., Stecher, G., Bakry, R., and Bonn, G.K., Recent progress in highperformance capillary bioseparations. Electrophoresis, 2003. 24(22-23): p. 39773997.

5. Kostal, V., Katzenmeyer, J., and Arriaga, E.A., Capillary electrophoresis in bioanalysis. Analytical Chemistry, 2008. 80(12): p. 4533-4550.

6. Landers, J.P., Handbook of capillary electrophoresis. 1994: CRC press, INC.

7. Terabe, S., Otsuka, K., Ichikawa, K., Tsuchiya, A., and Ando, T., Electrokinetic separations with micellar solutions and open-tubular capillaries. Analytical Chemistry, 1984. 56(1): p. 111-113.

8. Cohen, A.S., Najarian, D.R., Paulus, A., Guttman, A., Smith, J.A., and Karger, B.L., Rapid separation and purification of oligonucleotides by high-performance capillary gel electrophoresis. Proceedings of the National Academy of Sciences of the United States of America, 1988. 85(24): p. 9660-9663.

9. Liu, J., Dolnik, V., Hsieh, Y.Z., and Novotny, M., Experimental evaluation of the separation efficiency in capillary electrophoresis using open tubular and gel-filled columns. Analytical Chemistry, 1992. 64(13): p. 1328-1336. 
10. Grossman, P.D. and Soane, D.S., Capillary electrophoresis of DNA in entangled polymer solutions. Journal of Chromatography A, 1991. 559(1-2): p. 257-266.

11. Boughtflower, R., Underwood, T., and Paterson, C., Capillary electrochromatography - some important considerations in the preparation of packed capillaries and the choice of mobile phase buffers. Chromatographia, 1995. 40(5): p. 329-335.

12. Kitagawa, S. and Tsuda, T., Effects of ph and organic solvent on chromatographic behavior in capillary electrochromatography. Journal of Microcolumn Separations, 1994. 6(2): p. 91-96.

13. Thormann, W., Tsai, A., Michaud, J.-P., Mosher, R.A., and Bier, M., Capillary isoelectric focusing : Effects of capillary geometry, voltage gradient and addition of linear polymer. Journal of Chromatography A, 1987. 389: p. 75-86.

14. Tsuda, T., Nomura, K., and Nakagawa, G., Open-tubular microcapillary liquid chromatography with electro-osmosis flow using a uv detector. Journal of Chromatography A, 1982. 248(2): p. 241-247.

15. Chen, S.-M. and Wiktorowicz, J.E., Isoelectric focusing by free solutioncapillary electrophoresis. Analytical Biochemistry, 1992. 206(1): p. 84-90.

16. Choudhary, G. and Horváth, C., Dynamics of capillary electrochromatography experimental study on the electrosmotic flow and conductance in open and packed capillaries. Journal of Chromatography A, 1997. 781(1-2): p. 161-183.

17. Lamb, H., Hydrodynamics. 1932: Dover: New York. 
18. Rose, D.J. and Jorgenson, J.W., Characterization and automation of sample introduction methods for capillary zone electrophoresis. Analytical Chemistry, 1988. 60(7): p. 642-648.

19. Lucy, C.A., MacDonald, A.M., and Gulcev, M.D., Non-covalent capillary coatings for protein separations in capillary electrophoresis. Journal of Chromatography A, 2008. 1184(1-2): p. 81-105.

20. Norde, W. and Haynes, C.A., Proteins at interfaces ii: Fundamentals and applications. 1995: American Chemical Society,Washington, DC.

21. Stutz, H., Protein attachment onto silica surfaces - a survey of molecular fundamentals, resulting effects and novel preventive strategies in ce. Electrophoresis, 2009. 30(12): p. 2032-2061.

22. Smith, J.T. and Rassi, Z.E., Capillary zone electrophoresis of biological substances with fused silica capillaries having zero or constant electroosmotic flow. Electrophoresis, 1993. 14(1): p. 396-406.

23. Millot, M.-C. and Vidal-Madjar, C., Overview of the surface modification techniques for the capillary electrophoresis of proteins. Advances in chromatography. 2000. 40: p. $427-466$.

24. Kamande, M.W., Kapnissi, C.P., Zhu, X., Akbay, C., and Warner, I.M., Open-tubular capillary electrochromatography using a polymeric surfactant coating. Electrophoresis, 2003. 24(6): p. 945-951.

25. Belder, D. and Schomburg, G., Modification of silica surfaces for cze by adsorption of non-ionic hydrophilic polymers or use of radial electric fields. Journal of High Resolution Chromatography, 1992. 15(10): p. 686-693. 
26. Znaleziona, J., Petr, J., Knob, R., Maier, V., and Ševčík, J., Dynamic coating agents in ce. Chromatographia, 2008. 67(0): p. 5-12.

27. Hjerten, S. and From Journal of Chromatography (1985), 191-198.

28. Luzzati, V. and Husson, F., The structure of the liquid-crystalline phases of lipidwater systems. Journal of Cell Biology, 1962. 12(2): p. 207-219.

29. Vold, R.R. and Prosser, R.S., Magnetically oriented phospholipid bilayered micelles for structural studies of polypeptides: Does the ideal bicelle exist? Journal of Magnetic Resonance Series B, 1996. 113: p. 267-71.

30. van Dam, L., Karlsson, G., and Edwards, K., Direct observation and characterization of dmpc/dhpc aggregates under conditions relevant for biological solution nmr. Biochimica Et Biophysica Acta-Biomembranes, 2004. 1664(2): p. 241-256.

31. Harroun, T.A., Koslowsky, M., Nieh, M.-P., de_Lannoy, C.-F., Raghunathan, V.A., and Katsaras, J., Comprehensive examination of mesophases formed by dmpc and dhpc mixtures. Langmuir, 2005. 21: p. 5356-61.

32. Nieh, M.P., Raghunathan, V.A., Glinka, C.J., Harroun, T.A., Pabst, G., and Katsaras, J., Magnetically alignable phase of phospholipid "Bicelle" Mixtures is a chiral nematic made up of wormlike micelles. Langmuir, 2004. 20: p. 7893-7.

33. Triba, M.N., Devaux, P.F., and Warschawski, D.E., Effects of lipid chain length and unsaturation on bicelles stability. A phosphorus nmr study. Biophysical Journal, 2006. 91(4): p. 1357-1367.

34. van Dam, L., G. Karlsson, and K. Edwards, Direct observation and characterization of DMPC/DHPC aggregates under conditions relevant for biological solution NMR. Biochimica Et Biophysica Acta-Biomembranes, 2004. 1664(2): p. 241-256. 
35. Prosser, R.S., Hwang, J.S., and Vold, R.R., Magnetically aligned phospholipid bilayers with positive ordering: A new model membrane system. Biophysical Journal, 1998. 74: p. 2405-18.

36. Rowe, B.A. and Neal, S.L., Fluorescence probe study of bicelle structure as a function of temperature: Developing a practical bicelle structure model. Langmuir, 2003. 19: p. 2039-48.

37. Pappas, T.J. and Holland, L.A., Fluid steering in a microfluidic chip by means of thermally responsive phospholipids. Sensors and Actuators B-Chemical, 2008. 128(2): p. 427-434.

38. Holland, L.A. and Leigh, A.M., Bilayered phospholipid micelles and capillary electrophoresis: A new additive for electrokinetic chromatography. Electrophoresis, 2003. 24: p. 2935-2939.

39. Mills, J.O. and Holland, L.A., Membrane mediated capillary electrophoresis: Interaction of cationic peptides with bicelles. Electrophoresis, 2004. 25: p. 1237-42.

40. Ross, E.E., Mansfield, E., Huang, Y., and Aspinwall, C.A., In situ fabrication of three-dimensional chemical patterns in fused silica separation capillaries with polymerized phospholipids. J. Am. Chem. Soc., 2005. 127(48): p. 16756-16757.

41. Huang, B., Wu, H., Kim, S., Kobilka, B.K., and Zare, R.N., Phospholipid biotinylation of polydimethylsiloxane (pdms) for protein immobilization. Lab on a Chip, 2006. 6(3): p. 369-373.

42. Cunliffe, J.M., Baryla, N.E., and Lucy, C.A., Phospholipid bilayer coatings for the separation of proteins in capillary electrophoresis. Anal. Chem., 2002. 74: p. 776783. 
43. Wang, C. and Lucy, C.A., Oligomerized phospholipid bilayers as semipermanent coatings in capillary electrophoresis. Anal. Chem., 2005. 77: p. 2015-2021.

44. Wang, C. and Lucy, C.A., Mixed cationic/anionic surfactants for semipermanent wall coatings in capillary electrophoresis. Electrophoresis, 2004. 25: p. 825-832.

45. Yassine, M.M. and Lucy, C.A., Factors affecting the temporal stability of semipermanent bilayer coatings in capillary electrophoresis prepared using doublechained surfactants. Anal. Chem., 2004. 76: p. 2983-2990.

46. Baryla, N.E., Melanson, J.E., McDermott, M.T., and Lucy, C.A., Characterization of surfactant coatings in capillary electrophoresis by atomic force microscopy. Anal. Chem., 2001. 73: p. 4558-4565.

47. White, C.M., Luo, R., Archer-Hartmann, S.A., and Holland, L.A., Electrophoretic screening of ligands under suppressed electroosmotic flow with an inert phospholipid coating. Electrophoresis, 2007. 28(17): p. 3049-55.

48. Zhang, Y., Zhang, R., Hjertén, S., and Lundahl, P., Liposome capillary electrophoresis for analysis of interactions between lipid bilayers and solutes. Electrophoresis, 1995. 16(8): p. 1519-23.

49. Nilsson, C., Becker, K., Harwigsson, I., Bulow, L., Birnbaum, S., and Nilsson, S., Hydrophobic interaction capillary electrochromatography of protein mutants. Use of lipid-based liquid crystalline nanoparticles as pseudostationary phase. Analytical Chemistry, 2009. 81(1): p. 315-321. 
Chapter 2: Separation of Oligosaccharides by Capillary Electrophoresis Using Phospholipid Additives 


\subsubsection{Introduction}

\subsubsection{Basics of carbohydrate structure.}

Carbohydrates are one of the most abundant biological molecules in living systems. They exist in plants, bacteria, animals and human beings. These organic compounds are comprised of basic units known as monosaccharides. A carbohydrate molecule could be ranging from less than 200 Daltons up to millions of Daltons, depending on the number of monosaccharide units covalently linked together. Carbohydrates with more than two monosaccharide are classified into oligosaccharides and polysaccharides [1]. Oligosaccharides are often found in glycoproteins and lipids. In this research, oligosaccharides derived from glycoproteins are analyzed. These oligosaccharides play key roles in biological processes such as cell-cell recognition, cellmatrix recognition, and cell regulation [2-3].

As a part of a glycoprotein, oligosaccharides are covalently bound to polypeptides during posttranslational modification of the protein. Based on the conjugation between proteins and carbohydrates, oligosaccharides are separated into two major categories: $\mathrm{N}$ glycan and $\mathrm{O}$-glycan. $\mathrm{N}$-glycans are those linked to a protein through asparagine amino acid residue of the protein; O-glycans conjugate to a protein through a serine or threonine amino acid residue.

The structure details of glycans have been well documented earlier, especially by Novotny et al and Pierce et al [4-5]. A brief summary of these reviews is included here. The most common monosaccharides found in N-glycans are $\mathrm{N}$-acetylglucoseamine (GlcNAc), galactose (Gal), glucose (Glc), mannose (Man), fucose (Fuc), and Nacetylneuraminic acid (NeuAc). Their structures are shown in Figure 2-1. One of the 
GlcNAc units on the sugar is linked to asparagine residue of a protein via an amide bond (see Figure 2-2). Hence, they are called N-glycans. For O-glycans, in most cases, Nacetylgalactosamine is linked via an oxide bond to a serine or threonine residue of a protein. Glycans are complex structures because of variations in sequence and linkage between the individual monomers. N-glycans are less complex than O-glycans because they contain the core region shown in see Figure 2-3. However, the variation of antennae regions attached to the core of $\mathrm{N}$-glycans makes analysis of these oligosaccharides more problematic. These variations arise from sugar unit, $\alpha$ - or $\beta$-conformation, position of linkage and degree of branching. For instance, two identical monosaccharides can potentially give rise to 11 disaccharides, while two identical peptides can originate only one peptide (see Figure 2-4). These features make them structurally complex biomolecules. Any small difference in glycan structure could affect the related biological process.

\subsubsection{Difficulties of analyzing glycans.}

In addition to the complexity of glycan structure, some properties of glycoproteins also cause difficulties with glycan studies [6]. First, different types of protein are glycosylated to different extent, with the carbohydrate content varying from less than $1 \%$ to more than $90 \%$ by weight [7]. The carbohydrate abundance depends on protein size and the number of asparagine, serine and threonine residues available from the polypeptide backbone. The distance between each glycosylation site also determines the extent of glycosylation. The glysosylation sites are not always occupied by carbohydrates. 


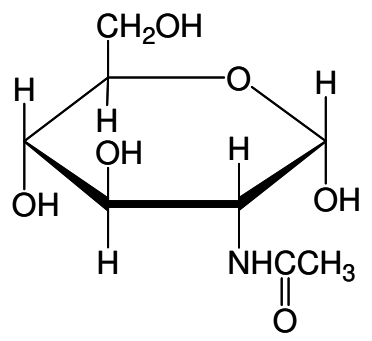

a-D-N-acetylglucosamine (GlcNAc)

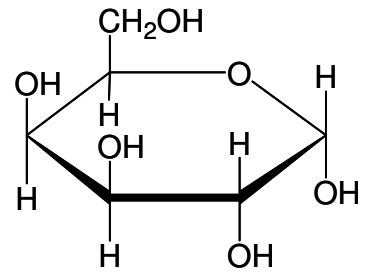

$$
\alpha-D-G a l a c t o s e(G a l)
$$
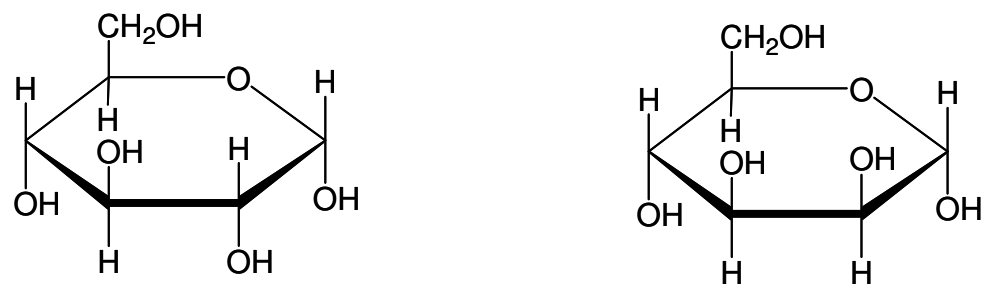

$\alpha-D-G l u c o s e(G l c)$

a-D-Mannose (Man)
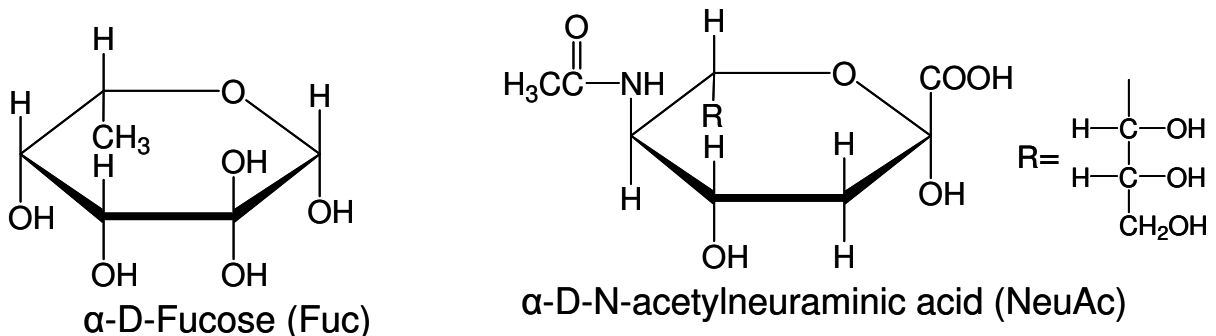

a-D-N-acetylneuraminic acid (NeuAc)

Figure 2-1 Haworth projection of common monosacharides found in N-glycans derived from glycoproteins. Note: each sugar could exist as either $\alpha$ - or $\beta$ configuration. 


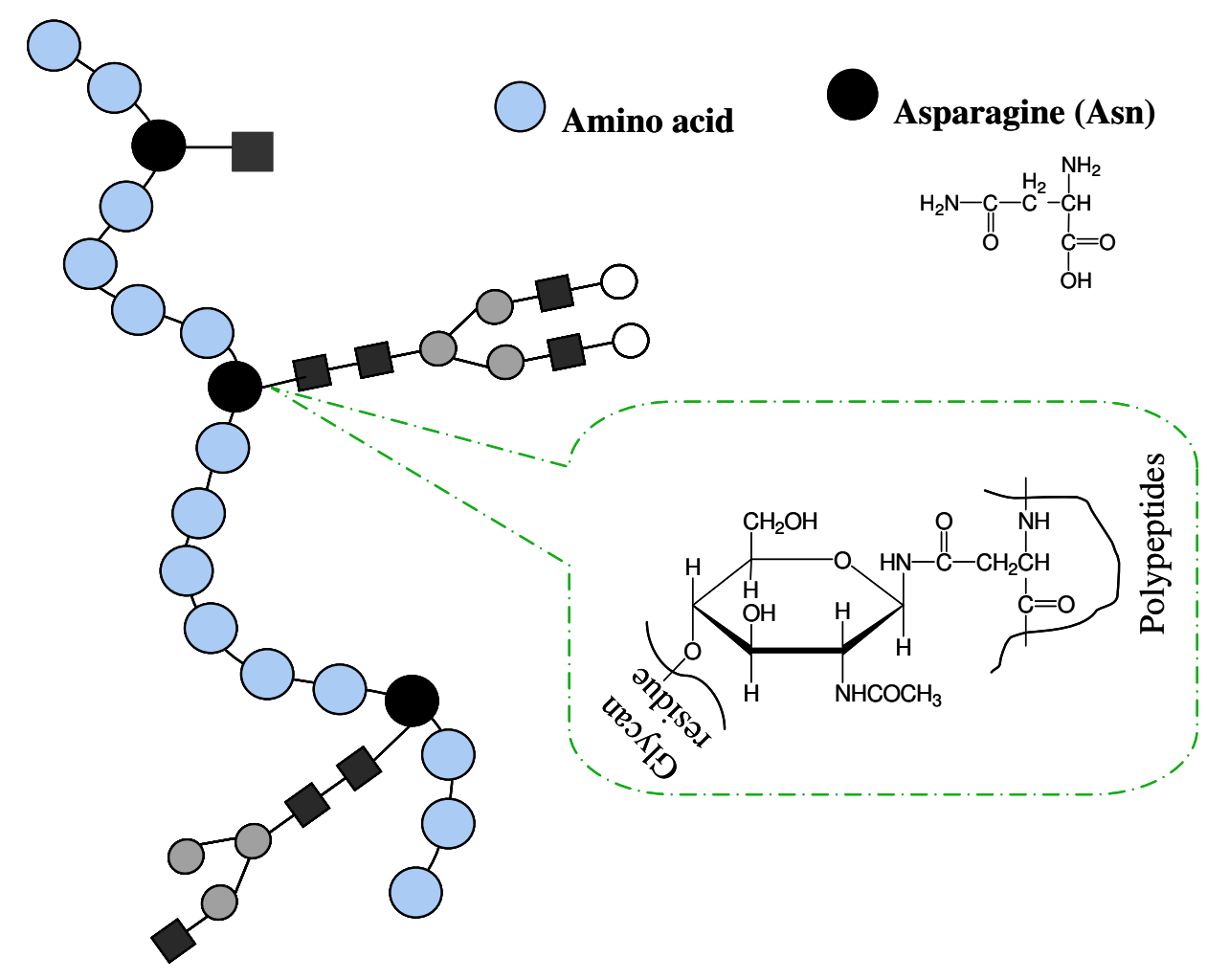

Figure 2-2 Linkage between glycan residue and polypeptides in a typical glycoprotein. 
A

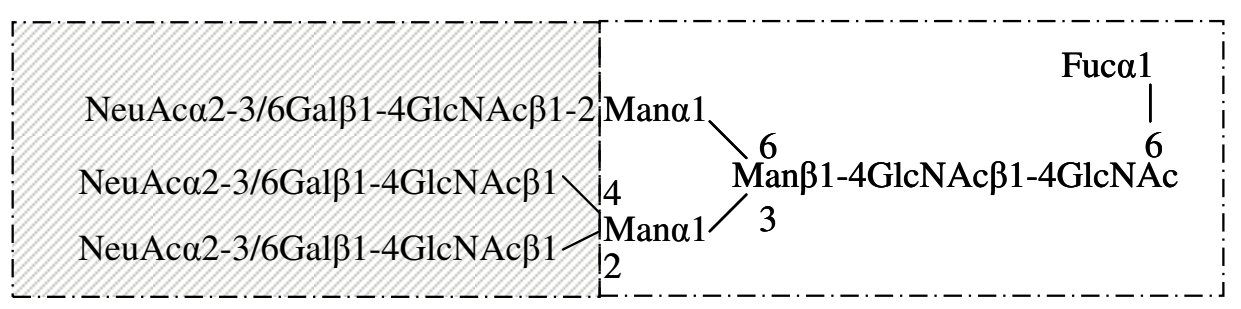

B

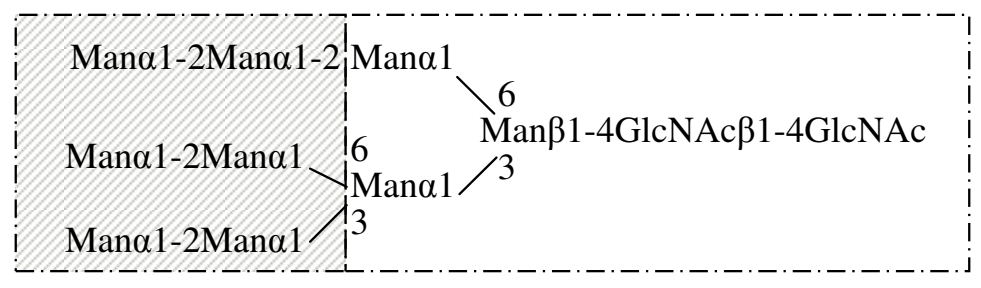

C

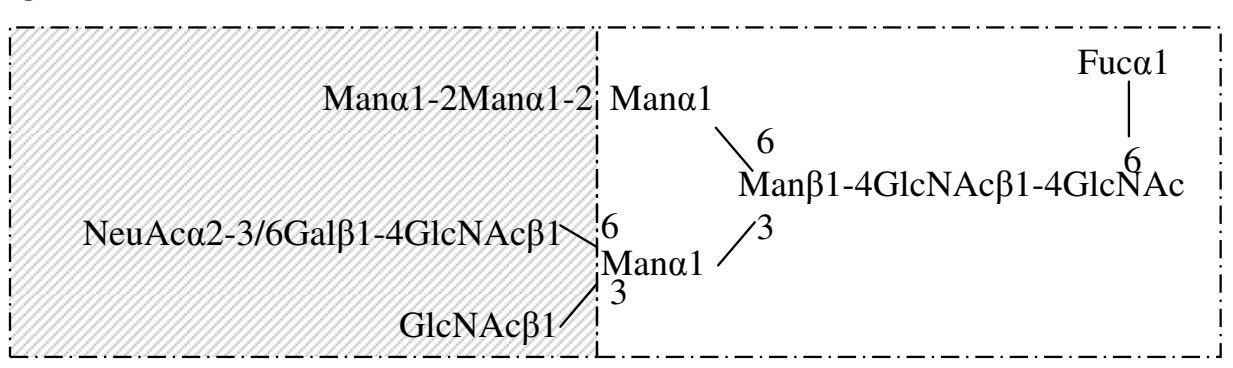

1.T. Antennal region

Figure2-3 Typical structures of N-glycans. A is complex type, B is high mannose type and $\mathrm{C}$ is hybrid type which combines structure characters of $\mathrm{A}$ and $\mathrm{B}$. Adapted from references [4-5]. 

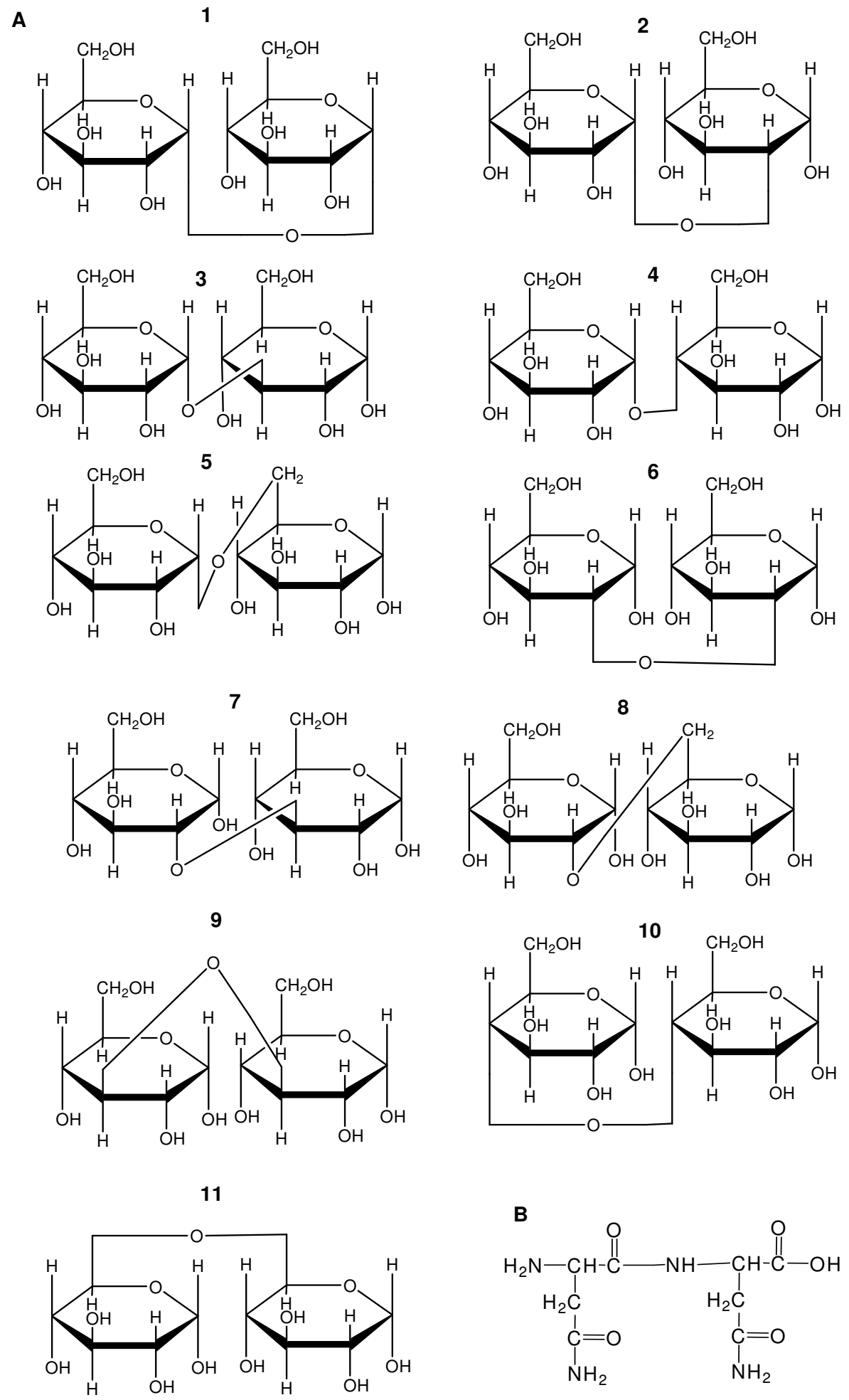

Figure 2-4 Potential disaccharides composed with two $\alpha$-D-glucose units (A) and (B) a peptide made of two asparagine amino acids. 
Any glycoprotein is actually a mixture of variants having same polypeptide backbone, but fairly variable substitution of glycans. These variants are known as glycoforms. This property of a glycoprotein is called microheterogeneity, which increases the complexity of glycan analysis.

\subsubsection{Biological roles of glycans.}

As already discussed, most proteins are glycoproteins, including enzymes, transport proteins, receptors, hormones, and structural proteins [8]. Carbohydrates play several important biological roles through the entire spectrum of these protein activities. The biological functions of glycans in organism have increasingly been recognized during last few decades [9-11]. Glycans attached to proteins modulate protein function by impacting protein folding or conformation stability of the protein. Glycans serve as markers or ligands that interact with other biomolecules. N-glycans are involved in the immune system [12-13], neurodegenerative diseases, and inflammation [14-15]. Variations in glycan structure and content occur during development of cancer and other diseases [16]. Oligosaccharides are a more sensitive marker for cell metabolism than proteins and genes; and are therapeutic targets [16-18].

\subsubsection{Background of glycan analysis.}

Much less is known about glycans than of nucleic acid and proteins [19-20]. Not until recent decades has the importance of carbohydrates been realized [20]. Advances in glycan analysis remain slow. Biosynthesis of glycans is a stepwise process. The complexity of glycan structure adds more difficulties to glycan analysis as mentioned earlier. 
The use of a variety of analytical methodologies facilitates the understanding of glycan composition, especially at the molecular level. These techniques mainly include: (1) separation or purification based methods such as high performance liquid chromatography (HPLC) and capillary electrophoresis (CE); and (2) structural clarification based techniques including mass spectrometry (MS) and nuclear magnetic resonance spectroscopy (NMR). Combination of these approaches is required to fully decode the composition and structures of glycans in a glycan pool. Other methodologies used in various fields like molecular biology and enzymology are important tools for elucidating the biological functions of glycans [21]. However, they are beyond the scope of this dissertation.

In liquid chromatography, separation is achieved through different extent of analyte partitioning in both stationary phase and mobile phase in a column. Based on the materials or functional groups (stationary phase) packed in the column, different types of HPLC have been extensively employed for oligosaccharide separation and fractionation [5, 22-23]. Column selection depends on glycan structure and substitution. Derivatization can be used to enhance optical detection [24].

As early as 1989, CE was applied in carbohydrate analysis [25]. CE is used for carbohydrate analysis in pharmaceutical, clinical and food applications [26-29]. CE provides rapid separation, increased resolution, and nanoliter-scale sample size requirements. $\mathrm{CE}$ is also versatile as many modes and buffers can be used for carbohydrate analysis. These modes include: (1) capillary zone electrophoresis (CZE) [30]; (2) capillary gel electrophoresis (CGE) [31]; and (3) micellar electrokinetic chromatography (MEKC) [32]. The separation performance reported in the literature for 
$\mathrm{N}$-glycans from the glycoproteins studied in this chapter is listed in Table 2-1. Although the use of CE continues to advance carbohydrate analysis, the complexity of glycan systems still requires new separation methods for improved oligosaccharide separations.

Mass spectrometry and NMR are predominant tools for structural determination of glycans [33-34]. They provide information about monosaccharide sequence, fine structure such as anomericity, and linkage between monomers [35-38]. The combination of MS and NMR with high performance separation techniques provides the best opportunity for structural analysis of complex glycan mixtures [39].

\subsubsection{Chemical labeling of carbohydrates in CE separation.}

Optical detectors are routinely employed in separation techniques because they are easily coupled to separations. Oligosaccharides weakly absorb UV radiation at $\sim 200 \mathrm{~nm}$ or less [40]. Therefore, optical methods of detection used in the chemical separation of carbohydrates generally incorporate chemical derivatization. Chemical labeling to facilitate fluorescence detection is beneficial to $\mathrm{CE}$ as the process imparts charge to the glycans, which in turn enhances the electrophoretic separation. A variety of derivatization reagents has been reported for fluorescence detection of saccharides by laser induced fluorescence detector coupled with CE. Liu et al demonstrated the use of 3(4-carboxybenzoyl)-2-quinolinecarboxaldehyde (CBQCA) [41]. Chiesa and Horvath reported capillary electrophoresis separations of saccharides accomplished with 8aminonaphthalene- 1,3,6-trisulfonic acid (ANTS) [42]. Guttman and Pritchett demonstrated the effectiveness of 1-aminopyrene-3, 6, 8-trisulfonic acid 
Table 2-1 Separation of glycans from AGP, fetuin and RNase B glycoproeins with CE reported in the literature.

\begin{tabular}{|c|c|c|c|c|c|}
\hline $\begin{array}{l}\text { glycan } \\
\text { source }\end{array}$ & $\begin{array}{l}\text { CE mode(coating or } \\
\text { separation media) }\end{array}$ & $\begin{array}{l}\text { labeling } \\
\text { agent }\end{array}$ & $\begin{array}{c}\text { reported resolution } \\
\text { or separation performance }\end{array}$ & detection & ref \\
\hline AGP & $\begin{array}{l}\text { CZE } \\
\text { MEKC(anionic CD) } \\
\text { CZE(DDM-MC) })^{a}\end{array}$ & $\begin{array}{l}\text { ANTS } \\
\text { AB } \\
\text { APTS }\end{array}$ & $\begin{array}{l}\text { (sialyted) } 10 \text { peaks } \\
\text { AIV/AV: barely separated } \\
\text { AII/AIII }=0.984 ; \text { AIV/AV }=0.896\end{array}$ & $\begin{array}{l}\mathrm{LIF}(\mathrm{HeCd}) \\
\text { UV254nm } \\
\text { fluorescence }\end{array}$ & $\begin{array}{l}{[43]} \\
{[44]} \\
{[45]}\end{array}$ \\
\hline fetuin & $\begin{array}{l}\text { CZE } \\
\text { CZE } \\
\text { CZE } \\
\text { CGE(PVA }{ }^{b}+\text { PEO) } \\
\text { CGE(CHO }{ }^{b}+\text { PEO) } \\
\text { CZE } \\
\text { CGE(PEO) } \\
\text { MEKC }^{c} \\
\text { MEKC }^{c} \\
\text { MEKC(SDS) }^{\text {CZE (LPA) }}{ }^{b} \\
\text { CZE(DDM-MC) } \\
\text { CGE(N/A) } \\
\text { CZE(LPA) }^{b}\end{array}$ & $\begin{array}{l}\text { CBQCA } \\
\text { ANTS } \\
\text { ANTS } \\
\text { APTS } \\
\text { APTS } \\
\text { APTS } \\
\text { APTS } \\
\text { AMAC } \\
\text { AMAC } \\
\text { NBD } \\
\text { APTS } \\
\text { APTS } \\
\text { APTS } \\
\text { APTS }\end{array}$ & $\begin{array}{l}\text { (sialyted) } 7 \text { peaks } \\
\text { (sialyted) } 7 \text { peaks } \\
\text { (sialyted) } 4 \text { major peaks } \\
\text { (sialyted) } 8 \text { peaks } \\
\text { (sialyted) } 4 \text { major peaks } \\
\text { (sialyted) } 3 \text { major peaks } \\
\text { comparable with our results } \\
\text { 2-peak feature for AII and FII } \\
\text { 2-peak feature for AII and FII } \\
\text { (sialyted) } 4 \text { major peaks } \\
\text { 2-peak feature for AII and FII } \\
\text { no separation for AII and FII } \\
\text { barely two peaks for AII and FII } \\
\text { comparable with our results }\end{array}$ & $\begin{array}{l}\text { LIF(Ar ion) } \\
\text { LIF(HeCd) } \\
\text { LIF(HeCd) } \\
\text { LIF(Ar ion) } \\
\text { LIF(Ar ion) } \\
\text { LIF(Ar ion) } \\
\text { LIF(Ar ion) } \\
\text { LIF(Ar ion) } \\
\text { LIF(HeCd) } \\
\text { LIF(Ar ion) } \\
\text { LIF(Ar ion) } \\
\text { fluorescence } \\
\text { fluorescence } \\
\text { fluorescence }\end{array}$ & $\begin{array}{l}{[41]} \\
{[46]} \\
{[43]} \\
{[47]} \\
{[48]} \\
{[30]} \\
{[49]} \\
{[32]} \\
{[50]} \\
{[51]} \\
{[52]} \\
{[45]} \\
{[53]} \\
{[54]}\end{array}$ \\
\hline Rnase B & $\begin{array}{l}\text { CZE } \\
\text { CZE } \\
\text { CGE } \\
\text { CGE } \\
\text { CZE } \\
\text { CZE(PEO) } \\
\text { CZE } \\
\text { MEKC(anionic CD) }_{\text {MEKC }^{c}} \\
\text { MEKC }^{c} \\
\text { MEKC }^{c} \\
\text { CZE(DDM-MC) } \\
\text { CZE(LPA) } \\
\text { CZE } \\
\text { CGE(N/A) } \\
\text { CZE(PVA) }\end{array}$ & $\begin{array}{l}\text { ANTS } \\
\text { ANS } \\
\text { APTS } \\
\text { APTS } \\
\text { APTS } \\
\text { APTS } \\
\text { APTS } \\
\text { AB } \\
\text { AMAC } \\
\text { AMAC } \\
\text { AMAC } \\
\text { APTS } \\
\text { APTS } \\
\text { APTS } \\
\text { APTS } \\
\text { APTS }\end{array}$ & $\begin{array}{l}\text { barely } 2 \text { peak for M7 } \\
\text { 1 peak for M7 } \\
\text { baseline separation of M7 } \\
\text { 3-peak feature of M7 } \\
\text { 3-peak feature of M7 } \\
\text { 3-peak feature of M7 } \\
\text { M7: 1peak } \\
\text { M7: } 2 \text { peaks; M8+M9: no sep } \\
\text { M7: } 2 \text { peaks } \\
\text { M7: } 2 \text { peaks } \\
\text { M7: better than our result } \\
\text { barely 3-peak feature of M7 } \\
\text { 3-peak feature of M7 and M8 } \\
\text { 3-peak feature of M7 } \\
\text { 3-peak feature of M7 } \\
\text { 3-peak feature of M7 }\end{array}$ & $\begin{array}{l}\text { UV 235nm } \\
\text { UV 235nm } \\
\text { LIF(Ar ion) } \\
\text { LIF(Ar ion) } \\
\text { LIF(Ar ion) } \\
\text { LIF(Ar ion) } \\
\text { UV254nm } \\
\text { UV254nm } \\
\text { LIF(Ar ion) } \\
\text { LIF(Ar ion) } \\
\text { LIF(HeCd) } \\
\text { fluorescence } \\
\text { fluorescence } \\
\text { LIF(Ar ion) } \\
\text { fluorescence } \\
\text { LIF }\end{array}$ & $\begin{array}{l}{[55]} \\
{[55]} \\
{[31]} \\
{[56]} \\
{[30]} \\
{[49]} \\
{[57]} \\
{[44]} \\
{[32]} \\
{[58]} \\
{[59]} \\
{[45]} \\
{[54]} \\
{[60]} \\
{[53]} \\
{[61]}\end{array}$ \\
\hline
\end{tabular}

Note: MS and NMR data are not included. For the resolution values not reported in the literatures, phases such as 3-peak feature are used to describe the separation.

Abbreviations:

AB: 2 -aminobenzamide; DDM - MC: $n$-dodecyl $\beta$-D-maltoside (DDM) - methyl cellulose (MC)

LPA: polyacrylamide; PVA: polyvinyl alcohol; CD: cyclodextrins

CBQCA: 3-(4-carboxybenzoyl)-2-quinolinecarboxaldehyde

AMAC: 2-aminoacridone; NBD: 7-nitro-2, 1, 3-benzoxadiazole

ANTS: LIF (HeCd325/520nm); AMAC: LIF (HeCd442/525nm)

${ }^{a}$ dynamic coating; ${ }^{b}$ permanent coating; ${ }^{c}$ taurodeoxycholate 
(APTS), which has since been widely utilized in capillary electrophoresis for fluorescence detection of saccharides [31, 62-63].

The process of chemical labeling with APTS is shown in Figure 2-5. The amine group from the labeling reagent attaches to anomeric carbon which is a carbonyl group on the sugar. A Schiff base is produced via this reductive amination, and further reduced by sodium cyanoborohydride to generate a stable secondary amine for detection. The APTS label also provides three negative charges for each carbohydrate molecule, which enables the electrophoretic movement of carbohydrates in the electric field at $\mathrm{pH}=7$.

\subsubsection{Separation of oligosaccharides with phospholipid additives.}

Phospholipid additives have not yet been utilized for glycan separations, although they have been used to enhance a variety of chemical separations. As mentioned earlier, phospholipids have been employed for studies of membrane affinity, lipophilicity, liposome interaction, protein separation and passivation of capillary surface. Aqueous phospholipid preparations comprised of 1, 2-dimyristoyl-sn-glycero-3-phosphocholine (DMPC) and 1, 2-dihexanoyl-sn-glycero-3-phosphocholine (DHPC) display atypical temperature-dependent viscosity, which affects analyte mobility. The temperatureinduced change in viscosity of aqueous phospholipid preparations is a function of the $q$ value as well as the percent hydration. To better utilize phospholipid additives in capillary electrophoresis, the separation performance of these materials must be examined.

The majority of the following research in this chapter is from the paper published recently in Analytical chemistry (Ruijuan Luo, Stephanie A. Archer-Hartmann, and Lisa A. Holland. Anal. Chem. 2010, 82, 1228-1233) [64]. In this study, phospholipids are 

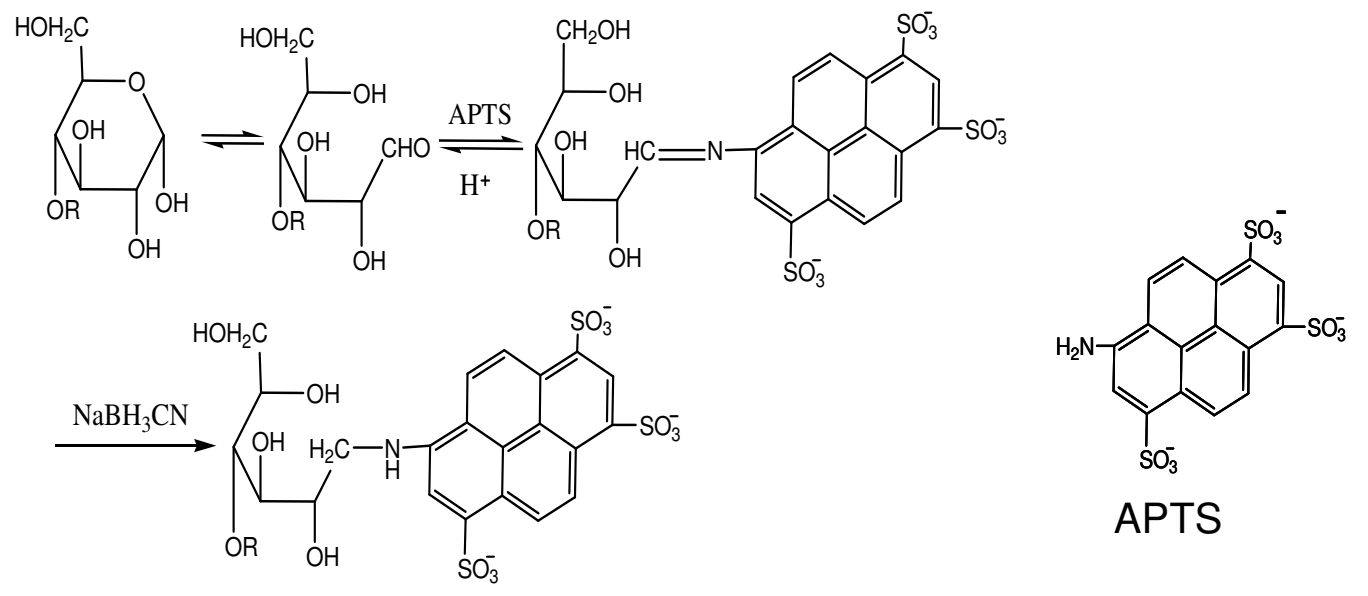

Figure 2-5 Derivatizations of carbohydrates with APTS. Adapted from reference [63]. 
employed as a new media for capillary electrophoresis separations of glycans. As the physicochemical properties of phospholipid preparation vary with morphology, the effects of temperature, phospholipid content, and composition on separation performance are investigated. The separation method is characterized using glycans derived from glycoproteins. These glycans are well separated by incorporating phospholipids in the separation media.

\subsubsection{MATERIALS AND METHODS}

\subsubsection{Chemicals.}

Asialofetuin from fetal calf serum, maltooligosaccharide standards, 3- $(\mathrm{N}-$ morpholino)-propanesulfonic acid (MOPS), and sodium hydroxide were purchased from Sigma-Aldrich (St. Louis, MO). Bovine $\alpha 1$-acid glycoprotein (AGP), tetrahydrofuran, and calcium chloride dihydrate were obtained from Calbiochem (LaJolla, CA). Glycan standards purchased from V-laboratories (Covington, LA) included AI (C0920, asialo, galactosylated, biantennary $\mathrm{N}$-glycan), AII (C1124 asialo, galacosylated, triantennary $\mathrm{N}$ glycan), and Man5 (MC0731 oligomannose-5). Ribonuclease B (RNase B), a12,3mannosidase, and a peptide $N$-glycosidase (PNGase F) kit were obtained from New England Biolabs (Ipswich, MA). The PNGase F kit was supplied with 10x G7 reaction buffer (0.5 M sodium phosphate buffered at $\mathrm{pH} 7.5), 10 \mathrm{x}$ glycoprotein denaturing buffer (5\% sodium dodecyl sulfate, $0.4 \mathrm{M}$ dithiothreitol), and a $10 \%$ aqueous solution of the nonionic surfactant NP-40. APTS was acquired from Biotium (Hayward, CA). The lipids DMPC and DHPC were obtained from Avanti Polar Lipids (Alabaster, AL). Sodium cyanoborohydride $\left(\mathrm{NaCNBH}_{3}\right)$ was purchased from Stem Chemicals (Newburyport, MA), and acetic acid was purchased from Fisher Scientific (Pittsburgh, 
PA). Deionized water was obtained from an Elga Purelab ultra water system (Lowell, MA).

\subsubsection{Preparation of Phospholipid Mixture.}

Phospholipids were prepared as described previously [65]. Briefly, the appropriate amount of DMPC was weighed out. Then the amount of DHPC was calculated based on the q value, which is mole ratio of DMPC to DHPC and weighed out into same container. This powder mixture was then dissolved in proper amount of 100 mM MOPS solution buffered at $\mathrm{pH} 7$, upon on hydration of lipids prepared, followed by three freeze-thaw cycles. After an opaque and stable suspension was obtained with these three cycles, it was centrifuged for $10 \mathrm{~min}$ at $10000 \mathrm{rpm}$ at $4{ }^{\circ} \mathrm{C}$. After centrifugation, the lipids were divided into PCR vials and stored in the $-20{ }^{\circ} \mathrm{C}$. Prior to use, the lipids were thawed and then vacuum degassed for 2 minutes.

In order that the findings may be related to literature reports, preparations consisted of molar ratios of DMPC to DHPC of $\mathrm{q}=1.5,2.0$, and 2.5 and hydration with aqueous buffer at 5\%,10\%, and 15\%. The total phospholipid concentration of 5\% preparations was approximately $70 \mathrm{mM}$, assuming a specific volume of phospholipids is approximately $1 \mathrm{~mL} / \mathrm{g}$ [66]. The concentrations for a $\mathrm{q}=1.5, \mathrm{q}=2.0$, and $\mathrm{q}=2.5$ were estimated at $49 \mathrm{mM}$ DMPC and $21 \mathrm{mM}$ DHPC, $52 \mathrm{mM}$ DMPC and $18 \mathrm{mM}$ DHPC, and $55 \mathrm{mM}$ DMPC and $15 \mathrm{mM}$ DHPC, respectively. A $10 \%$ preparation of $\mathrm{q}=2.5$ had an estimated concentration of $134 \mathrm{mM}$ (106 mM DMPC, $28 \mathrm{mM}$ DHPC), while a 15\% preparation had an estimated concentration of $193 \mathrm{mM}$ (152 mM DMPC, $41 \mathrm{mM}$ DHPC). 


\subsubsection{Sample Preparation and Derivatization.}

The glycans were cleaved from glycoproteins using a PNGase F kit. A deglycosylation procedure described in the literature was used here [45]. Glycoprotein (AGP, asialofetuin or RNase B) $(200 \mu \mathrm{g})$ was dissolved in $35 \mu \mathrm{L}$ of deionized water in a $500-\mu \mathrm{L}$ microcentrifuge tube. Then $5 \mu \mathrm{L}$ of $10 \mathrm{X}$ reaction buffer and $2.5 \mu \mathrm{L}$ of denaturation solution were added into that solution. The mixture was then heated at 100

${ }^{\circ} \mathrm{C}$ for 10 minutes. After the heated solution was cooled down to room temperature, 3.5 $\mu \mathrm{L}$ of $10 \%$ NP-40 and $2 \mu \mathrm{L}$ of PNGase F were added to the tube. The reaction mixture was then incubated at $37{ }^{\circ} \mathrm{C}$ for 24 hours. The cleaved glycans were collected by adding $150 \mu \mathrm{L}$ of ice-cold ethanol and centrifugation for 10 minutes at $10000 \mathrm{rpm}$ and $4{ }^{\circ} \mathrm{C}$. The ethanol fraction containing free glycan was removed and dried with nitrogen gas. The glycan was reconstituted in $2 \mathrm{M}$ acetic acid $(50 \mu \mathrm{L})$ and incubated at $80{ }^{\circ} \mathrm{C}$ for $2 \mathrm{~h}$ to remove sialic acid. After removal of sialic acid, the glycan or maltooligosaccharide standards $(5 \mu$ mole) was mixed with $5 \mu \mathrm{L}$ of 0.1 M APTS dissolved in $15 \%$ acetic acid and $10 \mu \mathrm{L}$ of $0.5 \mathrm{M} \mathrm{NaCNBH}_{3}$ in tetrahydrofuran and incubated at $55{ }^{\circ} \mathrm{C}$ for $2 \mathrm{~h}$. This derivatization reaction was terminated by adding $100 \mu \mathrm{L}$ of deionized water. Excess labeling reagent was removed by chromatographic separation with a strong anion exchange column (Alltech, catalog no. 287513). The mobile phase (80 mM ammonium acetate) flow rate was $0.5 \mathrm{~mL} / \mathrm{min}$. A Waters 470 scanning fluorescence detector was used to monitor the elution with $\lambda_{\mathrm{ex}}=480 \mathrm{~nm}$ and $\lambda_{\mathrm{em}}=520 \mathrm{~nm}$. Following separation, the carbohydrate was stored at $-20{ }^{\circ} \mathrm{C}$ and diluted with $50 \mathrm{mM}$ MOPS buffered at $\mathrm{pH} 7.0$ prior to use. 


\subsubsection{Capillary Electrophoresis.}

Capillary electrophoresis separations were performed on a Beckman/Coulter P/ACE MDQ (Beckman Coulter, Fullerton, CA) equipped with laser induced fluorescence detection (air cooled argon ion, $\lambda_{\mathrm{ex}}=488 \mathrm{~nm}, \lambda_{\mathrm{em}}=520 \mathrm{~nm}$ ). Unless otherwise noted, separations were accomplished with a $50 \mu \mathrm{m}$ internal diameter fused silica capillary (Polymicro Technologies, Phoenix, AZ), with total length $40 \mathrm{~cm}$ and effective length $30.2 \mathrm{~cm}$. At the beginning of the day, the capillary was subject to the following rinse sequence: $1 \mathrm{M} \mathrm{NaOH}$ for $30 \mathrm{~min}$ at $140 \mathrm{kPa}$ (20 psi), deionized water for $15 \mathrm{~min}$ at $140 \mathrm{kPa}$, methanol for $15 \mathrm{~min}$ at $140 \mathrm{kPa}$, and deionized water for $15 \mathrm{~min}$ at $140 \mathrm{kPa}$. The capillary was coated with $\mathrm{q}=0.5-5 \%$ phospholipid containing $\mathrm{Ca}^{2+}$ at the beginning of the day $(20 \mathrm{~min}$ at $140 \mathrm{kPa}$ ). The capillary was filled with phospholipid additive at $19{ }^{\circ} \mathrm{C}(3 \mathrm{~min}$ at $140 \mathrm{kPa})$. Between each run, the capillary temperature was dropped to $19^{\circ} \mathrm{C}$ and the capillary was refilled with phospholipids.

Figure 2-6 outlined the configuration of the capillary cartridge for the Beckman P/ACE instrument. In this capillary cartridge holder, the detection window was located at $10 \mathrm{~cm}$ from one end of the capillary and a variable distance from the other end of the capillary. For this work, a sample was injected into the end of capillary on the left side, and the $30.2 \mathrm{~cm}$ effective separation was the capillary length from the end of capillary on the left side to the detection window. If the ends of the capillary were not subject to thermal control, fluctuations in the ambient room temperature resulted in variation of the migration times. Consequently, a portable air conditioner was positioned near the instrument to maintain ambient temperature at approximately $20{ }^{\circ} \mathrm{C}$, which improved 


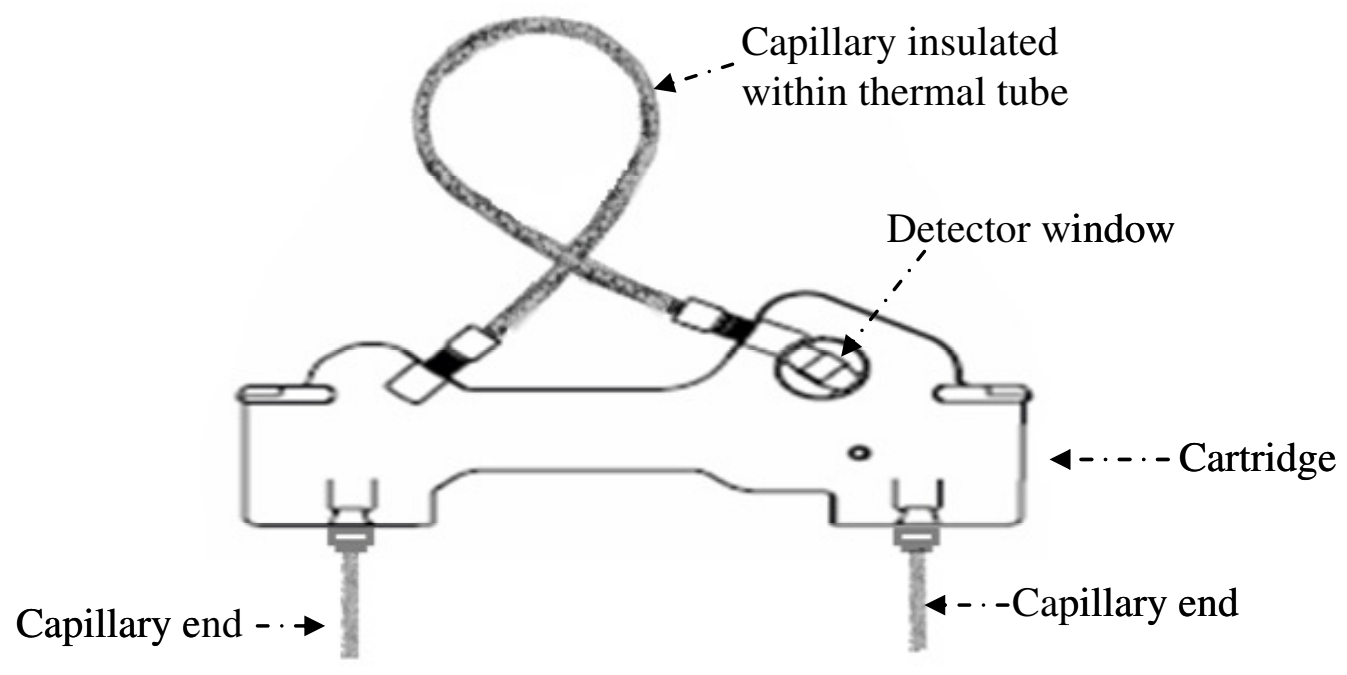

Figure 2-6 Schematic of capillary cartridge in the commercial CE instrumental from Beckman coulter. The picture was adapted from the manufacture's web site. 
measurement reproducibility. Once the capillary was loaded with phospholipids, the temperature of the separation cartridge was increased to the desired temperature and then the sample injection protocol was employed to introduce sample into the capillary. Electrokinetic injection involved three steps. First, a plug of MOPS running buffer was introduced into the capillary for $6 \mathrm{~s}$ at $3 \mathrm{kPa}(0.5 \mathrm{psi})$ prior to electrokinetic sample injection. Then, sample was injected into the capillary at $-5 \mathrm{kV}$ for $6 \mathrm{~s}$ (reverse polarity). Following sample injection, a plug of MOPS running buffer was introduced into the capillary for $5 \mathrm{~s}$ at $3 \mathrm{kPa}$. Separation was achieved with $-16 \mathrm{kV}$ (reverse polarity). Data collection and analysis were performed using 32 Karat Software version 5.0 (Beckman Coulter). Theoretical plates were calculated by using 32Karat Gold software with the "USP plates" criterion.

\subsubsection{Results and discussion}

\subsubsection{Preliminary study with linear oligosaccharides}

\subsubsection{1 $10 \mathrm{~cm}$ effective separation}

The research started with commercially available and relatively simple oligosaccharides, maltooligosaccharide. Maltooligosaccharides are $\alpha-(1,4)$-linked Dglucose polymers [67-68]. They are linearly linked carbohydrates and their structure is shown in Figure 2-7. The APTS labeled maltooligosaccharide ladder used to characterize the separation ranges from a 3-mer $(n=1)$ to a 7 -mer $(n=5)$. Several different q values $(q=1.0,1.5,2.0,2.5$ and 3.0) were tested. The experiments were performed with low lipid content (5\%). As shown in Table 2-2, temperatures including $20{ }^{\circ} \mathrm{C}, 25{ }^{\circ} \mathrm{C}, 30{ }^{\circ} \mathrm{C}$, and $35^{\circ} \mathrm{C}$ were compared. These temperatures were chosen because they are often used 


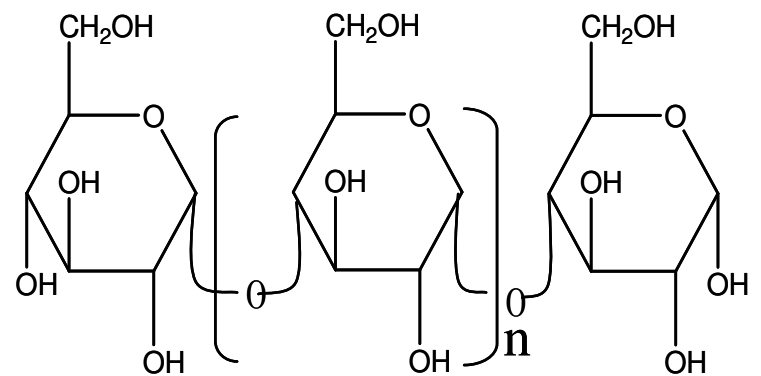

Figure 2-7 Structure of maltooligosaccharide, $n=1$ to 5 . 


\begin{tabular}{|c|c|c|c|c|c|}
\hline $\operatorname{Temp}\left({ }^{\circ} \mathrm{C}\right)$ & $q$ value & $\mathbf{G}_{3}, \mathbf{G}_{4}$ & $\mathbf{G}_{\mathbf{4}}, \mathbf{G}_{5}$ & $\mathbf{G}_{5}, \mathbf{G}_{6}$ & $\mathbf{G}_{6}, \mathbf{G}_{7}$ \\
\hline 20 & $\begin{array}{l}\mathrm{q} 1.5 \\
\mathrm{q} 2.0 \\
\mathrm{q} 2.5^{1}\end{array}$ & $\begin{array}{l}1.8 \pm 0.1_{0} \\
1.1 \pm 0.02 \\
2.0\end{array}$ & $\begin{array}{l}1.1 \pm 0.1 \\
1.0 \pm 0.1 \\
1.4\end{array}$ & $\begin{array}{l}1.1 \pm 0.1_{1} \\
1.0 \pm 0.0_{4} \\
1.3\end{array}$ & $\begin{array}{l}1.4 \pm 0.0_{8} \\
1.0 \pm 0.2 \\
1.0\end{array}$ \\
\hline 25 & $\begin{array}{l}\mathrm{q} 1.5 \\
\mathrm{q} 2.0 \\
\mathrm{q} 2.5^{1}\end{array}$ & $\begin{array}{l}1.4 \pm 0.1_{5} \\
1.3 \pm 0.0_{5} \\
1.4\end{array}$ & $\begin{array}{l}1.0 \pm 0.0_{6} \\
1.1 \pm 0.1 \\
1.5\end{array}$ & $\begin{array}{l}1.0 \pm 0.0_{3} \\
1.0 \pm 0.0_{5} \\
1.4\end{array}$ & $\begin{array}{l}0.80 \pm 0.3 \\
1.1 \pm 0.2 \\
1.7\end{array}$ \\
\hline 30 & $\begin{array}{l}\mathrm{q} 1.5 \\
\mathrm{q} 2.0 \\
\mathrm{q} 2.5^{1}\end{array}$ & $\begin{array}{l}1.2 \pm 0.0_{8} \\
1.4 \pm 0.0_{3} \\
1.4\end{array}$ & $\begin{array}{l}1.0 \pm 0.0_{4} \\
1.1 \pm 0.0_{1} \\
1.9\end{array}$ & $\begin{array}{l}1.1 \pm 0.0_{2} \\
1.0 \pm 0.0_{0} \\
1.3\end{array}$ & $\begin{array}{l}0.72 \pm 0.0_{1} \\
1.3 \pm 0.0_{7} \\
1.6\end{array}$ \\
\hline 35 & $\begin{array}{l}\mathrm{q} 1.5 \\
\mathrm{q} 2.0 \\
\mathrm{q} 2.5^{1}\end{array}$ & $\begin{array}{c}1.1 \pm 0.0_{2} \\
1.3 \pm 0.1_{3} \\
-\end{array}$ & $\begin{array}{c}1.1 \pm 0.0_{8} \\
1.2 \pm 0.1_{5} \\
-\end{array}$ & $\begin{array}{c}1.0 \pm 0.0_{2} \\
1.0 \pm 0.0_{4} \\
-\end{array}$ & $\begin{array}{c}1.2 \pm 0.0_{3} \\
1.1 \pm 0.2 \\
-\end{array}$ \\
\hline \multicolumn{6}{|c|}{$\begin{array}{l}\text { All data is performed in triplicate except as noted. } \\
{ }^{1} \text { the data of } \mathrm{q} 2.5-5 \% \text { is from single run }(\mathrm{n}=1)\end{array}$} \\
\hline
\end{tabular}

Table 2-2 Resolution of maltoses in 5\% lipids. The total length of capillary was $40 \mathrm{~cm}$ and effective separation length was $10 \mathrm{~cm}$. The injection condition was $3.5 \mathrm{kPa}(0.5 \mathrm{psi}) 5 \mathrm{sec}$. The separation voltage was $16 \mathrm{kV}$. 
as separation temperature in $\mathrm{CE}$ and because of the interesting viscosity profile in this temperature range [69]. The resolution between two adjacent peaks changed with temperature and phospholipid content as shown in the Table 2-2. This study revealed that q 2.5 - 5\% gave the best resolution for bigger sugars in most instances.

These preliminary studies revealed that phospholipids can separate linear sugars. These runs were fast (separation time $<1 \mathrm{~min}$ at $35^{\circ} \mathrm{C}$ to $<3$ min at $20{ }^{\circ} \mathrm{C}$ ) and showed that high q preparations provided better separations than small $q$ preparations. Different temperatures yielded different resolutions, which meant that separation performance can be tuned by changing the phospholipid condition and properties. These results were promising, but separations with high q preparations were not reproducible at certain temperatures. The fact that some peaks disappeared made it impossible to compare with other conditions as shown in Table 2-2. The missing data with q $2.5-5 \%$ lipids at $35^{\circ} \mathrm{C}$ or single-run data at other temperatures were because no peak or a much smaller peak was observed. An important source of error was attributed to the limited thermal regulation. Only $6 \mathrm{~cm}$ of the capillary out of the $10 \mathrm{~cm}$ effective separation length was thermostatted. The remaining $4 \mathrm{~cm}$ was exposed to the room temperature. The variation of room temperature led to irreproducible data. The thermal regulation was built for temperature control. The reproducibility was surely improved with small $\mathrm{q}$ values such as q 1.5 but not that much with high q value such as q 2.5. This suggested that some other factors contributed to irreproducibility of experiments. The research carried out later on demonstrated that the problem came from the injection of sample. 


\subsubsection{Improvement of separation performance by using $30 \mathrm{~cm}$ effective separation.}

Instead of using an effective separation length of $10 \mathrm{~cm}$, a $30 \mathrm{~cm}$ effective separation length was employed in this section. Previously, the highest resolution was observed with q 2.5 - 5\% lipids. In this section, the different lipid hydrations at q 2.5 were investigated in addition to $\mathrm{q}$ value. The resolution values obtained from lipids solution q $2.0-5 \%$, q $2.5-5 \%$, q $2.5-10 \%$ and q $2.5-20 \%$ were shown in Table 2-3 for the separation of maltooligosaccharides. In contrast to the studies performed with a 10 $\mathrm{cm}$ effective length, the resolution values with q 2.0 - 5\% lipids in $30 \mathrm{~cm}$ effective separation are approximately 2 times larger than the values from $10 \mathrm{~cm}$ separation at same conditions in most case; the resolution values obtained using q $2.5-5 \%$ lipid additive with a $30 \mathrm{~cm}$ effective length was about 3 times larger than that from $10 \mathrm{~cm}$ separation in most cases (see Table 2-4). The q $2.5-10 \%$ gave similar or slightly higher resolution as compared to q $2.5-5 \%$. The resolution obtained with q $2.5-20 \%$ lipids decreased as compared to $\mathrm{q} 2.5-5 \%$. The problem of poor reproducibility mentioned in last section was solved by optimization of sample injection protocol, which will be discussed in next section.

\subsubsection{Separation of complex carbohydrates with phospholipids.}

Phospholipid additives were used to separate branched oligosachharides derived from three standard glycoproteins. These glycoproteins included AGP, fetuin and RNase B. AGP is a serum glycoprotein involved in transport and immunomodulation of inflammation [70], and the microheterogeneity of glycan expression changes with physiological dysfunction [71]. AGP is $41-43 \mathrm{kDa}$ in molecular mass and consists of approximately $45 \%$ carbohydrate attached in the form of five complex-type $\mathrm{N}$-linked 


\begin{tabular}{|c|c|c|c|c|c|}
\hline $\operatorname{Temp}\left({ }^{\circ} \mathrm{C}\right)$ & Lipids & $\mathbf{G}_{3}, \mathbf{G}_{\mathbf{4}}$ & $\mathbf{G}_{\mathbf{4}}, \mathbf{G}_{\mathbf{5}}$ & $\mathbf{G}_{5}, \mathbf{G}_{6}$ & $\mathbf{G}_{6}, \mathbf{G}_{7}$ \\
\hline 20 & $\begin{array}{l}\mathrm{q} 2.0-5 \% \\
\mathrm{q} 2.5-5 \% \\
\mathrm{q} 2.5-10 \% \\
\mathrm{q} 2.5-20 \%\end{array}$ & $\begin{array}{l}2.7 \pm 0.1 \\
4.6 \pm 0.8 \\
4.5 \pm 0.2 \\
4.0\end{array}$ & $\begin{array}{l}2.5 \pm 0.1 \\
4.5 \pm 0.4 \\
4.0 \pm 0.2 \\
3.9\end{array}$ & $\begin{array}{l}2.3 \pm 0.1 \\
4.2 \pm 0.2 \\
3.6 \pm 0.3 \\
3.0\end{array}$ & $\begin{array}{l}2.0 \pm 0.0_{2} \\
3.6 \pm 0.3 \\
3.3 \pm 0.2 \\
2.8\end{array}$ \\
\hline 25 & $\begin{array}{l}\mathrm{q} 2.0-5 \% \\
\mathrm{q} 2.5-5 \%{ }^{2} \\
\mathrm{q} 2.5-10 \% \\
\mathrm{q} 2.5-20 \%\end{array}$ & $\begin{array}{l}2.6 \pm 0.0_{4} \\
4.5 \\
5.9 \pm 0.3 \\
4.5\end{array}$ & $\begin{array}{l}2.3 \pm 0.1 \\
3.9 \\
5.4 \pm 0.2 \\
4.2\end{array}$ & $\begin{array}{l}2.1 \pm 0.2 \\
3.5 \\
5.0 \pm 0.2 \\
3.3\end{array}$ & $\begin{array}{l}1.9 \pm 0.1 \\
3.3 \\
4.2 \pm 0.3 \\
3.6\end{array}$ \\
\hline 30 & $\begin{array}{l}\mathrm{q} 2.0-5 \% \\
\mathrm{q} 2.5-5 \% \\
\mathrm{q} 2.5-10 \% \\
\mathrm{q} 2.5-20 \%\end{array}$ & $\begin{array}{l}2.6 \pm 0.0_{4} \\
5.4 \pm 0.4 \\
4.7 \pm 0.3 \\
3.9\end{array}$ & $\begin{array}{l}2.4 \pm 0.1 \\
4.4 \pm 1 \\
4.5 \pm 0.0_{3} \\
3.4\end{array}$ & $\begin{array}{l}2.2 \pm 0.0_{5} \\
4.1 \pm 1 \\
3.3 \pm 0.3 \\
3.3\end{array}$ & $\begin{array}{l}1.8 \pm 0.0_{2} \\
4 .{ }_{3} \pm 1 \\
3.3 \pm 0.7 \\
3.6\end{array}$ \\
\hline 35 & $\begin{array}{l}\mathrm{q} 2.0-5 \% \\
\mathrm{q} 2.5-5 \% \\
\mathrm{q} 2.5-10 \% \\
\mathrm{q} 2.5-20 \%\end{array}$ & $\begin{array}{l}2.5 \pm 0.0_{4} \\
4.4 \pm 0.4 \\
3.6 \pm 0.3 \\
2.7\end{array}$ & $\begin{array}{l}2.4 \pm 0.1 \\
4.1 \pm 0.6 \\
3.5 \pm 0.3 \\
2.9\end{array}$ & $\begin{array}{l}2.0 \pm 0.1 \\
3.5 \pm 0.6 \\
4.2 \pm 0.8 \\
2.4\end{array}$ & $\begin{array}{l}1.8 \pm 0.0_{2} \\
3.4 \pm 1.0 \\
4.0 \pm 0.7 \\
2.4\end{array}$ \\
\hline $\begin{array}{l}\text { All data c } \\
{ }^{1} \text { value de } \\
{ }^{2} \text { value de }\end{array}$ & $\begin{array}{l}\text { ected in } \mathrm{t} \\
\text { red from } \mathrm{s}\end{array}$ & $\begin{array}{l}\text { icate exce } \\
\text { le determi } \\
\text { icate deter }\end{array}$ & $\begin{array}{l}(n=1) \\
\text { ions }(n=2)\end{array}$ & & \\
\hline
\end{tabular}

Table 2-3 Resolution of maltoses with different lipids. The total length of capillary was $40 \mathrm{~cm}$ and effective separation length was $30 \mathrm{~cm}$. The injection condition was $5 \mathrm{kV} 6 \mathrm{sec}$ with both front and behind mops plugs (explained in next section). The separation voltage was $-16 \mathrm{kV}$. 


\begin{tabular}{|cc|c|c|c|c|}
\hline \multirow{2}{*}{ Tem $\left({ }^{\circ} \mathbf{C}\right)$} & Lipids & \multicolumn{4}{|c|}{$\mathbf{R}_{\mathbf{3 0}} / \mathbf{R}_{\mathbf{1 0}}$} \\
\cline { 3 - 6 } & $\mathbf{G 3}, \mathbf{G 4}$ & $\mathbf{G 4}, \mathbf{G 5}$ & $\mathbf{G 5}, \mathbf{G 6}$ & $\mathbf{G 6}, \mathbf{G 7}$ \\
\hline 20 & $\mathrm{q} 2.0-5 \%$ & 2.5 & 2.5 & 2.3 & 2.0 \\
& $\mathrm{q} 2.5-5 \%$ & 2.3 & 3.2 & 3.2 & 3.6 \\
& & & & & \\
25 & $\mathrm{q} 2.0-5 \%$ & 2.0 & 2.1 & 2.1 & 1.7 \\
& $\mathrm{q} 2.5-5 \%$ & 3.2 & 2.6 & 2.5 & 1.9 \\
& & & & & \\
30 & $\mathrm{q} 2.0-5 \%$ & 1.9 & 2.2 & 2.2 & 2.7 \\
& $\mathrm{q} 2.5-5 \%$ & 3.9 & 2.3 & 3.2 & 2.7 \\
& & & & & \\
35 & $\mathrm{q} 2.0-5 \%$ & 1.9 & 2.0 & 2.0 & 1.6 \\
& $\mathrm{q} 2.5-5 \%$ & - & - & - & - \\
\hline
\end{tabular}

Table 2-4 Comparison of resolutions with $30 \mathrm{~cm}$ effective capillary separation $\left(\mathrm{R}_{30}\right)$ to 10 $\mathrm{cm}\left(\mathrm{R}_{10}\right)$ effective capillary separation. The values included in this table were calculated by taking resolution values $\left(R_{30}\right)$ in Table 2-3 divided by the values $\left(R_{10}\right)$ in Table 2-2. 
carbohydrate chains. The carbohydrate moiety of AGP has been thoroughly investigated because AGP is one of the few serum glycoproteins that contains diantennary, triantennary, and tetraantennary N-linked glycans [72]. Fetuin is an inhibitor of calcification, yielding diantennary and triantennary glycans [73]. These glycoproteins are used as standard samples for developing methodology with different techniques.

\subsubsection{Enhancement of CE Separations of Glycans with Phospholipid Additives.}

The effectiveness of phospholipid additives to distinguish linkage isomers was demonstrated with asialo-glycans released from fetuin. The asialyted glycans AI and AII were contained in both fetuin and AGP. The asialo-glycans FII and AII derived from fetuin are comprised of the same monomers and possess the same branched structure. These glycans differ only in the linkage of the terminal galactose in the middle antenna; FII is a $\beta 1,3$-linkage, while AII is a $\beta 1,4$ linkage (see Figure 2-8). The resolution of the FII/AII asialo-glycan pair was used as a measure of separation performance. As shown in Figure 2-8, FII and AII can be resolved under suppressed electroosmotic flow with a phospholipids enhanced separation; however they can not be discriminated in a bare fused silica capillary. To compare these two separations, samples were injected into the capillary with pressure for $2 \mathrm{~s}$ at $19{ }^{\circ} \mathrm{C}$. The applied pressure was adjusted $(2 \mathrm{kPa}$ for trace $\mathrm{A}$ and $3 \mathrm{kPa}$ for trace $\mathrm{B}$ ) so that the peak area of $\mathrm{AI}$ in each electropherogram varied no more than $2 \%$ to ensure that the injection volume was similar. The FII and AII peaks were barely resolved in a well-coated capillary; however, when a coated capillary was filled with phospholipid additives inside, the resolution of FII/AII from fetuin improved from 0.55 to 0.86 (see Table 2-5). 

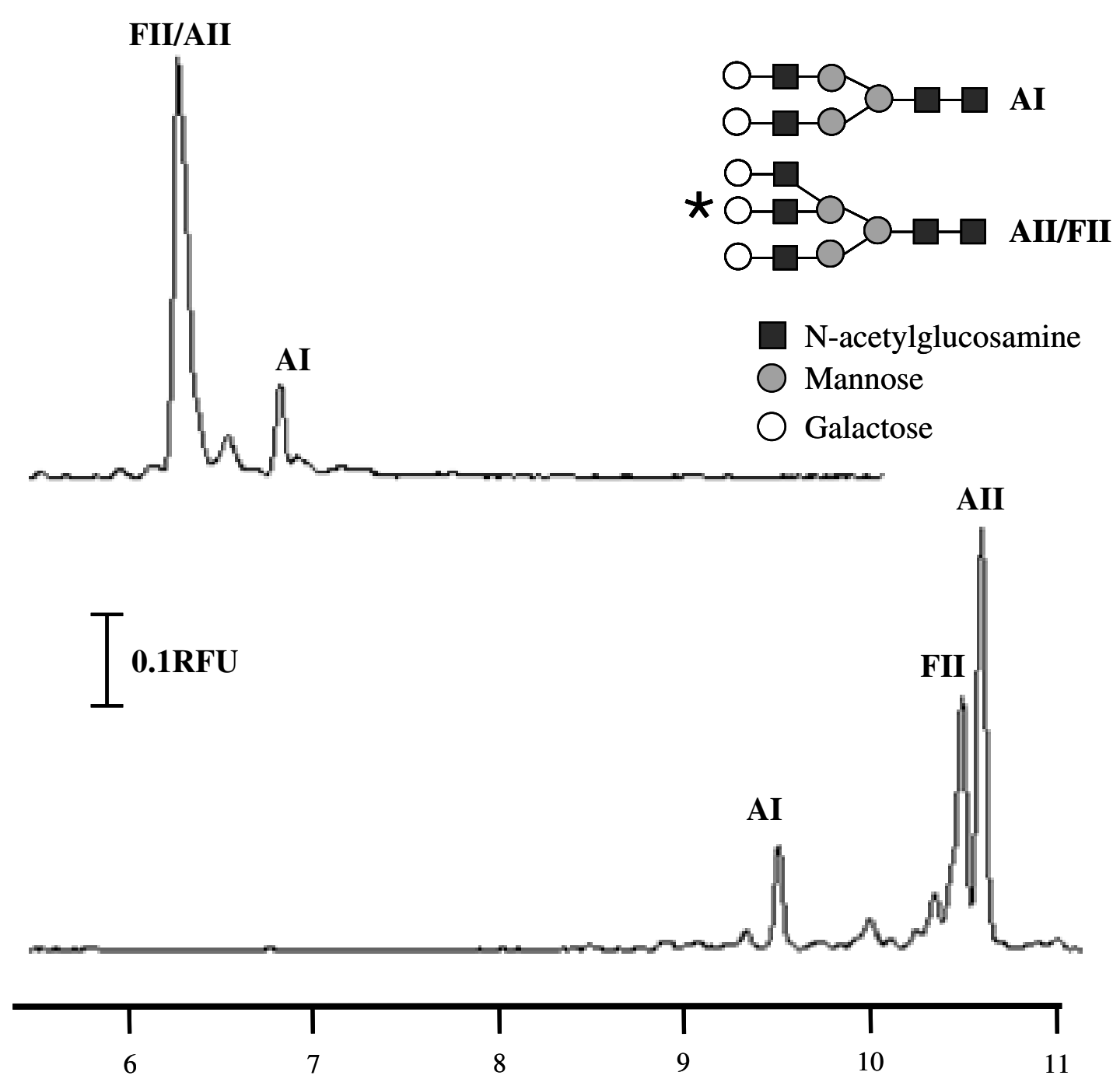

Migration time (min)

Figure 2-8 Demonstration of the advantage of using phospholipid additives to separate asialo-glycan isomers AII and FII derived from fetuin. The linkage to the galactose monomer labeled with the asterisk (*) is 1,3 in FII and 1, 4 in AII. The separation in trace A was accomplished in a bare fused silica capillary under normal polarity. The separation in trace B was obtained using phospholipid additive and a phospholipid coated capillary under identical conditions, except that it was performed with reversed polarity at $-16 \mathrm{kV}$. The total length of capillary was $40 \mathrm{~cm}$ and effective separation length was $30 \mathrm{~cm}$. The injection condition was described in the related paragraph. Reprinted with permission from reference [64]. Copyright 2010 American Chemical Society. 


\begin{tabular}{lllllll}
\hline & \multicolumn{2}{l}{$\begin{array}{l}\text { Untreated capillary } \\
\text { 0\% phospholipid }\end{array}$} & \multicolumn{2}{c}{$\begin{array}{l}\text { Coated capillary } \\
0 \% \text { phospholipid }\end{array}$} & \multicolumn{2}{c}{$\begin{array}{l}\text { Coated capillary } \\
10 \% \text { phospholipid }\end{array}$} \\
& $\mathrm{N}\left(\mathrm{X} 10^{3}\right)$ & $\mathrm{R}$ & $\mathrm{N}\left(\mathrm{X} 10^{3}\right)$ & $\mathrm{R}$ & $\mathrm{N}\left(\mathrm{X} 10^{3}\right)$ & $\mathrm{R}$ \\
\hline Fetuin & & & & & & \\
AI & $93 \pm 6$ & - & $150 \pm 9$ & - & $230 \pm 10$ & - \\
FII & - & - & $89 \pm 10$ & 6.7 & $250 \pm 20$ & 7.8 \\
All & - & - & $130 \pm 10$ & 0.55 & $270 \pm 20$ & 0.86 \\
& & & & & & \\
AGP & & & & & & \\
Al & $150 \pm 6$ & - & $150 \pm 6$ & - & $230 \pm 5$ & - \\
All & $150 \pm 4$ & 3.0 & $160 \pm 7$ & 4.5 & $240 \pm 5$ & 7.2 \\
AllI & $130 \pm 3$ & 0.70 & $150 \pm 8$ & 1.1 & $250 \pm 10$ & 2.1 \\
AIV & $150 \pm 3$ & 1.3 & $160 \pm 9$ & 2.1 & $240 \pm 10$ & 3.8 \\
AV & $130 \pm 5$ & 0.70 & $120 \pm 7$ & 1.2 & $200 \pm 5$ & 1.6 \\
\hline
\end{tabular}

Table 2-5 Theoretical plates $(\mathrm{N})$ and resolution $(\mathrm{R})$ for glycans derived from both fetiun and AGP. Reprinted with permission from reference [64]. Copyright 2010 American Chemical Society. 


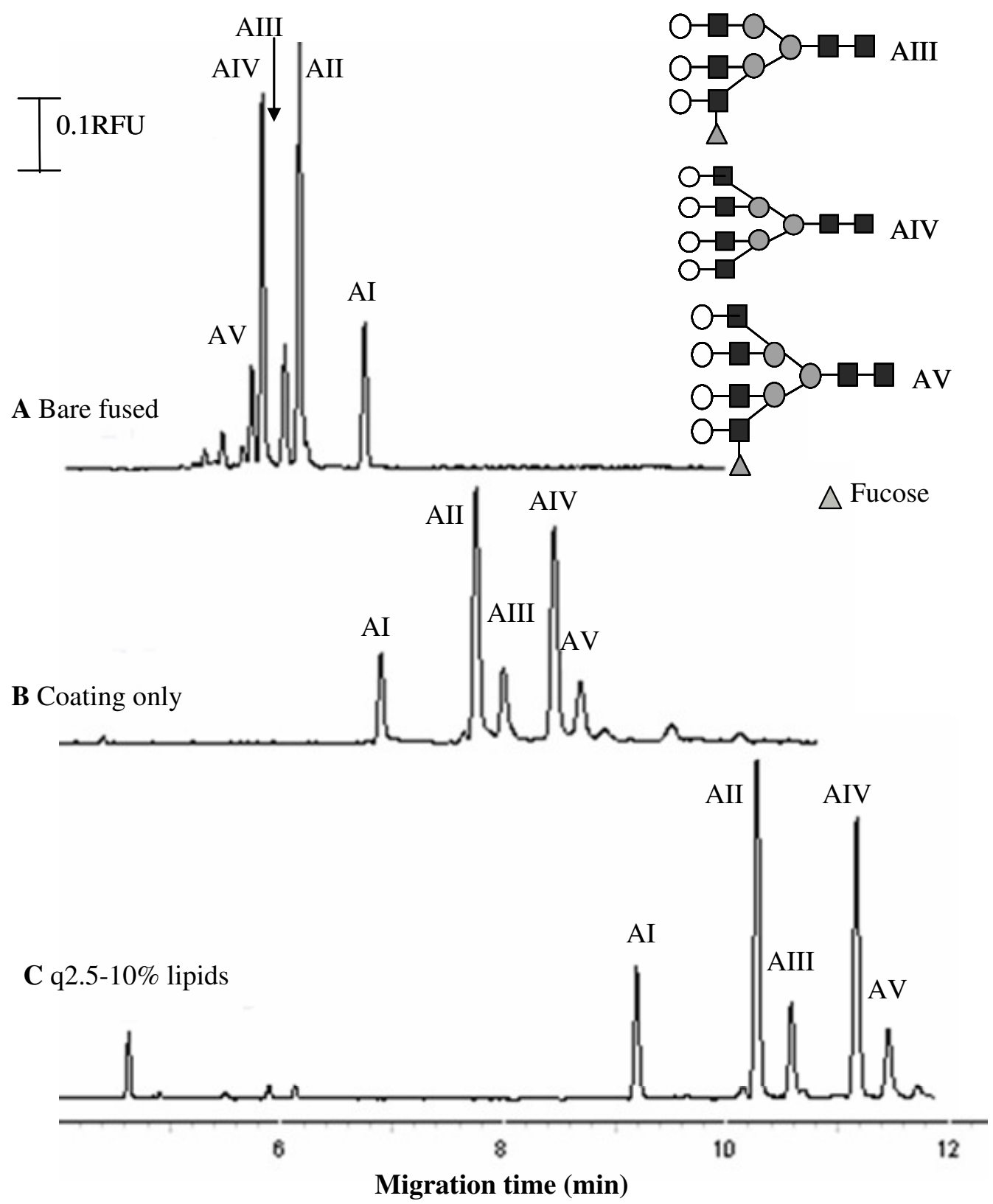

Figure 2-9 electrophoregrams of $\mathrm{N}$-glycans separation derived from AGP. The injection was adjusted to make sure that similar amount of sample was introduced into capillary. The separation condition was same to that described in Figure 2-8. 
In the case of glycans derived from AGP, the only difference for two glycan pairs including peak AII and AIII, and AIV and AV, is that AII and AIV have one more sugar unit (fucose) compare to AIII and AV respectively. The electrophoregrams in Figure 2-9 presented separations of $\mathrm{N}$-linked asialoglycans released from AGP at different conditions. The injection was also adjusted to make sure that similar amount of sample was introduced into capillary at different separation condition. Resolutions between these five sugars were significantly improved from a bare fused silica, relative to a lipid filled capillary. In the q 2.5-10\% lipid, all five asialoglycans were well resolved. The resolution was 2.2 to 3 times larger than the resolution from the bare fused silica condition. The theoretical plates of all glycans were better with q $2.5-10 \%$ lipids in the capillary (except AV in the bare fused silica condition) compared to both coating only and bare fused condition. The theoretical plates of AII derived from AGP, which does not contain FII, was used as a measure of separation efficiency and correlated with the resolution of the FII/AII glycans in fetuin. The theoretical plates increased from 160000 to 240000 for AII derived from AGP while introducing phospholipids additives into a coating only capillary as listed in Table 2-5.

The theoretical plate count of the AI peak found in both AGP and fetuin was measured and averaged from $21{ }^{\circ} \mathrm{C}$ to $35^{\circ} \mathrm{C}$ (see Tables $2-6$ and 2-7). At $25^{\circ} \mathrm{C}$, the plate count of the AI peak found in both AGP and fetuin ranged from 160000 to 240000 for $5 \%$ preparations $(\mathrm{q}=1.5,2.0,2.5)$ and from 180000 to 230000 for q 2.5 preparations (hydration $=5,10,15 \%$ ). Within the error of the measurement, most values were similar to that obtained for AII derived from AGP. 


\begin{tabular}{cccc}
$\begin{array}{c}\text { Theoretical Plates }(\mathbf{N}) \times \mathbf{1 0}^{3}, \mathbf{n}=\mathbf{6} \\
\mathrm{T}\left({ }^{\circ} \mathrm{C}\right)\end{array}$ & $\mathrm{q}=1.5$ & $\mathrm{q}=2.0$ & $\mathrm{q}=2.5$ \\
\hline 21 & ${ }^{*} 180 \pm 20$ & ${ }^{*} 150 \pm 10$ & $140 \pm 5$ \\
23 & ${ }^{*} 200 \pm 6$ & $240 \pm 20$ & $220 \pm 20$ \\
25 & $160 \pm 10$ & $240 \pm 20$ & $180 \pm 20$ \\
27 & $160 \pm 20$ & ${ }^{*} 200 \pm 5$ & $180 \pm 40$ \\
29 & $170 \pm 10$ & $170 \pm 9$ & $160 \pm 60$ \\
31 & $180 \pm 20$ & $130 \pm 20$ & $150 \pm 40$ \\
33 & ${ }^{*} 160 \pm 10$ & ${ }^{*} 140 \pm 20$ & $150 \pm 30$ \\
35 & $90 \pm 20$ & $140 \pm 40$ & $130 \pm 30$ \\
\hline
\end{tabular}

${ }^{*}$ Following application of the Q-test at $95 \%$ confidence one data point is removed.

Table 2-6 Efficiency (AI), $5 \%$ Hydration. Reprinted with permission from reference [64]. Copyright 2010 American Chemical Society.

Theoretical Plates (N) X $10^{3}, n=6$

\begin{tabular}{cccc}
$\mathrm{T}\left({ }^{\circ} \mathrm{C}\right)$ & $5 \%$ & $10 \%$ & $15 \%$ \\
\hline 21 & $140 \pm 5$ & $99 \pm 8$ & $72 \pm 8$ \\
23 & $220 \pm 20$ & $210 \pm 10$ & $150 \pm 20$ \\
25 & $180 \pm 20$ & $230 \pm 10$ & ${ }^{*} 220 \pm 10$ \\
27 & $180 \pm 40$ & $230 \pm 8$ & $210 \pm 30$ \\
29 & $160 \pm 60$ & $210 \pm 9$ & $220 \pm 20$ \\
31 & $150 \pm 40$ & $190 \pm 4$ & $200 \pm 30$ \\
33 & $150 \pm 30$ & $180 \pm 9$ & ${ }^{2} 200 \pm 8$ \\
35 & $130 \pm 30$ & $150 \pm 20$ & $160 \pm 40$ \\
\hline
\end{tabular}

${ }^{*}$ Following application of the Q-test at $95 \%$ confidence one data point is removed.

Table 2-7 Efficiency (AI), $\mathrm{q}=2.5$. Reprinted with permission from reference [64]. Copyright 2010 American Chemical Society. 


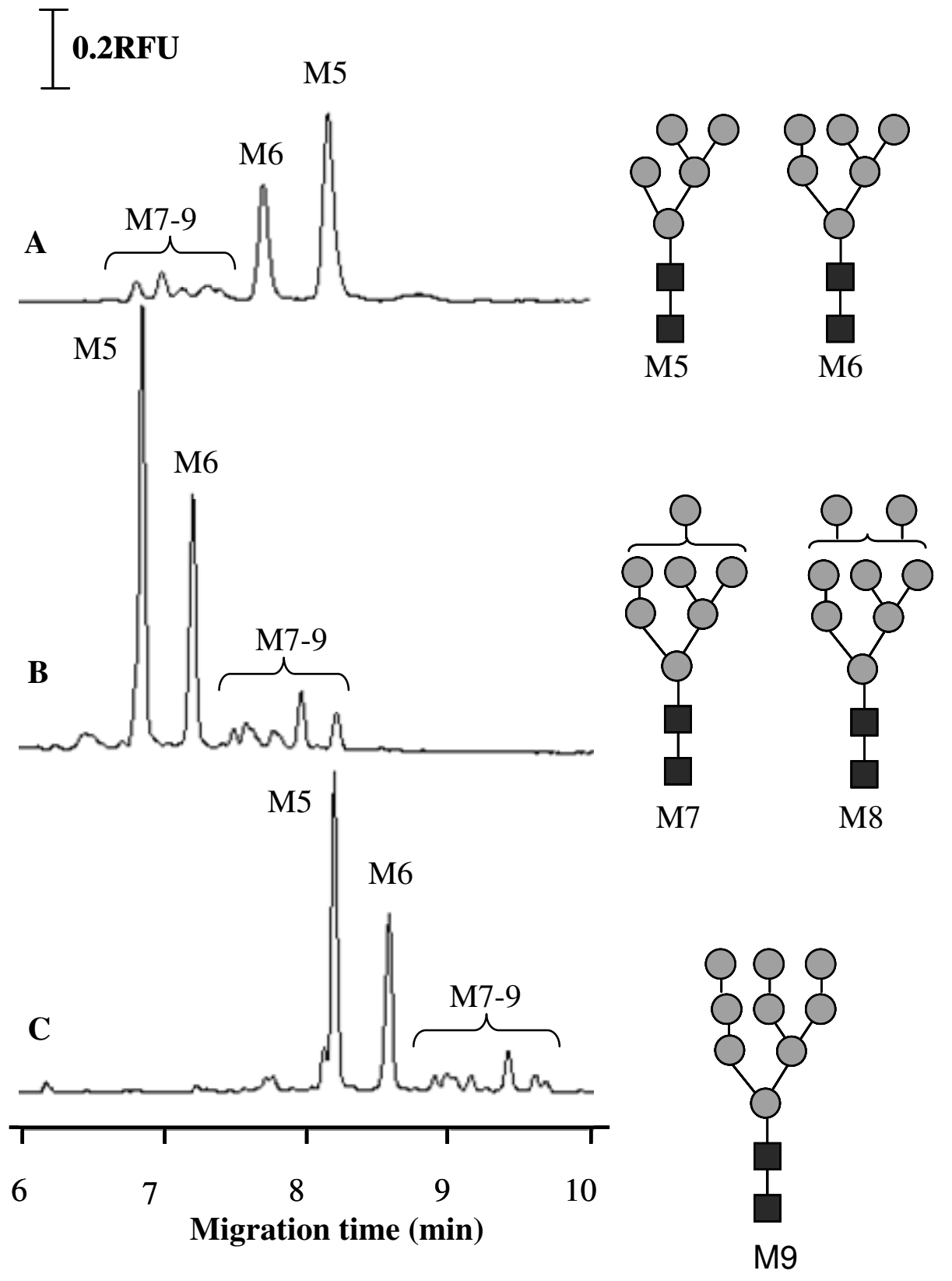

Figure 2-10 Electrophoregrams of glycans derived from RNase B. Separation conditions were identical to that in Figure 2-8, trace B. The structures of RNase B glycans were included. The symbols for glycan monomers were defined in Figure 2-8. 
RNase B is the glycosylated form of Ribonuclease A, an enzyme that catalyzes the breakdown of phosphodiester linkages of RNA [74]. RNase B contains asparaginelinked high mannose glycans. There are three positional isomers identified in both M7 and M8 from Rnase B in the literature [54]. In Figure 2-10, the peaks labeled with M7-9 should include three positional isomers from M7 and M8 respectively. Although most peaks were not baseline resolved, more peaks were apparent with q 2.5 - $10 \%$ lipids than bare fused and coating only capillary that further confirmed the ability of lipids to separate branched sugars with subtle differences.

\subsubsection{Sample Introduction for CE Separations that Incorporate Phospholipids.}

The viscosity of the phospholipid media is significantly dependent on temperature. The sample introduction for phospholipid-mediated capillary electrophoresis separations must account for this viscosity change. Hydrodynamic injections were performed for phospholipid preparations of different viscosity by injecting samples at temperatures below the gel-phase transition at which all phospholipid preparations display similar low viscosity. Following the injection, the capillary temperature was increased to a specified value and the separation proceeds. Electrokinetic sample introduction was frequently employed in capillary gel electrophoresis, and the use of an aqueous plug prior to injection in gel electrophoresis improves sample introduction [75]. Incorporation of a post injection aqueous plug reduces peak tailing [76]. Aqueous plugs may also be integrated in phospholipids separations to increase peak area, improve reproducibility in peak area, and reduce peak tailing. As demonstrated in the separations of AGP shown in Figure 2-11, trace A was 

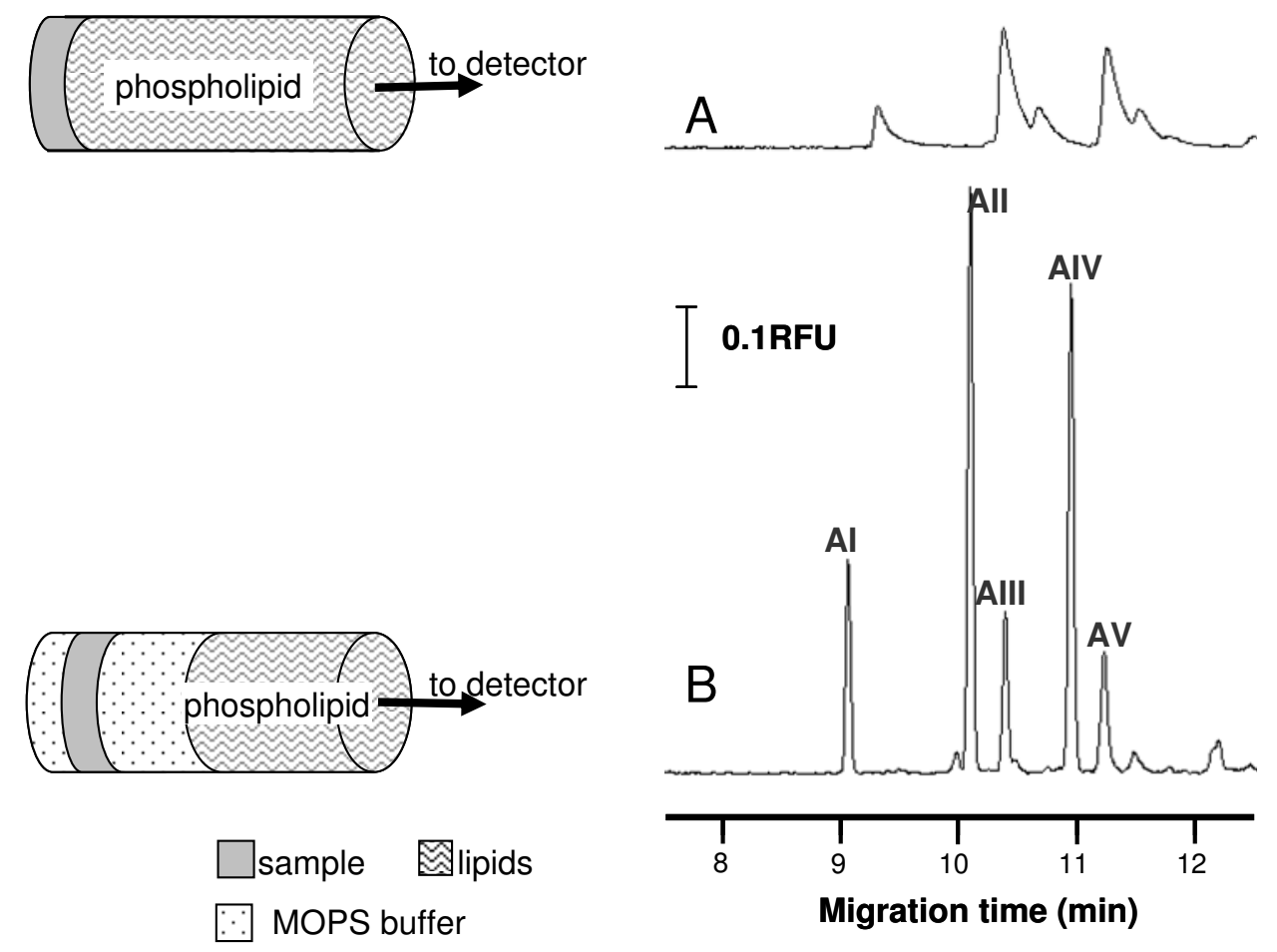

Figure 2-11 Illustration of the need for the injection procedure used in trace $B$ to evaluate separation performance of phospholipid media. As shown in the schematic to the left, the sample (solid gray) was introduced into the capillary with an electrokinetic injection directly into phospholipid (wavy lines) or with aqueous buffer plugs (dotted) introduced before and after the sample injection. The separation was achieved at $25^{\circ} \mathrm{C}$, with $q 2.5-10 \%$ phospholipid at $-16 \mathrm{kV}, 50 \mu \mathrm{m}$ inner diameter, effective capillary length $30.2 \mathrm{~cm}$, total capillary length $40 \mathrm{~cm}$. Reprinted with permission from reference [64]. Copyright 2010 American Chemical Society. 
injected directly into the phospholipid while trace B was obtained with a plug of aqueous MOPS buffer devoid of phospholipid additives that was introduced before and after the sample. For both separations, the capillary was filled with phospholipid preparation at 19 ${ }^{\circ} \mathrm{C}$ and then the temperature was increased for the separation. The coefficient of variation of peak area for $\mathrm{AI}(n=3)$ was $8 \%$ when the injection protocol incorporates aqueous plugs, as compared to $15 \%$ without the aqueous plugs. The peak asymmetry for AI $(n=3)$ was 1.04 with and 2.3 without the use of aqueous plugs during injection.

With the injection methods described in Figure 2-11 trace B, sample plug can be introduced hydrodynamically or electrokinetically. The reproducibility of both methods was evaluated for this injection protocol. As shown in Table 2-8, electrokinetic injection resulted in better reproducibility for peak area and peak width. In the electrophoregrams shown in Figure 2-12, an unknown peak (a) in trace B, which was not seen in trace A of pressure injection also showed the advantage to using EK injection in this research.

Contribution of this injection process to band broadening was evaluated here. The injection variance has been exclusively studied in chromatography first [77-78], and then was adapted into capillary electrophoresis system [79-80]. The studies from these groups indicated that a less than $10 \%$ variance from injection could be considered small and did not cause obvious change on theoretical plate or plate height [54, 77, 81].

Equation 3 shows two potential sources of variance in the phospholipid separation, where $\sigma_{\text {inj }}^{2}$ and $\sigma^{2}$ diff are variances due to injection and diffusion in the lipid filled capillary, respectively.

$$
\sigma_{\text {tot }}^{2}=\sigma_{\text {inj }}^{2}+\sigma_{\text {diff }}^{2}
$$

For an ideal rectangular plug injected, the variance $\sigma_{\text {inj }}^{2}$ is written as 
A. $0.7 \mathrm{kPa}(0.1 \mathrm{psi}) 3 \mathrm{sec}$ injection (based on 5 replicate runs)

\begin{tabular}{ccccccc}
\hline glycan & Tm(min) & RSD $\%$ & Area & RSD\% & Width & RSD(\%) \\
Al & 7.436 & 1 & 25129 & 19 & 0.152 & 6 \\
All & 8.282 & 1 & 77689 & 19 & 0.170 & 9 \\
Alll & 8.523 & 1 & 19747 & 20 & 0.142 & 6 \\
AIV & 8.971 & 1 & 74253 & 20 & 0.186 & 3 \\
AV & 9.195 & 1 & 18418 & 19 & 0.164 & 5 \\
\hline
\end{tabular}

B. $5 \mathrm{kV} 6 \mathrm{sec}$ sample injection (based on 4 replicate runs)

\begin{tabular}{ccccccc}
\hline glycan & Tm(min) & RSD\% & Area & RSD\% & Width & RSD\% \\
Al & 7.361 & 1 & 50408 & 8 & 0.130 & 0 \\
All & 8.164 & 1 & 138532 & 9 & 0.130 & 0 \\
All & 8.392 & 1 & 36670 & 9 & 0.128 & 4 \\
AIV & 8.815 & 1 & 121713 & 12 & 0.148 & 3 \\
AV & 9.025 & 1 & 30345 & 10 & 0.120 & 0 \\
\hline
\end{tabular}

Table 2-8 Comparison of pressure injection and EK injection performance. Two MOPS plugs described in Figure 2-10. B was applied in both injection methods. The separation was obtained with q $2.5-10 \%$ lipids at $29^{\circ} \mathrm{C}$ in the $400 \mathrm{~V} / \mathrm{cm}$ electric field. 

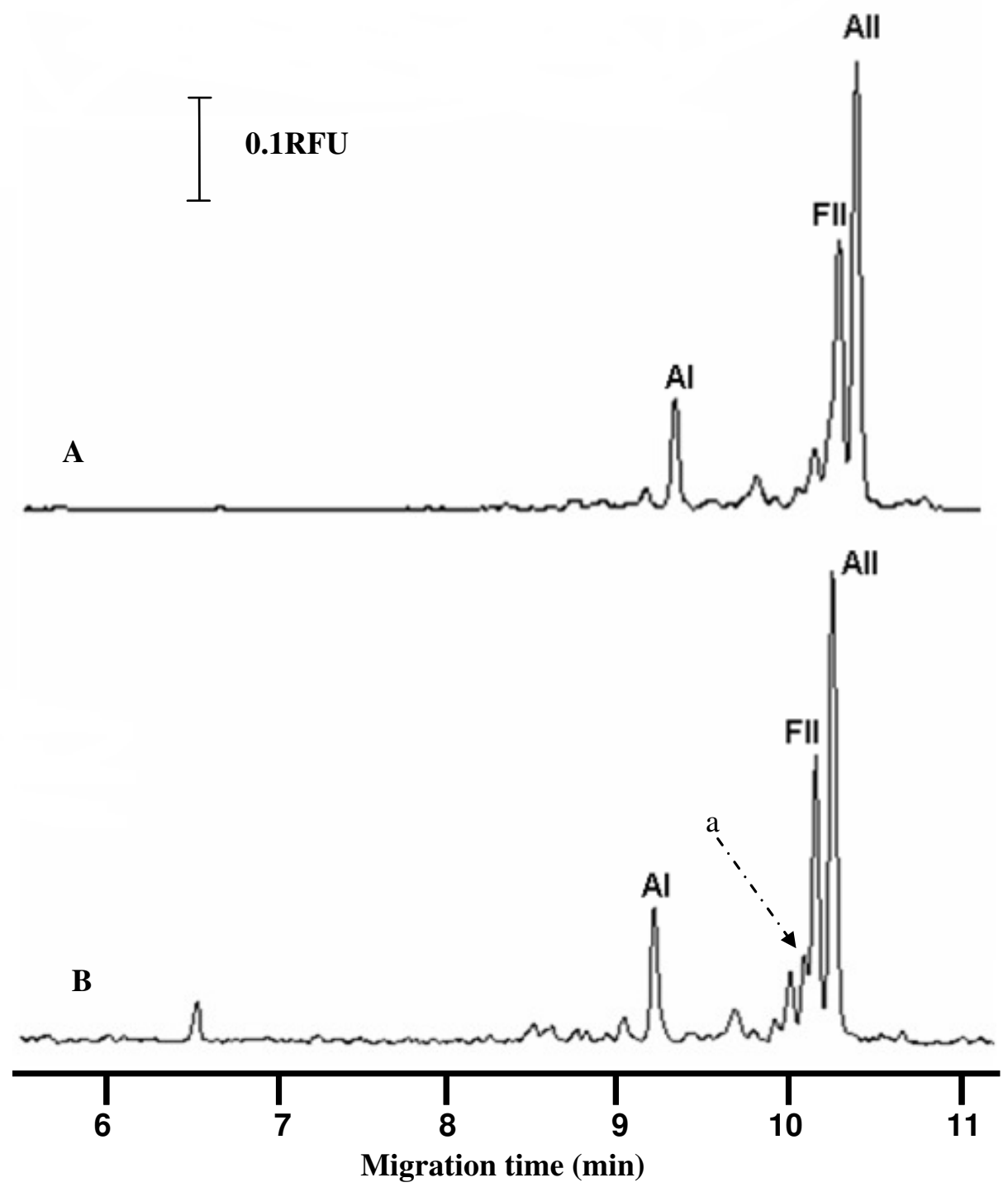

Figure 2-12 The injection method described in Figure 2-10 (B) was used here except that (A) was from pressure injection of $0.7 \mathrm{kPa}(0.1 \mathrm{psi}) 2 \mathrm{sec}$ and (B) was from EK injection (5 kV $6 \mathrm{sec})$. 


$$
\sigma_{\text {inj }}^{2}=l^{2} / 12
$$

where lis the width of injected sample plug [82]. A method used by Liu et al is adapted here for the calculation of variance [81]. Based on their method, a simplified equation can be used to estimate l values

$$
l=v_{\text {eph }} t_{\text {inj }}=L E_{\text {inj }} /\left(E_{\text {sep }} t_{\text {mig }}\right) t_{\text {inj }}
$$

where $v_{\mathrm{eph}}$ is the electrophoretic velocity of solutes, $\mathrm{t}_{\mathrm{inj}}$ is the injection time, $\mathrm{E}_{\mathrm{inj}}$ and $\mathrm{E}_{\mathrm{sep}}$ are the electrical field for injection and separation respectively, L is the effective separation length and $t_{\text {mig }}$ is the migration time of solute [81]. The calculated $l$ values at different lipid condition were applied to the equation (2-2). The data from q $2.5-5 \%$, $10 \%$ and $15 \%$ from $25{ }^{\circ} \mathrm{C}$ to $35{ }^{\circ} \mathrm{C}$ were plotted into these equations. Table 2-9 showed the calculated variances using AII peak from AGP and AI peak from fetuin. As shown in this table, contribution of $\sigma_{\text {inj }}^{2}$ was less than $7 \%$ at most separation condition examined. With this result, we know that a bias from $\sigma_{\text {inj }}^{2}$ was not taken account into the separation efficiency of lipids themselves while theoretical plates and resolution were compared at different temperature, q values and hydrations.

\subsubsection{Factors Relevant to Evaluate Separation Performance of Phospholipids Assisted CE.}

This study focused on five different phospholipid preparations comprising two different sets of running buffer additives. The first set contained 5\% w/v phospholipids/aqueous MOPS at different $q$ values. The second set of running buffers were prepared at a DMPC/DHPC molar ratio of $\mathrm{q}=2.5$ but varying content at $5 \%, 10 \%$, and $15 \%$ phospholipid by weight. The aqueous MOPS buffer was selected to keep the separation current low $\left(<25 \mu \mathrm{A}\right.$ at $\left.25^{\circ} \mathrm{C}\right)$ to reduce the likelihood of Joule heating and to 


\begin{tabular}{|c|c|c|c|c|c|c|}
\hline \multirow[b]{3}{*}{ Tem $\left({ }^{\circ} \mathrm{C}\right)$} & \multicolumn{3}{|c|}{ All from AGP } & \multicolumn{3}{|c|}{ Al from fetuin } \\
\hline & \multicolumn{3}{|c|}{$\sigma^{2}{ }_{\text {inj }} / \sigma^{2}{ }_{\text {tot }}(\%)$} & \multicolumn{3}{|c|}{$\sigma^{2}{ }_{\text {inj }} / \sigma^{2}{ }_{\text {tot }}(\%)$} \\
\hline & q2.5-5\% & q2.5-1( & $2.5-15 \%$ & q2.5-5\% & q2.5-10 & $2.5-15 \%$ \\
\hline 25 & 6.6 & 5.3 & 3.6 & 8.1 & 5.6 & 5.0 \\
\hline 27 & 5.8 & 5.5 & 4.5 & 9.0 & 6.3 & 7.0 \\
\hline 29 & 4.5 & 6.3 & 4.3 & 9.6 & 6.6 & 5.3 \\
\hline 31 & 6.3 & 5.1 & 4.9 & 7.7 & 5.3 & 6.6 \\
\hline 33 & 7.0 & 4.9 & 5.8 & 9.0 & 7.3 & 5.8 \\
\hline 35 & 5.1 & 3.0 & 3.7 & 8.1 & 7.0 & 4.2 \\
\hline
\end{tabular}

Table 2-9 Injection variances contributing to band broadening. The calculation was based on triplet runs. 
maintain the $\mathrm{pH}$ at 7 . The addition of phospholipids in the running buffer did not increase the separation current.

\subsubsection{Effect of $q$ Value on Separation Performance.}

Three preparations of $5 \%$ phospholipid $(\mathrm{q}=1.5, \mathrm{q}=2.0, \mathrm{q}=2.5)$ were evaluated for separation performance. At constant temperature, the migration time of analyte generally decreased with increasing DMPC content. As temperature increased, the migration time of glycans decreased with all $q$ values (see Figure 2-13). The reproducibility of migration time depended on the temperature and $q$ value. The $q=2.5$ preparation was most reproducible with a coefficient of variation for AII migration time ranging from 0.2 to $3 \%$. For the $\mathrm{q}=2.0$ preparation, AII migration ranged from 0.1 to $20 \%$ and from 0.1 to $10 \%$ for the $\mathrm{q}=1.5$ preparation. There was no clear trend in the theoretical plate count of AII or FII/AII resolution for separations obtained with $5 \%$ phospholipid preparations (Tables 2-10). Reproducible separations were necessary to determine the most suitable preparation for separation. Therefore, only the $q=2.5$ preparation was characterized further.

\subsubsection{Effect of Hydration $(q=2.5)$ on Separation Performance.}

The $\mathrm{q}=2.5-10 \%$ preparation performed better than the $\mathrm{q}=2.5-5 \%$ and $15 \%$ preparations. It produced the highest theoretical plate count (240 000) and resolution (0.86) of the FII/AII pair from fetuin (see Tables 2-11 and 2-12). The analyte migration time decreased with decreasing phospholipid content (see Figure 2-14). The most reproducible migration times were obtained with the $q=2.5-10 \%$ phospholipid preparation, with the coefficient of variation for AII migration time ranging from 0.1 to $0.9 \%$ (CV for AII for $5 \%$ and $15 \%$ is $0.2-3 \%$ and $0.1-0.9 \%$, respectively). 


\section{Change in All Migration Time with Temperature (5\% Phospholipid)}

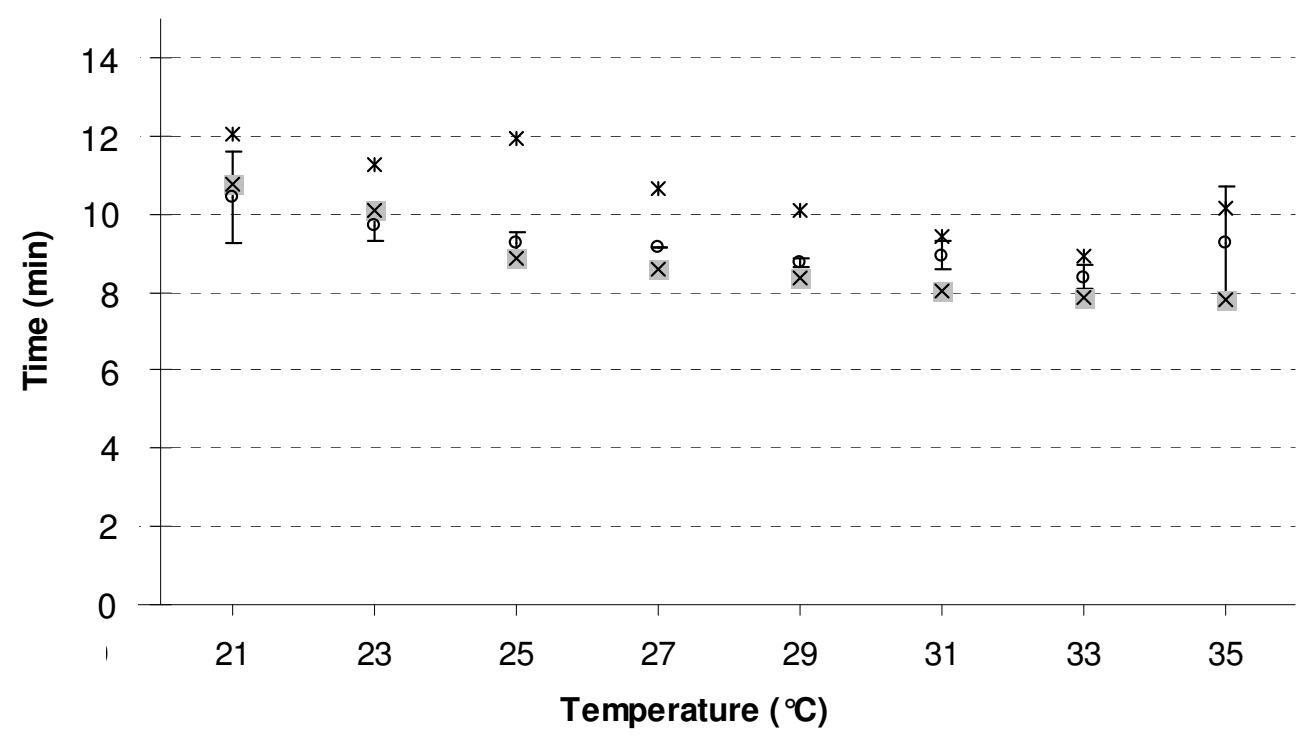

Figure 2-13 displays the change in migration time for AII derived from AGP $(\mathrm{n}=3)$ with increasing temperature for a $5 \% \mathrm{q}=2.5(\mathrm{X}), \mathrm{q}=2 \%(\%)$, and $\mathrm{q}=$ 1.5 (ж) preparation. The separation conditions are identical to that described for Figure 2 trace B. For clarity, error bars in are included only for q 2.0, which had the least reproducible migration times of the three preparations. Reprinted with permission from reference [64]. Copyright 2010 American Chemical Society. 
Change in All Migration Time with Temperature (q2.5 Phospholipid)

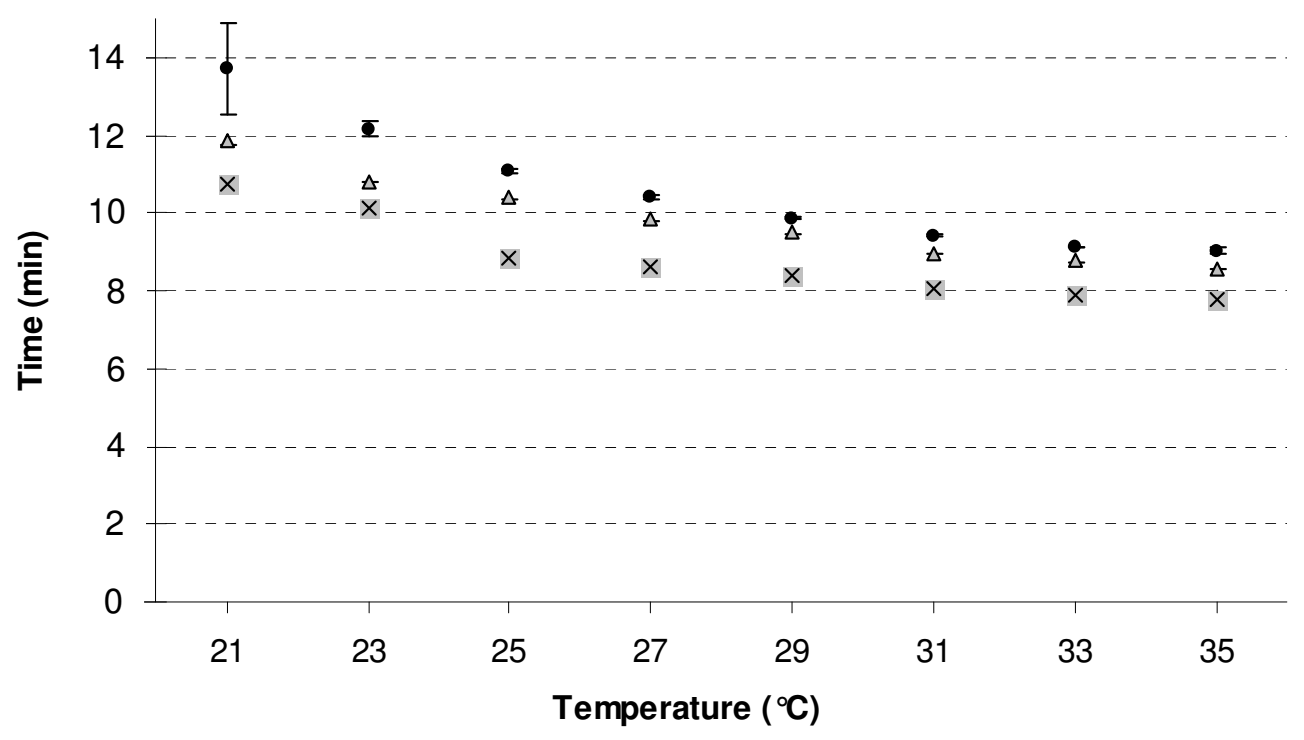

Figure 2-14 Change in migration time for AII derived from AGP with increasing temperature for a q $2.5-5 \%(x), 10 \%(\Delta)$, and $15 \%(\bullet)$ preparation. The separation conditions were identical to that described for Figure 2, trace B. Reprinted with permission from reference [64]. Copyright 2010 American Chemical Society. 
A. Efficiency (AlI), 5\% hydration.

\begin{tabular}{cccc}
$\begin{array}{c}\text { Theoretical Plates }(\mathrm{N}) \\
\mathrm{T}\left({ }^{\circ} \mathrm{C}\right)\end{array}$ & $\mathbf{1} \mathbf{0}^{3}, \mathbf{n}=3$ & \\
\hline 21 & $\mathrm{q}=1.5$ & $\mathrm{q}=2.0$ & $\mathrm{q}=2.5$ \\
23 & $190 \pm 10$ & $160 \pm 0.6$ & $120 \pm 4$ \\
25 & $200 \pm 30$ & $240 \pm 5$ & $220 \pm 4$ \\
27 & $140 \pm 0.3$ & $200 \pm 7$ & $190 \pm 5$ \\
29 & $160 \pm 0.7$ & $200 \pm 8$ & $150 \pm 30$ \\
31 & $160 \pm 20$ & $180 \pm 3$ & $110 \pm 10$ \\
33 & $160 \pm 3$ & $130 \pm 20$ & $120 \pm 4$ \\
35 & $150 \pm 4$ & $150 \pm 20$ & $130 \pm 10$ \\
\hline
\end{tabular}

B. Resolution (FII/AII), 5\% hydration, $\mathrm{n}=3$.

\begin{tabular}{cccc}
$\mathrm{T}\left({ }^{\circ} \mathrm{C}\right)$ & $\mathrm{q}=1.5$ & $\mathrm{q}=2.0$ & $\mathrm{q}=2.5$ \\
\hline 21 & 0.80 & 0.64 & 0.67 \\
23 & 0.72 & 0.76 & 0.72 \\
25 & 0.87 & 0.67 & 0.57 \\
27 & 0.68 & 0.67 & 0.69 \\
29 & 0.69 & 0.66 & 0.64 \\
31 & 0.75 & 0.47 & 0.58 \\
33 & 0.69 & 0.61 & 0.58 \\
35 & 0.56 & 0.67 & 0.58 \\
\hline
\end{tabular}

Table 2-10 Reprinted with permission from reference [64]. Copyright 2010 American Chemical Society. 


\begin{tabular}{cccc}
$\mathrm{T}\left({ }^{\circ} \mathrm{C}\right)$ & $5 \%$ & $10 \%$ & $15 \%$ \\
\hline 21 & 0.67 & 0.62 & 0.62 \\
23 & 0.72 & 0.72 & 0.70 \\
25 & 0.57 & 0.86 & 0.81 \\
27 & 0.69 & 0.82 & 0.77 \\
29 & 0.64 & 0.65 & 0.73 \\
31 & 0.58 & 0.64 & 0.72 \\
33 & 0.58 & 0.68 & 0.62 \\
35 & 0.58 & 0.61 & 0.73 \\
\hline
\end{tabular}

CV ranges from $0.01-4 \%$.

Table 2-11 Resolution (FII/AII), $\mathrm{q}=2.5, n=3$. Reprinted with permission from reference [64]. Copyright 2010 American Chemical Society.

\begin{tabular}{l}
$\begin{array}{l}\text { Theoretical Plates }(\mathbf{N}) \mathbf{X} \mathbf{1 0}^{\mathbf{3}}(\mathbf{n}=\mathbf{3}) \\
\mathrm{T}\left({ }^{\circ} \mathrm{C}\right)\end{array}$ \\
\hline $2 \%$
\end{tabular}

Table 2-12 Efficiency (AII), $\mathrm{q}=2.5$. Reprinted with permission from reference [64]. Copyright 2010 American Chemical Society. 

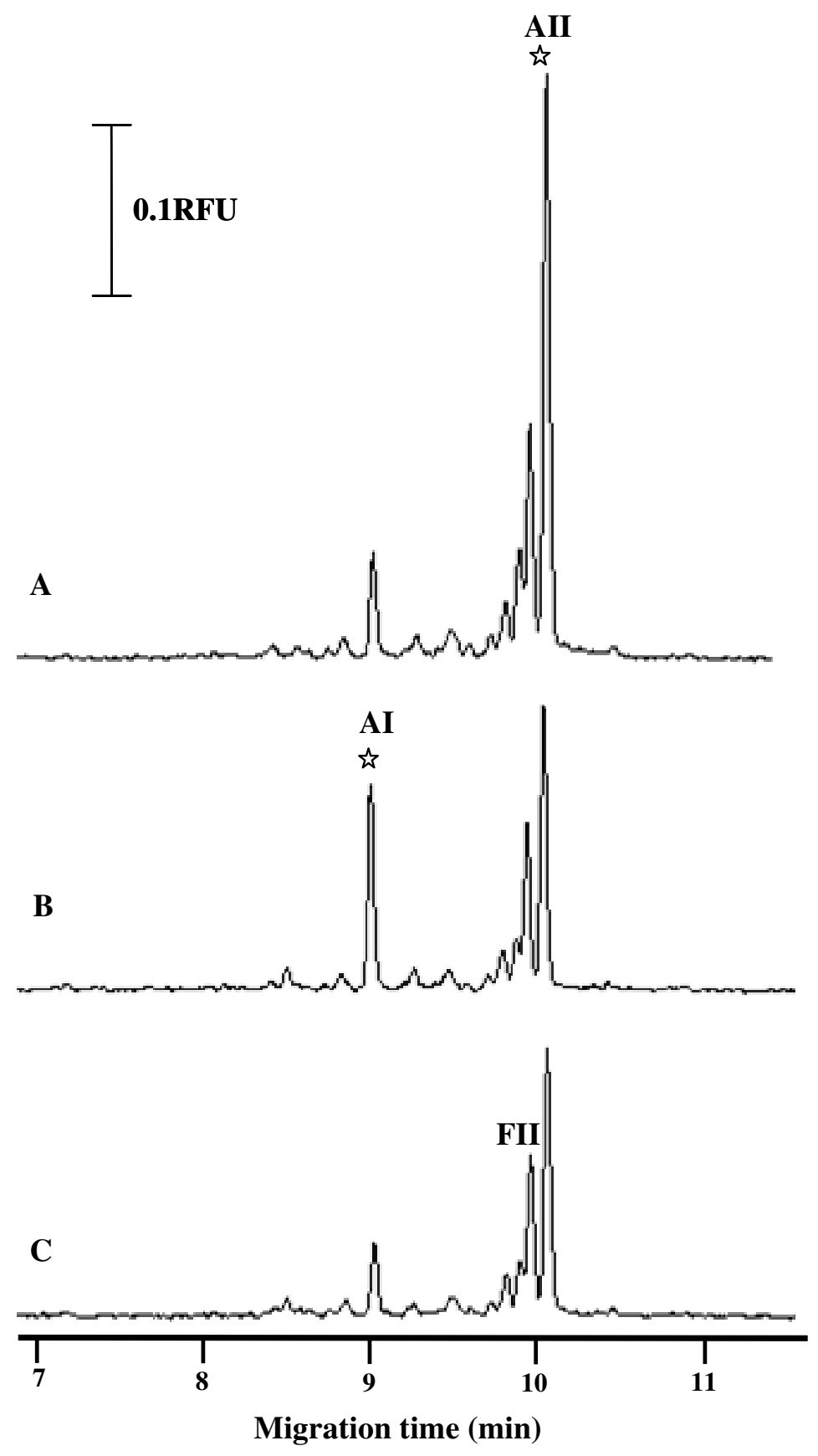

Figure 2-15 Displays the process of peak identification for asialofetuin using standards. The electrophoregrams in traces A and B were spiked with a standard solution of AII (trace A) or AI (trace B). The electrophoregram of asialofetuin in trace $\mathrm{C}$ was obtained prior to adding standard. The separations were achieved with q $2.5-10 \%$ phospholipid at $16 \mathrm{kV}$, reversed polarity, at $25{ }^{\circ} \mathrm{C}$. Samples were injected for $6 \mathrm{sec}$ at $5 \mathrm{kV}$ at $25{ }^{\circ} \mathrm{C}$. 


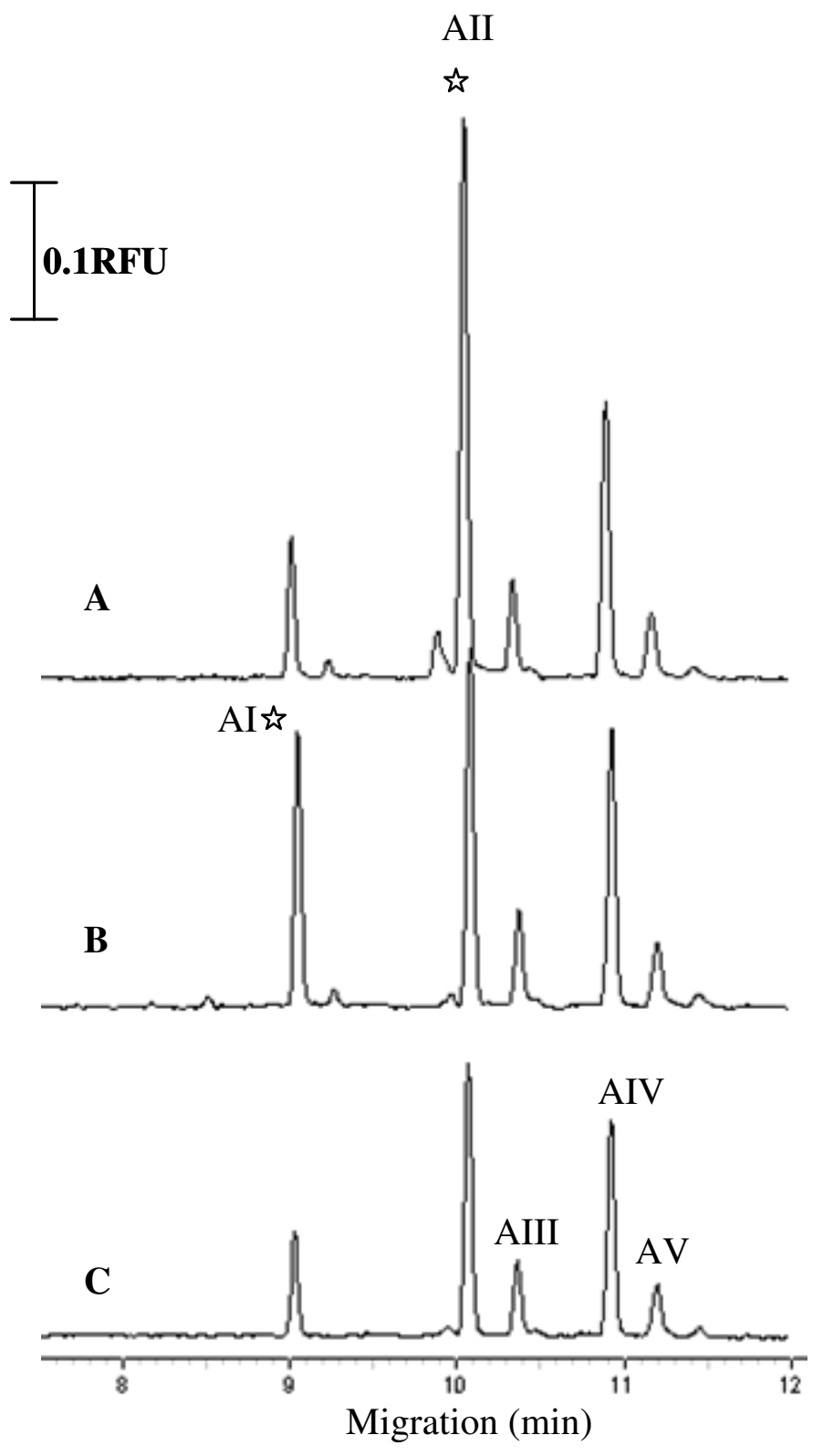

Figure 2-16 shows standard identification of AGP. The sample was spiked with standard AII (A), AI (B), and without addition of standard (C). The spiked peak was labeled with an asterisk. The separation and injection were identical to that reported in Figure 2-15. 
In this work, commercially available standards AI, AII, and Man5 were used for glycan identification. Glycan samples from fetuin and AGP were spiked with AI and AII glycan standards respectively. As shown in Figure 2-15 and Figure 2-16, compared to the original sample, an obvious increase of a peak height in a standard spiked sample confirmed the presence of that molecule in this sample. The remaining peaks were identified through comparisons with literately reported electrophoregrams.

\subsubsection{Phospholipids Assisted Separation at $25^{\circ} \mathrm{C}$.}

The highest separation efficiency for the glycans used in this study was observed for $\mathrm{q}=2.5-10 \%$ additive at $25^{\circ} \mathrm{C}$. Viscosity measurements performed in fused silica capillary in the absence of electric field indicate $25{ }^{\circ} \mathrm{C}$ was the onset for viscosity increase. When phospholipid-assisted separations were accomplished in a $50 \mu \mathrm{m}$ inner diameter capillary at $25^{\circ} \mathrm{C}$ with increasing field strength, the best separation efficiency is obtained at $400 \mathrm{~V} / \mathrm{cm}$. Joule heating could potentially increase the internal capillary temperature, which would in turn change the phospholipid morphology. Monitoring separation efficiency with applied field strength can reveal significant thermal effects [83]. However, phospholipid-assisted separations with $q=2.5-10 \%$ additive accomplished using a $25 \mu \mathrm{m}$ inner diameter capillary thermostatted at $25{ }^{\circ} \mathrm{C}$ also provided the best separation efficiency at $400 \mathrm{~V} / \mathrm{cm}$ (separation current $=5 \mu \mathrm{A}$ ) as shown in Figure 2-17. If temperature gradients were significant in the $50 \mu \mathrm{m}$ inner diameter capillary, the decreased separation current and improved heat dissipation of the smaller diameter capillary should have substantially improved separation performance. As investigated by nuclear magnetic resonance (NMR) methodology, phospholipids 


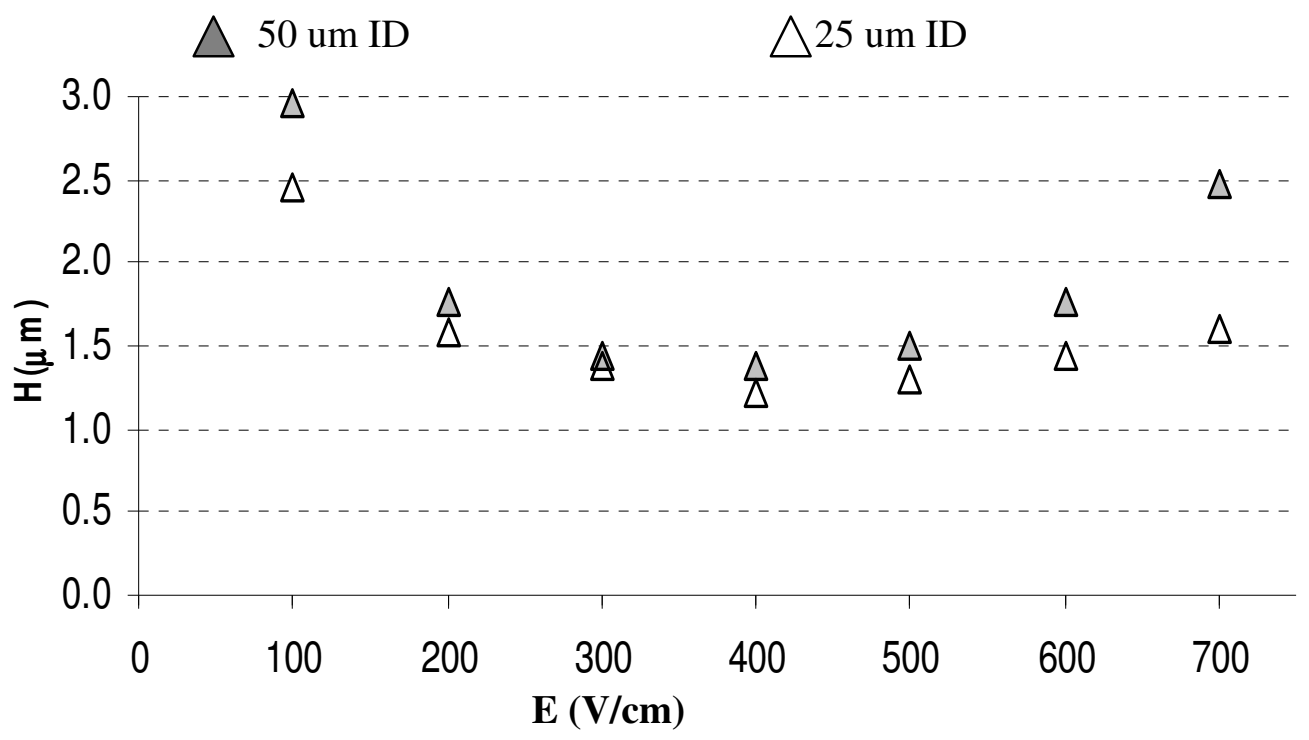

Figure 2-17 Separation efficiency (AI) as a function of electric field. 
assemble as bicelles under $25^{\circ} \mathrm{C}$, and form ribbons and lamelle sheets above $31{ }^{\circ} \mathrm{C}$. It seems to imply that the separation performance might have some thing to do with lipid morphology, assuming same morphologies are adapted under the tested electric field. However, quite different separation performances were obtained with same lipids at 27 ${ }^{\circ} \mathrm{C}$ compared to $25{ }^{\circ} \mathrm{C}$, although $27{ }^{\circ} \mathrm{C}$ were reported in same morphology domain with $25{ }^{\circ} \mathrm{C}$.

The use of phospholipid additive was simple to implement and improves glycan separations. Based on the observations in this article, the most likely source of improved separations was differences in viscosity of the phospholipid preparations. An increase in the running buffer viscosity affects frictional drag and decreases electrophoretic mobility. In these experiments, as the lipid content increased the migration time increased. Electroosmotic flow was effectively suppressed with the coating procedure and is not affected by a change in viscosity of the running buffer. In capillary zone electrophoresis, where diffusion is the only main source for band broadening, resolution between two peaks can be expressed with following equation

$$
R_{\mathrm{s}}=0.177 \Delta \mu_{\theta p} \sqrt{\frac{F I}{\left(\mu_{\theta p}+\mu_{\theta \theta}\right) D_{m}}}
$$

where $\Delta \mu_{\mathrm{ep}}$ is the difference in mobility between two analytes, $\mathrm{D}_{\mathrm{m}}$ is the diffusion coefficient of analytes [84]. Based on this equation and the investigation by Schure et al, the resolution between two peaks could be improved when the direction of EOF was opposite to electrophoretic mobility of analytes and the apparent mobility of solutes decreases while adding viscous additives into separation buffer [85]. Viscosity was suspected not the only source for the improved separation; otherwise, $15 \%$ lipids would offer better separation performance than $10 \%$ lipids. However, this equation is invalid 
when other sources are involved into main factors of band broadening. Increased migration time with increased lipid content could potentially be attributed to weak interaction between the derivatized oligosaccharides and the phospholipid additive similar to chromatographic retention; however, further studies are necessary to substantiate this.

Glycan separations accomplished with capillary gel electrophoresis were not attributed to sieving $[31,47,86]$. An early work incorporating polyethylene oxide in the running buffer reported a separation mechanism based on differences in charge-to-mass ratio. This group fit their data with a plot of the logarithm of velocity vs. logarithm of molecular mass of a homologous series [86]. Migration of analytes in a gel solution is typically said sieving in an electric field while a different slope above and below the entanglement of polymer solution are obtained from these plots. With their experiments, the data fit was linear $\left(R^{2}=0.998\right)$ and the slope was the same above and below the entanglement threshold for the polymer, which excluded the sieving behavior of sugar molecular. Logarithmic plots of the data obtained with phospholipid additives, yield good linear fits $\left(R^{2}=0.999\right)$ and similar slope $(-0.620)$ for separations regardless of q value or percent hydration (Table 2-13). Although the data set obtained with phospholipids additives was limited, analyses of linear and branched glycans using plots of logarithm mobility vs. percent hydration (Ferguson plots) did not confirm sieving.

\subsubsection{CONCLUSIONS}

This chapter demonstrated the use of phospholipid additives for efficient glycan separations. The separation was accomplished without covalent modification of the capillary surface to suppress electroosmotic flow. The most efficient separations were 


\begin{tabular}{cccccc}
$\mathrm{T}\left({ }^{\circ} \mathrm{C}\right)$ & $\mathrm{q}=1.0$ & $\mathrm{q}=1.5$ & $\mathrm{q}=2.0$ & $\mathrm{q}=2.5$ & $\mathrm{q}=2.5$ \\
& $5 \%$ & $5 \%$ & $5 \%$ & $5 \%$ & $10 \%$ \\
\hline 20 & 0.709 & 0.746 & 0.614 & 0.620 & 0.581 \\
25 & 0.570 & 0.671 & 0.600 & $0.607^{\star}$ & 0.606 \\
30 & 0.626 & 0.603 & 0.600 & 0.600 & $0.586^{\star}$ \\
35 & 0.671 & 0.586 & 0.605 & 0.614 & 0.584 \\
\hline
\end{tabular}

Data is derived from maltooligosaccharides G3, G4, G5, G6, G7. Mobility collected in triplicate, except for points indicated by "*" for which $n=2$.

Table 2-13 Slope log mobility vs. $\log$ MW. Reprinted with permission from reference [64]. Copyright 2010 American Chemical Society. 
obtained with a q 2.5 - 10\% preparation and can be accomplished in a 50 or $25 \mu \mathrm{m}$ inner diameter capillary. The elimination of covalent surface modification and the ease with which the preparation was introduced into separation capillaries at low temperature (and low viscosity) make it particularly interesting for microfluidic separations or separations. Continued characterization of preparations of different composition and hydration is currently underway to expand the application of this additive and determine if other separation mechanisms may be implemented with phospholipids. 


\section{References}

1. Lindhorst, T.K., Essentials of carbohydrate chemistry and biochemistry. 2nd edition ed. 2003: Wiley-Vch.

2. Lowe, J.B. and Marth, J.D., A genetic approach to mammalian glycan function. Annual Review of Biochemistry, 2003. 72(1): p. 643-691.

3. Park, S., Lee, M.-R., and Shin, I., Chemical tools for functional studies of glycans. Chemical Society Reviews, 2008. 37(8): p. 1579-1591.

4. Mechref, Y. and Novotny, M.V., Structural investigations of glycoconjugates at high sensitivity. Chemical Review, 2002. 102: p. 321-369.

5. Rassi, Z.E., Carbohydrate analysis by modern chromatography and electrophoresis. 2002: Elsevier.

6. DeMarco, M.L. and Woods, R.J., Structural glycobiology: A game of snakes and ladders. Glycobiology, 2008. 18(6): p. 426-440.

7. Donald Voet and Voet, J.G., Biochemistry (3nd edition). 2004.

8. Apweiler, R., Hermjakob, H., and Sharon, N., On the frequency of protein glycosylation, as deduced from analysis of the swiss-prot database. Biochimica et Biophysica Acta (BBA) - General Subjects, 1999. 1473(1): p. 4-8.

9. Dwek, R.A., Glycobiology: Toward understanding the function of sugars. Chemical Reviews, 1996. 96(2): p. 683-720.

10. Varki, A. and Lowe, J.B., in Essentials of glycobiology (2nd edition). 2009. p. 7588. 
11. Olden, K., Bernard, B.A., Humphries, M.J., Yeo, T.-K., Yeo, K.-T., White, S.L., Newton, S.A., Bauer, H.C., and Parent, J.B., Function of glycoprotein glycans. Trends in Biochemical Sciences, 1985. 10(2): p. 78-82.

12. Rudd, P.M., Elliott, T., Cresswell, P., Wilson, I.A., and Dwek, R.A., Glycosylation and the immune system. science, 2001. 291(5512): p. 2370.

13. Pikora, C.A., Glycosylation of the env spike of primate immunodeficiency viruses and antibody neutralization. Current HIV Research, 2004. 2(3): p. 243-254.

14. Prusiner, S.B., Prion diseases and the bse crisis. science, 1997. 278(5336): p. 245.

15. Collinge, J., Sidle, K.C.L., Meads, J., Ironside, J., and Hill, A.F., Molecular analysis of prion strain variation and the aetiology of 'new variant' cjd. Nature, 1996. 383(6602): p. 685-690.

16. Hakomori, S., Glycosylation defining cancer malignancy: New wine in an old bottle. Proceedings of the National Academy of Sciences of the United States of America, 2002. 99(16): p. 10231-10233.

17. Rudd, P.M., Wormald, M.R., and Dwek, R.A., Sugar-mediated ligand-receptor interactions in the immune system. Trends in Biotechnology, 2004. 22(10): p. 524-530.

18. Shriver, Z., Raguram, S., and Sasisekharan, R., Glycomics: A pathway to a class of new and improved therapeutics. Nature Reviews Drug Discovery, 2004. 3(10): p. $863-873$.

19. Montreuil, J., Chapter 1 the history of glycoprotein research, a personal view, in New comprehensive biochemistry, J. Montreuil, J.F.G.V. and Schachter, H., Editors. 1995, Elsevier. p. 1-12. 
20. Walker, D., Joshi, G., and Davis, A., Progress in biomimetic carbohydrate recognition. Cellular and Molecular Life Sciences, 2009. 66(19): p. 3177-3191.

21. Bertozzi, C.R. and Kiessling, L.L., Chemical glycobiology.. (cover story). Science, 2001. 291(5512): p. 2357.

22. Yuan Chuan, L., Tracing the development of structural elucidation of n-glycans Trends in Glycoscience and Glycotechnology, 2009. 21(118): p. 53-69.

23. Gohlke, M., Separation of n-glycans by hplc. Methods in molecular biology (Clifton, N.J.), 2002. 194: p. 45-61.

24. Erika, L., Method for investigation of oligosaccharides using phenylhydrazine derivatization. Methods in molecular biology (Clifton, N.J.). 534: p. 65-77.

25. Honda, S., Iwase, S., Makino, A., and Fujiwara, S., Simultaneous determination of reducing monosaccharides by capillary zone electrophoresis as the borate complexes of n-2-pyridylglycamines. Analytical Biochemistry, 1989. 176(1): p. 72-77.

26. Smyth, W.F., Recent applications of capillary electrophoresis-electrospray ionisation-mass spectrometry in drug analysis. Electrophoresis, 2005. 26(7-8): p. 1334-1357.

27. Jabeen, R., Payne, D., Wiktorowicz, J., Mohammad, A., and Petersen, J., Capillary electrophoresis and the clinical laboratory. Electrophoresis, 2006. 27(12): p. 2413-2438.

28. Herrero, M., García-Cañas, V., Simo, C., and Cifuentes, A., Recent advances in the application of capillary electromigration methods for food analysis and foodomics. Electrophoresis, 2010. 31(1): p. 205-228. 
29. Wang, A. and Fang, Y., Applications of capillary electrophoresis with electrochemical detection in pharmaceutical and biomedical analyses. Electrophoresis, 2000. 21(7): p. 1281-1290.

30. Evangelista, R.A., Chen, F.-T.A., and Guttman, A., Reductive amination of nlinked oligosaccharides using organic acid catalysts. Journal of Chromatography A, 1996. 745(1-2): p. 273-280.

31. Guttman, A. and Pritchett, T., Capillary gel electrophoresis separation of highmannose type oligosaccharides derivatized by 1-aminopyrene-3,6,8-trisulfonic acid. Electrophoresis, 1995. 16(1): p. 1906-1911.

32. Camilleri, P., Harland, G.B., and Okafo, G., High resolution and rapid analysis of branched oligosaccharides by capillary electrophoresis. Analytical Biochemistry, 1995. 230(1): p. 115-122.

33. Petrescu, A.-J., Wormald, M.R., and Dwek, R.A., Structural aspects of glycomes with a focus on n-glycosylation and glycoprotein folding. Current Opinion in Structural Biology, 2006. 16(5): p. 600-607.

34. Haslam, S.M., North, S.J., and Dell, A., Mass spectrometric analysis of n- and oglycosylation of tissues and cells. Current Opinion in Structural Biology, 2006. 16(5): p. 584-591.

35. Harvey, D.J., Matrix-assisted laser desorption/ionization mass spectrometry of carbohydrates. Mass Spectrometry Reviews, 1999. 18(6): p. 349-450.

36. Harvey, D.J., Identification of protein-bound carbohydrates by mass spectrometry. Proteomics, 2001. 1(2): p. 311-328. 
37. Mechref, Y. and Novotny, M.V., Mass spectrometric mapping and sequencing of n-linked oligosaccharides derived from submicrogram amounts of glycoproteins. Analytical Chemistry, 1998. 70(3): p. 455-463.

38. van Halbeek, H., ${ }^{1} \mathrm{H}$ nuclear magnetic resonance spectroscopy of carbohydrate chains of glycoproteins, in Methods in enzymology, William, J.L. and Gerald, W.H., Editors. 1994, Academic Press. p. 132-168.

39. Campa, C., Coslovi, A., Flamigni, A., and Rossi, M., Overview on advances in capillary electrophoresis-mass spectrometry of carbohydrates: A tabulated review. Electrophoresis, 2006. 27(11): p. 2027-2050.

40. Rassi, Z.E. and Mechref, Y., Recent advances in capillary electrophoresis of carbohydrates. Electrophoresis, 1996. 17(2): p. 275-301.

41. Liu, J.P., Shirota, O., Wiesler, D., and Novotny, M., Ultrasensitive fluorometric detection of carbohydrates as derivatives in mixtures separated by capillary electrophoresis. Proceedings of the National Academy of Sciences of the United States of America, 1991. 88(6): p. 2302-2306.

42. Chiesa, C. and Horváth, C., Capillary zone electrophoresis of maltooligosaccharides derivatized with 8-aminonaphthalene-1,3,6-trisulfonic acid. Journal of Chromatography A, 1993. 645(2): p. 337-352.

43. Guttman, A. and Starr, C., Capillary and slab gel electrophoresis profiling of oligosaccharides. Electrophoresis, 1995. 16(1): p. 993-997.

44. Tran, N.T., Taverna, M., Deschamps, F.S., Morin, P., and Ferrier, D., Investigation of micelles and anionic cyclodextrins as pseudostationary phases 
for the capillary electrophoresis separation of oligosaccharides derivatized with 2-aminobenzamide. Electrophoresis, 1998. 19(15): p. 2630-2638.

45. Dang, F., Kakehi, K., Cheng, J., Tabata, O., Kurokawa, M., Nakajima, K., Ishikawa, M., and Baba, Y., Hybrid dynamic coating with n-dodecyl $\beta$-dmaltoside and methyl cellulose for high-performance carbohydrate analysis on poly(methyl methacrylate) chips. Analytical Chemistry, 2006. 78(5): p. 1452-1458.

46. Klockow, A., Amadò, R., Michael Widmer, H., and Paulus, A., Separation of 8aminonapthalene-1,3,6-trisulfonic acid-labelled neutral and sialylated $n$-linked complex oligosaccharides by capillary electrophoresis. Journal of Chromatography A, 1995. 716(1-2): p. 241-257.

47. Guttman, A., Chen, F.-T.A., and Evangelista, R.A., Separation of 1-aminopyrene3,6,8-trisulfonate-labeled asparagine-linked fetuin glycans by capillary gel electrophoresis. Electrophoresis, 1996. 17(2): p. 412-417.

48. Guttman, A., Multistructure sequencing of $<i>n</ i>$-linked fetuin glycans by capillary gel electrophoresis and enzyme matrix digestion. Electrophoresis, 1997. 18(7): p. 1136-1141.

49. Chen, F.-T.A. and Evangelista, R.A., Profiling glycoprotein $<i>n</ i>$-linked oligosaccharide by capillary electrophoresis. Electrophoresis, 1998. 19(15): p. 2639-2644.

50. Harland, G.B., Okafo, G., Matejtschuk, P., Sellick, I.C., Chapman, G.E., and Camilleri, P., Fingerprinting of glycans as their 2-aminoacridone derivatives by capillary electrophoresis and laserinduced fluorescence. Electrophoresis, 1996. 17(2): p. 406-411. 
51. Honda, S., Okeda, J., Iwanaga, H., Kawakami, S., Taga, A., Suzuki, S., and Imai, K., Ultramicroanalysis of reducing carbohydrates by capillary electrophoresis with laser-induced fluorescence detection as 7-nitro-2,1,3-benzoxadiazole-tagged n-methylglycamine derivatives. Analytical Biochemistry, 2000. 286(1): p. 99-111.

52. Huang, Y., Mechref, Y., and Novotny, M.V., Microscale nonreductive release of o-linked glycans for subsequent analysis through maldi mass spectrometry and capillary electrophoresis. Analytical Chemistry, 2001. 73(24): p. 6063-6069.

53. Olajos, M., Hajós, P.t., Bonn, G.K., and Guttman, A.s., Sample preparation for the analysis of complex carbohydrates by multicapillary gel electrophoresis with light-emitting diode induced fluorescence detection. Analytical Chemistry, 2008. 80(11): p. 4241-4246.

54. Zhuang, Z., Starkey, J.A., Mechref, Y., Novotny, M.V., and Jacobson, S.C., Electrophoretic analysis of $n$-glycans on microfluidic devices. Analytical Chemistry, 2007. 79(18): p. 7170-7175.

55. Chiesa, C. and O'Neill, R.A., Capillary zone electrophoresis of oligosaccharides derivatized with various aminonaphthalene sulfonic acids. Electrophoresis, 1994. 15(1): p. 1132-1140.

56. Guttman, A. and Herrick, S., Effect of the quantity and linkage position of mannose([alpha]1,2) residues in capillary gel electrophoresis of high-mannosetype oligosaccharides. Analytical Biochemistry, 1996. 235(2): p. 236-239.

57. Suzuki, H., Müller, O., Guttman, A., and Karger, B.L., Analysis of 1aminopyrene-3,6,8-trisulfonate-derivatized oligosaccharides by capillary 
electrophoresis with matrix-assisted laser desorption/ionization time-of-flight mass spectrometry. Analytical Chemistry, 1997. 69(22): p. 4554-4559.

58. Okafo, G., Burrow, L., Carr, S.A., Roberts, G.D., Johnson, W., and Camilleri, P., A coordinated high-performance liquid chromatographic, capillary electrophoretic, and mass spectrometric approach for the analysis of oligosaccharide mixtures derivatized with 2-aminoacridone. Analytical Chemistry, 1996. 68(24): p. 4424-4430.

59. Hutterer, K.M., Birrell, H., Camilleri, P., and Jorgenson, J.W., High resolution of oligosaccharide mixtures by ultrahigh voltage micellar electrokinetic capillary chromatography. Journal of Chromatography B: Biomedical Sciences and Applications, 2000. 745(2): p. 365-372.

60. Sandra, K., Van Beeumen, J., Stals, I., Sandra, P., Claeyssens, M., and Devreese, B., Characterization of cellobiohydrolase i n-glycans and differentiation of their phosphorylated isomers by capillary electrophoresis-q-trap mass spectrometry. Analytical Chemistry, 2004. 76(19): p. 5878-5886.

61. Szabo, Z., Guttman, A.s., and Karger, B.L., Rapid release of n-linked glycans from glycoproteins by pressure-cycling technology. Analytical Chemistry, 2010. 82(6): p. 2588-2593.

62. Evangelista, R.A., Liu, M.-S., and Chen, F.-T.A., Characterization of 9aminopyrene-1,4,6-trisulfonate derivatized sugars by capillary electrophoresis with laser-induced fluorescence detection. Analytical Chemistry, 1995. 67(13): p. 2239-2245. 
63. Guttman, A., Chen, F.-T.A., Evangelista, R.A., and Cooke, N., High-resolution capillary gel electrophoresis of reducing oligosaccharides labeled with 1aminopyrene-3,6,8-trisulfonate. Analytical Biochemistry, 1996. 233(2): p. 234242.

64. Luo, R., Archer-Hartmann, S.A., and Holland, L.A., Transformable capillary electrophoresis for oligosaccharide separations using phospholipid additives. Analytical Chemistry, 2010. 82(4): p. 1228-1233.

65. Mills, J.O. and Holland, L.A., Membrane-mediated capillary electrophoresis: Interaction of cationic peptides with bicelles. Electrophoresis, 2004. 25(9): p. 1237-1242.

66. Koynova, R., Koumanov, A., and Tenchov, B., Metastable rippled gel phase in saturated phosphatidylcholines: Calorimetric and densitometric characterization. Biochimica et Biophysica Acta (BBA) - Biomembranes, 1996. 1285(1): p. 101108.

67. Larew, L.A. and Johnson, D.C., Quantitation of chromatographically separated maltooligosaccharides with a single calibration curve using a postcolumn enzyme reactor and pulsed amperometric detection. Analytical Chemistry, 1988. 60(18): p. $1867-1872$.

68. Min, B.-C., Yoon, S.-H., Kim, J.-W., Lee, Y.-W., Kim, Y.-B., and Park, K.H., Cloning of novel maltooligosaccharide-producing amylases as antistaling agents for bread. Journal of Agricultural and Food Chemistry, 1998. 46(2): p. 779-782. 
69. Pappas, T.J. and Holland, L.A., Fluid steering in a microfluidic chip by means of thermally responsive phospholipids. Sensors and Actuators B: Chemical, 2008. 128(2): p. 427-434.

70. Lögdberg, L. and Wester, L., Immunocalins: A lipocalin subfamily that modulates immune and inflammatory responses. Biochimica et Biophysica Acta (BBA) Protein Structure and Molecular Enzymology, 2000. 1482(1-2): p. 284-297.

71. Ceciliani, F. and Pocacqua, V., The acute phase protein alfal-acid glycoprotein: A model for altered glycosylation during diseases. Current Protein and Peptide Science, 2007. 8: p. 91-108.

72. Fournier, T., Medjoubi-N, N., and Porquet, D., Alpha-1-acid glycoprotein. Biochimica et Biophysica Acta (BBA) - Protein Structure and Molecular Enzymology, 2000. 1482(1-2): p. 157-171.

73. Brown, W.M., Dziegielewska, K.M., Saunders, N.R., and Møsllgård, K., Fetuin an old friend revisited. BioEssays, 1992. 14(11): p. 749-755.

74. Raines, R.T., Ribonuclease a. Chemical Reviews, 1998. 98(3): p. 1045-1066.

75. Guttman, A. and Schwartz, H.E., Artifacts related to sample introduction in capillary gel electrophoresis affecting separation performance and quantitation. Analytical Chemistry, 1995. 67(13): p. 2279-2283.

76. Lux, J., Yin, H., and Schomburg, G., Construction, evaluation and analytical operation of a modular capillary electrophoresis instrument. Chromatographia, 1990. $30(1)$ : p. $7-15$.

77. Sternberg, J.C., Extra column contributions to chromatographic band broadening Advances in Chromatography, Chapter 6., 1966. 2: p. 226-239 
78. Snyder, L.R., Column efficiency in liquid-solid adsorption chromatography. H.E.T.P. [height equivalent to a theoretical plate] values as a function of separation conditions. Analytical Chemistry, 1967. 39(7): p. 698-704.

79. Foret, F., Deml, M., and Bocek, P., Capillary zone electrophoresis : Quantitative study of the effects of some dispersive processes on the separation efficiency. Journal of Chromatography A, 1988. 452: p. 601-613.

80. Terabe, S., Otsuka, K., and Ando, T., Band broadening in electrokinetic chromatography with micellar solutions and open-tubular capillaries. Analytical Chemistry, 1989. 61(3): p. 251-260.

81. Liu, J., Dolnik, V., Hsieh, Y.Z., and Novotny, M., Experimental evaluation of the separation efficiency in capillary electrophoresis using open tubular and gelfilled columns. Analytical Chemistry, 1992. 64(13): p. 1328-1336.

82. Harris, D.C., Quantitative chemical analysis, 6th edition. 2002: W. H. Freeman.

83. Grushka, E., McCormick, R.M., and Kirkland, J.J., Effect of temperature gradients on the efficiency of capillary zone electrophoresis separations. Analytical Chemistry, 1989. 61(3): p. 241-246.

84. Jorgenson, J.W. and Lukacs, K.D., Zone electrophoresis in open-tubular glass capillaries. Analytical Chemistry, 1981. 53(8): p. 1298-1302.

85. Schure, M.R. and Murphy, R.E., Viscous effects in capillary electrophoresis: Theory and experiment. Electrophoresis, 1995. 16(1): p. 2074-2085. 
86. Guttman, A., Cooke, N., and Starr, C.M., Capillary electrophoresis separation of oligosaccharides: I. Effect of operational variables. Electrophoresis, 1994. 15(1): p. $1518-1522$. 
Chapter 3: DNA Separation using Phospholipids as a New Matrix for CE 


\subsubsection{Introduction}

DNA encodes genetic information. Substantial effort has been devoted to separate and sequence DNA. An enormous number of publications has appeared analyzing single- and double-stranded DNA, including DNA sequencing, mapping or sizing fragments obtained from restriction enzymes, conforming single-strand polymorphism and screening the polymerase chain reaction products [1].

\subsubsection{DNA structure}

To better understand DNA separation, it is necessary examine DNA structure. DNA is a biopolymer consisting of three units: base, carbohydrate and phosphate ester. The four bases found in DNA are adenine (A), thymine (T), guanine $(\mathrm{G})$ and cytosine $(\mathrm{C})$ as shown in Figure 3-1. They are planar heterocyclic aromatic compounds. Adenine and guanine have purine structures. Thymine and cytosine are pyrimidine compounds. The sugar is 2'deoxyribose (see Figure 3-1). The anomeric carbon (C1) of this sugar bonds to a base via their nitrogen atom (N9 from $\mathrm{A}$ and $\mathrm{G}$ and $\mathrm{N} 1$ from $\mathrm{T}$ and $\mathrm{C}$ ), forming a nucleoside (see Figure 3-2). When the phosphate groups link to a nucleoside through the C3' or C5' of the sugar, a phosphoric acid ester of nucleoside is formed which is called nucleotide (see Figure 3-2). Nucleotide monomers are polymerized through a phosphodiester bond. Double stranded DNA molecule is made of two nucleotide chains (called strands) which wind around a central axis and form a double helix structure.

A double helix DNA has several major features. First, two polynucleotide chains are held together by base pairing via hydrogen bonds as shown in Figure 3-3. Each 


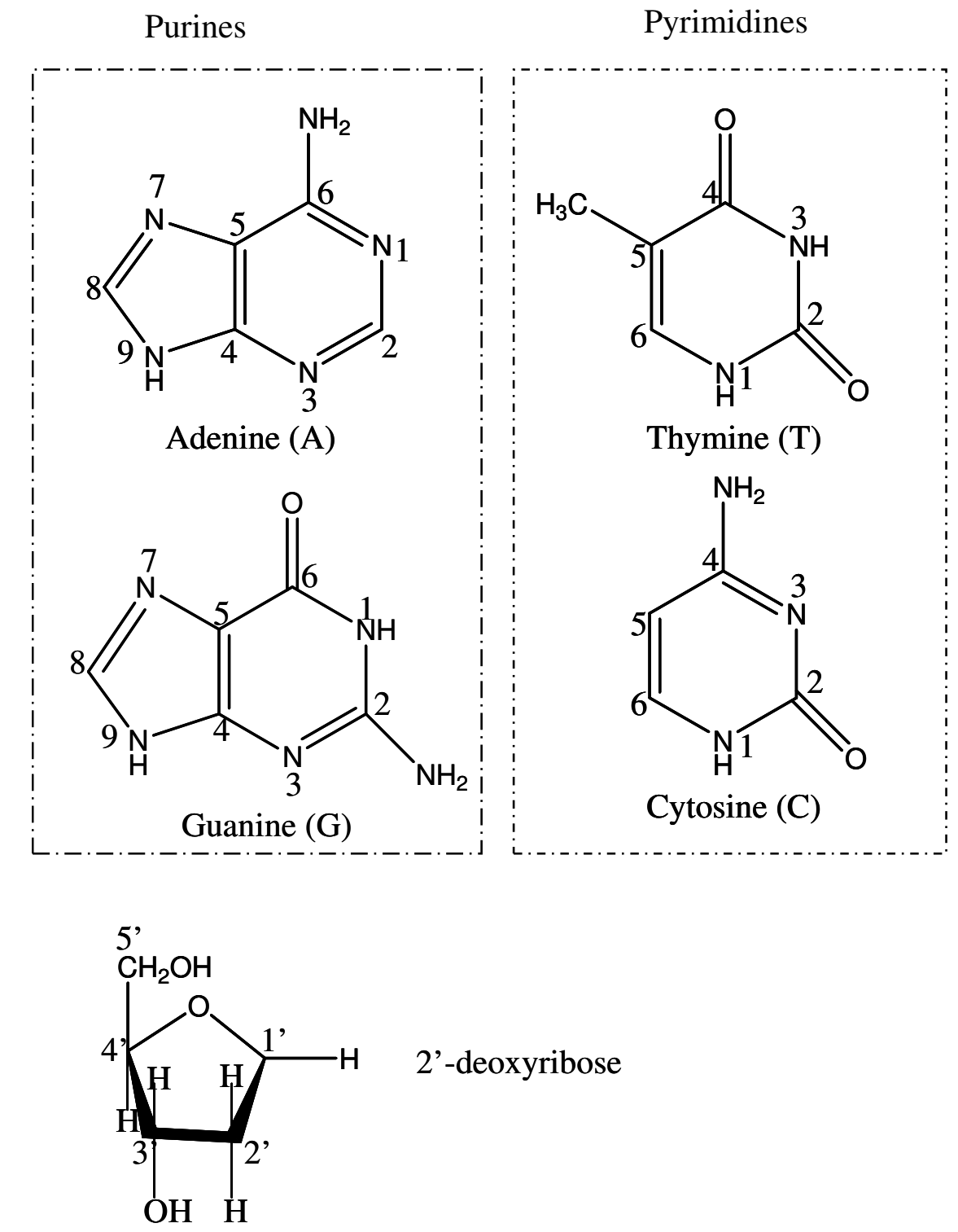

Figure 3-1 Chemical structure of bases and sugar in DNA. 


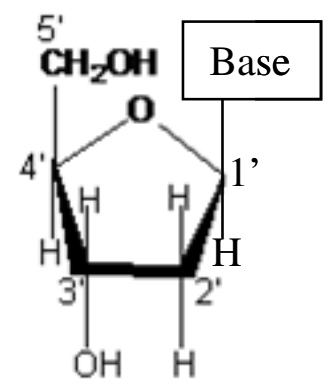

Nucleoside

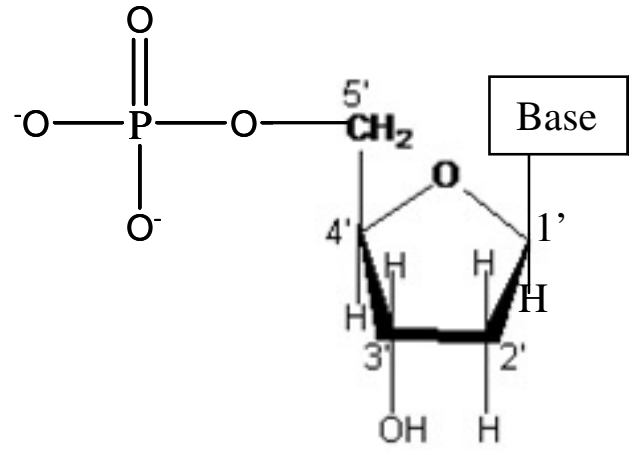

Nucleotide

Figure 3-2 Structure of a nucleoside and nucleotide. 


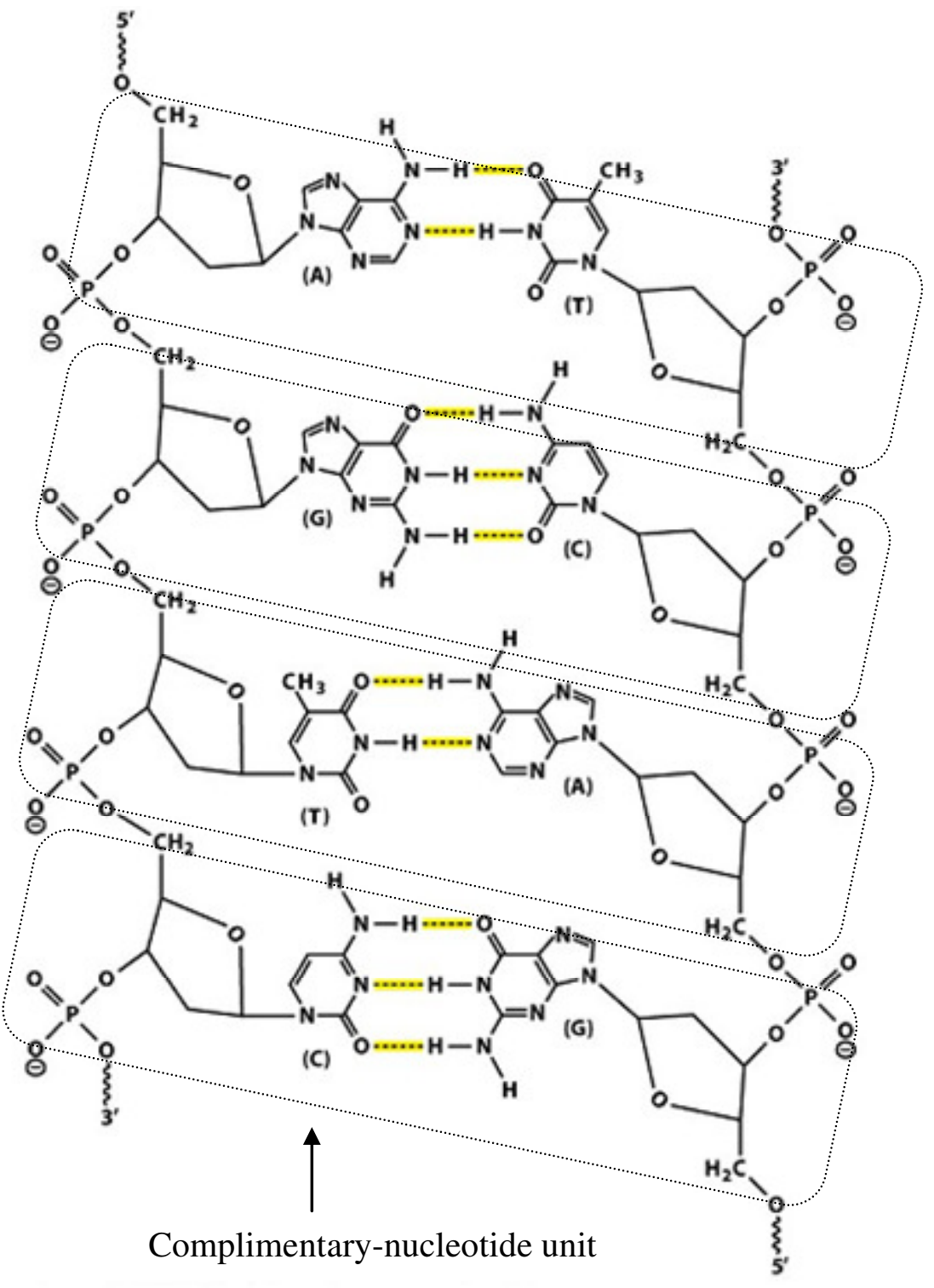

Figure 3-3 Complementary strands of DNA. Adapted from Voet, Donald and Voet, Judith G. Biochemistry, 3nd edition, 2004, Wiley. 
pair contains one purine base from one strand and one pyrimidine base from the complementary strand. An adenine residue must pair with a thymine residue. A guanine residue must pair with a cytosine residue. The bases located in the middle of the helix and sugar-phosphate chain run along the periphery. At a $\mathrm{pH}$ of 7 , the phosphate groups are negatively charged, and the DNA is anionic. All double-stranded DNA possesses a constant charge-to-size ratio, because the two strands contain complimentary nucleotide bases (see

Figure 3-3). Any two complimentary nucleotides have the same size because they are all comprised of the same pentose sugar residues, the same phosphate groups and because, as shown in Table 3-1, no matter which base pair is examined, each pair of bases is nearly identical in size. Each complimentary nucleotide pair also contributes two negative charges from phosphate groups. As a result, DNA molecules have constant electrophoretic mobility regardless of size [2-3].

\subsubsection{Slab gel electrophoresis on separation of nucleic acids}

As early as the 1960s, slab gel electrophoresis is the predominant method of separation for DNA separation [4]; and it is still widely used [5]. In this technique, agarose and crosslinked polyacrylamide are the two most common gel materials. These gels are porous media with pore size similar to the size of DNA molecules. Therefore, DNA can pass through these pores in the presence of electric field. The gel serves as an obstacle to DNA migration. Small DNA migrates faster than bigger DNA in the gel because the large DNA is subject to more retardation from the gel. Separation of DNA in gel electrophoresis is a size-dependant process [6].

The operation of slab gel electrophoresis is a manually intensive process. The gel is held between two pieces of glass or plastic. The sample is manually loaded into gel wells. 


\begin{tabular}{|c|c|c|c|}
\hline Base & $\begin{array}{c}\text { Molecular } \\
\text { weight }(\mathrm{g} / \mathrm{mole})\end{array}$ & $\begin{array}{c}\text { Pairing } \\
\text { base }\end{array}$ & $\begin{array}{c}\text { Total molecular weight of } \\
\text { two pairing bases } \\
\text { (g/mole) }\end{array}$ \\
\hline $\mathrm{A}$ & 135.13 & $\mathrm{~T}$ & 261.24 \\
\hline $\mathrm{T}$ & 126.11 & $\mathrm{~A}$ & 261.24 \\
\hline $\mathrm{G}$ & 151.13 & $\mathrm{C}$ & 261.23 \\
\hline $\mathrm{C}$ & 110.10 & $\mathrm{G}$ & 261.23 \\
\hline
\end{tabular}

Table 3-1 Molecular weight of possible base pairs in DNA. 
An electric field is applied and DNA fragments start migrating from cathode to anode. After the separation is complete, the gel is taken out and immersed in a staining solution in order to visualize the separated molecules. Staining is not effective for quantitative analysis. Run times for gel electrophoresis separation are from one to several hours. The manual operation including gel preparation, gel pouring, sample loading and detection is tedious, and time

consuming. Each gel can only be used once. Joule heat originating from the passage of electric current through the gel is not be effectively dissipated, which limits the voltage that can be applied and result in a long separation time [7].

\subsubsection{DNA separation with capillary electrophoresis}

Compared to conventional gel electrophoresis, CE offers higher resolution, shorter separation times, small sample volumes, and can be automated. CE has been used extensively for DNA analysis including genomics and genotyping during last two decades [1]. Capillary gel electrophoresis is an adaptation of traditional slab gel electrophoresis $[4,8]$. Chemically cross-linked gel and physical gel used in the slab gel electrophoresis were the first materials employed in DNA analysis with CE [9]. These gels have a rigid structure and form different pore sizes. Pore size ranging from a nanometer to a tenth of nanometer is often observed with polyacrylamide gel, which is suitable for oligonucleotide separation [10]. Agarose gels have a larger pore size that is suitable for the separation of large DNA fragments [11-12]. Although these gels offer satisfactory resolution for some DNA fragments, several drawbacks limit the use of these gels in capillary separations. The formation of bubbles due to Joule heating and the depletion of ions disrupt the conductance of sieving material. Furthermore, the capillary is not be regenerated once the gel degrades. Linear polymer solutions are a popular alternative because they are easily loaded into 
capillary compared to cross-linked gel. The use of aqueous polymer solutions as sieving matrices for DNA separations was first reported by Zhu et al [13]. Other polymers and materials have also been employed for DNA separations since [14-15]. These and other advances enabled sequencing of the human genome during in 1998 [16-17].

\subsubsection{Polymers used for DNA separation by CE}

A large number of polymers have been utilized for DNA separations. These include linear polyacylamide (LPA) [18-20], polyethylene oxide(PEO) [20-21], polyvinyl pyrrolidone (PVP) [22-23], polyethylene glycol (PEG) and hydroxyethylcellulose (HEC) for ssDNA as well as dsDNA [24-26]. The structures of these polymers are shown in Figure 3-4. Other additives such as polysaccharides (including cellulose and dextran) and copolymers also provide high performance [27-28]. The biggest benefit from the use of these polymer solutions is that they can be replaced after each run. This actually reduced the total analysis time by eliminating the time required for the preparation of cross-linked gel. DNA separation with capillary gel electrophoresis required that the EOF was suppressed. The suppression of EOF can be achieved by coating the capillary surface. Linear PEO and PVP polymers used for sieving also coat the fused silica surface and suppress EOF [20, 22, 29]. The effect of various polymer properties on DNA separation, including polymer type, viscosity, concentration, size of polymer and temperature, was studied to improve separation performance. As shown in Table 3-2, some polymers have relatively high viscosity at concentration resulting acceptable separation performance. 


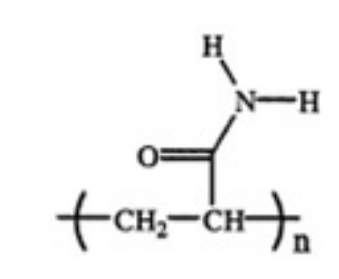

LPA

$\left.-\mathrm{O}-\mathrm{CH}_{2}-\mathrm{CH}_{2}\right)_{\mathrm{n}}$

PEO

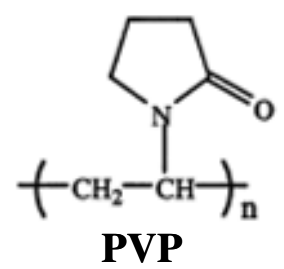

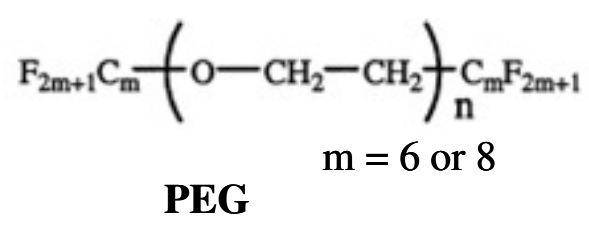

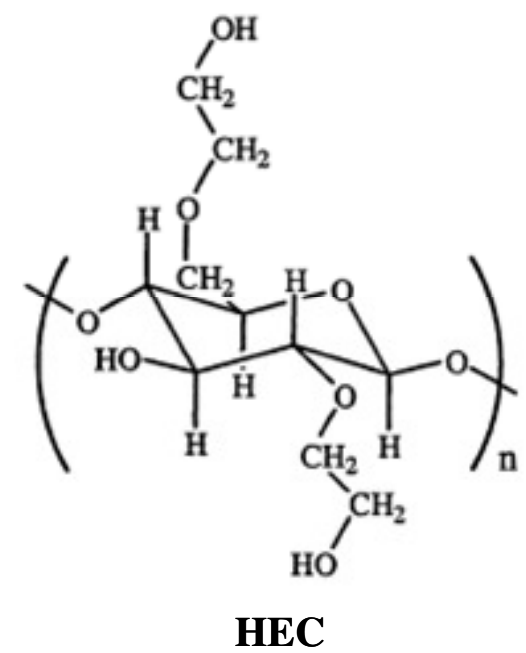

Figure 3-4 Chemical structure of most common polymers used in separation of DNA. 
For example, LPA, which was widely used for DNA sequencing has a high viscosity [29]. This requires a pressure injection system equipped to handle pressures as high as 1,000 p.s.i [30-31]. Table 3-2 includes the viscosity of polymer solution commonly used for DNA separation. A general rule observed in polymer mediated DNA separation is that highly entangled polymers can distinguish single-base difference; however, a high viscosity accompanies this.

\begin{tabular}{|l|l|l|l|l|l|}
\hline Polymer & $\begin{array}{l}\text { Molar } \\
\text { mass } \\
(\mathrm{kDa})\end{array}$ & $\begin{array}{l}\text { Compo- } \\
\text { sition } \\
(\mathrm{Wt} \%)\end{array}$ & $\mathbf{T}\left({ }^{\circ} \mathrm{C}\right)$ & $\begin{array}{l}\text { Viscosity } \\
(\mathrm{cP})\end{array}$ & Ref \\
\hline LPA & 9000 & 2 & 25 & 27400 & {$[32-33]$} \\
\hline PEO & $\begin{array}{l}8000+ \\
600\end{array}$ & $1.5+1.4$ & $\mathrm{RT}$ & 1200 & {$[20]$} \\
\hline PVP & 1000 & 4.5 & 20 & 27 & {$[22]$} \\
\hline PEG & 35 & 6 & N/A & 10000 & {$[24]$} \\
\hline HEC & 97 & 2 & 25 & 5000 & {$[34]$} \\
\hline
\end{tabular}

Table 3-2 Viscosity of polymer solutions commonly used to separate DNA in CE. Adapted from references [15] and [35].

\subsubsection{Other materials or methods used for DNA separation:}

Thermo-responsive or switchable-viscosity polymers are the materials that have thermally responsive viscosity and are easy to load at certain temperatures [33, 36]. The polymers were loaded into capillary at the critical temperature where they had very low viscosity. Then the temperature was switched to a point where polymers were much more entangled or viscous for higher selectivity of separation. As a separation medium of ФX174/HaeIII digested fragments, a thermo-responsive media, poly-N-isopropylacrylamide (PNIPA)-grafted -PEO provided a faster separation and comparable resolution to that of LPA [37-38]. 
Reports of the use of nonionic polymeric surfactants are quite interesting. The different structure formed by these surfactants serves either as a sieving or partitioning material for DNA analysis [39-41]. Recently, Grosser et al reported the use of micelles to separate DNA oligomers tagged with an amphiphile- $\mathrm{C}_{18}$ group [41].

Nanoparticles modified with polymers are used for DNA separation [42]. The nanoparticles, reported by Chang et al are used to separate dsDNA fragments up to $48.5 \mathrm{kbp}$ [42]. Nano-capillary and -channel devices are also employed to separate DNA in gel-free solution. The idea is based on size-dependant radial migration of DNA [43]. Large DNA fragments up to $200 \mathrm{kbp}$ were successfully separated within a nanochannel on a microfludic device [44]. A drawback associated with this method is the high pressure that accompanies decreasing the separation channel or capillary to nanoscale. The loss of path length due to reduced capillary diameter excludes the use of UV-visible absorption detection, which requires chemical labeling of DNA.

Another way to separate DNA using CE is to change the charge-to-size property of DNA in free solution. This can be accomplished by attaching a large, uncharged "drag-tag" such as a protein to the end of DNA [45]. By doing this, the balance between frictional force and electronic driving force is affected, and DNA migration becomes size-dependant in free solution. This method is called "end-labeled free-solution electrophoresis (ELFSE)" [46-47]. Although the approach avoids the use of polymer additives, the tagging process increases sample preparation and analysis cost.

\subsubsection{Phospholipids mediated DNA separation.}

In this research, the use of phospholipid additives was explored for DNA separation. An advantage to phospholipid additives is the thermally-dependant viscosity, which is easily 
prepared and loaded in the capillary. As a new separation material for DNA, the selectivity was investigated. Factors that determine the separation performance were investigated using a 50 bp dsDNA ladder as the sample. The separation mechanism was also discussed.

\subsubsection{Theory and mechanisms for DNA separation in CE.}

The mechanisms of transport for electrophoretic migration of DNA in polymeric matrices are Ogston sieving and reptation. These models were originally developed to explain the electrophoric separation of DNA in slab gel electrophoresis, and then adapted to DNA separations with cross-lined and linear polymers incorporated in capillary gel electrophoresis. The concentration of polymers can be divided into the following three regions: $\mathrm{C}_{\text {dilute }}<\mathrm{C}_{\text {semi-dilute }}<\mathrm{C}_{\text {entangled, }}$, where $\mathrm{C}$ is the concentration of polymer. The entangled regime is where Ogston sieving or reptation occurs.

\subsubsection{Ogston sieving}

Randomly entangled polymers form interconnected pores with an average pore size, $\xi$. Both pore size and DNA size determine how a DNA molecule moves through the polymer solution under an electric field. When the pore size is bigger than DNA size, the movement of DNA can be characterized as Ogston sieving [48]. The model assumes that the DNA molecule migrates through these pores as an undeformable spherical particle with a radius $\mathrm{R}$. Separation based on Ogston sieving results if the pore is big enough to accommodate the DNA. A mathematical expression of Ogston model is:

$$
\mu=\mu_{0} \exp \left(-K C(r+R)^{2}\right.
$$

where $\mu$ is mobility of a solute moving through polymer pores, $\mu_{0}$ is the mobility of the solute in the free solution, $\mathrm{K}$ is a constant of proportionality, and $\mathrm{r}$ is the thickness of polymer strands. The log of the mobility of the DNA is inversely proportional to size of DNA. The 
contribution of $r$ can be neglected if $r$ is significantly smaller than $\mathrm{R}$. A plot of $\log \mu$ versus C, called a Ferguson plot, yields a straight line [49].

\subsubsection{Reptation}

When the pore size is comparable with DNA size or smaller than DNA size, reptation, and a "snake-like" behavior allows DNA to travel through polymer solution. Instead of moving as an undeformable spherical particle, DNA will deform and squeeze through pores [50-51]. According to the reptation model, the mobility of DNA through a pore is inversely proportional to the DNA length or size [2]. A variation of reptation is called biased reptation. In this model, the effect of electric field on the DNA conformation is considered. A large electric field can induce orientation of DNA in the direction of electric field [52]. In the limiting case, DNA molecules become a rod-like conformation. Therefore, they lose the size-dependant mobility in the polymer. The following equation is used to describe this behavior

$$
\mu \approx \mathrm{K}\left(1 / \mathrm{N}+\mathrm{bE}^{2}\right)
$$

where $\mathrm{K}$ is a constant, $\mathrm{b}$ is related to both pore size of polymer and mass to charge ratio of solute and $\mathrm{E}$ is the strength of electric field [53]. Later, Duke et al proposed an improved model called biased reptation with fluctuations. In this model, the fluctuations in the length of the DNA molecule was considered [54].

Under low electric field similar to slab gel electrophoresis, these models are applicable in CE. However, under high electric fields commonly used CE, Ferguson plot are concave, and exhibit dependence of migration time on electric field [55-57]. Both Ogston and reptation mechanisms are effective models of DNA separations in concentrated, entangled 
polymer solution. DNA separations in polymer solution well below the entanglement threshold are described by collision with polymer strands $[18,26]$.

\subsubsection{Other observation with microscope for DNA separation}

Video microscopes are used to visualize the movement of DNA in both gel and polymer solutions [58-59]. DNA was observed taking either U- , J- or V-shaped conformations during electrophoresis in high molecular mass $(M s>300000)$ polymer solution [59-60]. In low molecular mass $(M s<200000)$ polymer solution, DNA molecules are globular [61]. In the dilute polymer solution, DNA exists mainly in a deformed globular conformation during electrophoresis. The elongation of DNA is observed at high electric field [60].

Compared to rigid pore in cross-linked gels, polymer solutions have "dynamic pores" because polymer strands randomly diffuse [62]. Instead of undeformable spherical conformation, small DNA exists as a rotating rod in the high electric field [63].

\subsubsection{Materials and methods}

\subsubsection{Chemicals}

The 50 bp DNA ladder was purchased from New England Biolabs (Ipswich, MA). 3( $N$-morpholino)-propanesulfonic acid (MOPS) and sodium hydroxide were purchased from Sigma-Aldrich (St. Louis, MO). The lipids DMPC and DHPC were obtained from Avanti Polar Lipids (Alabaster, AL). Deionized water was obtained from an ELGA PURELAB ultra water system (Lowell, MA).

\subsubsection{Capillary electrophoresis}

CE separations were performed on a Beckman/Coulter P/ACE MDQ (Beckman Coulter, Fullerton, CA) equipped with a UV detector. Unless otherwise noted, separations 
were accomplished with a $50 \mu \mathrm{m}$ internal diameter fused silica capillary (Polymicro Technologies, Phoenix, AZ), with total length $40 \mathrm{~cm}$ and effective length $30.2 \mathrm{~cm}$. At the beginning of the day, the capillary was subject to the following rinse sequence: $1 \mathrm{M} \mathrm{NaOH}$ for $30 \mathrm{~min}$ at $140 \mathrm{kPa}(20 \mathrm{psi})$, deionized water for $15 \mathrm{~min}$ at $140 \mathrm{kPa}$, methanol for $15 \mathrm{~min}$ at $140 \mathrm{kPa}$, and deionized water for $15 \mathrm{~min}$ at $140 \mathrm{kPa}$. The capillary was coated with $\mathrm{q}=0.5$ $5 \%$ phospholipid containing $\mathrm{Ca}^{2+}$ at the beginning of the day (20 min at $140 \mathrm{kPa}$ ) and then filled with phospholipid additives at $19{ }^{\circ} \mathrm{C}(3 \mathrm{~min}$ at $140 \mathrm{kPa})$. Between each run, the capillary temperature was dropped to $19{ }^{\circ} \mathrm{C}$ and the capillary was refilled with phospholipids.

\subsubsection{Sample preparation and injection}

Sample is prepared by dissolving $20 \mu \mathrm{L}$ of DNA stock solution provided by the manufacturer into $20 \mu \mathrm{L}$ of $10 \mathrm{mM}$ Mops solution buffered at $\mathrm{pH}=7$. The injection method discussed in chapter 2 is the sample injection protocol, except that sample was injected at 2 $\mathrm{kV}$ for $15 \mathrm{sec}$. More than 70 injections can be made from a single sample.

\subsubsection{Results and discussion}

Electrophoric separation of DNA includes ssDNA based sequencing and dsDNA separation. Separation of dsDNA is important for identifying PCR products, fragments from cleavage of restriction enzyme, and plasmids. Polymers used for ssDNA sequencing were also utilized for dsDNA separation. Phospholipids have been used for oligosaccharide separations described in chapter 2. The phospholipids attributed to viscosity rather than a size-based sieving media for sugar separation [64]. In this report, phospholipids were used for DNA separation. Commercial standards of double-stranded DNA fragments, which the manufacturer digested from a number of proprietary plasmids with restriction enzymes, were employed as a sample to explore the separation performance of phospholipids. Different 
separation parameters under investigation included hydration, temperature, and electric field. The separation mechanism was also discussed.

\subsubsection{Effect of lipid hydration on DNA separation}

Lipid hydration is an important factor for separation performance because it determines the property of lipid solution and additive porosity. The electrophoregrams in Figure 3-5, 3-6, 3-7 and 3-8 were the results of separation at different hydration at $25^{\circ} \mathrm{C}$ and $33^{\circ} \mathrm{C}$ in $100 \mathrm{~V} / \mathrm{cm}$ and $300 \mathrm{~V} / \mathrm{cm}$ electric field, respectively. The separation performance was dependant on hydration of lipids. Three different representative pairs of fragments: 50-100 bp (peak 1 and 2), 450-500 bp (peak 9 and 10), and 916-1350 bp (peak 16 and 17) were used to assess separation performance. For the $50-100 \mathrm{bp}$, the resolution increased from 1.3 to 3.0 with increasing the hydration of lipid from $6 \%$ to $15 \%$. For $450-500 \mathrm{bp}$ and $916-1350 \mathrm{bp}$, the resolution decreased with increasing the lipid hydration. The trend was different with the $450 \mathrm{bp}$ fragment. With increasing hydration, the resolution between fragments smaller than $450 \mathrm{bp}$ increased, while the resolution between fragments larger than $450 \mathrm{bp}$ decreased. These observations hold true at high electric fields and other temperatures. With polymeric additives, small DNA was better separated in a more entangled solution, and less entangled polymer was favorable for large DNA separation $[18,65]$. Our observation that smaller dsDNA separated better with higher lipid content and large dsDNA separated better in less concentrated lipid solution obeyed this general rule.

Figure 3-9. A, B showed the relationship between migration time of DNA fragments, and hydration of lipids. The migration time of DNA increased with increasing lipid content regardless size of DNA. However, with $15 \%$ lipid a drop in migration time was observed at $25^{\circ} \mathrm{C}$. This suggested that the phospholipid morphology for solutions of $15 \%$ lipid produced 


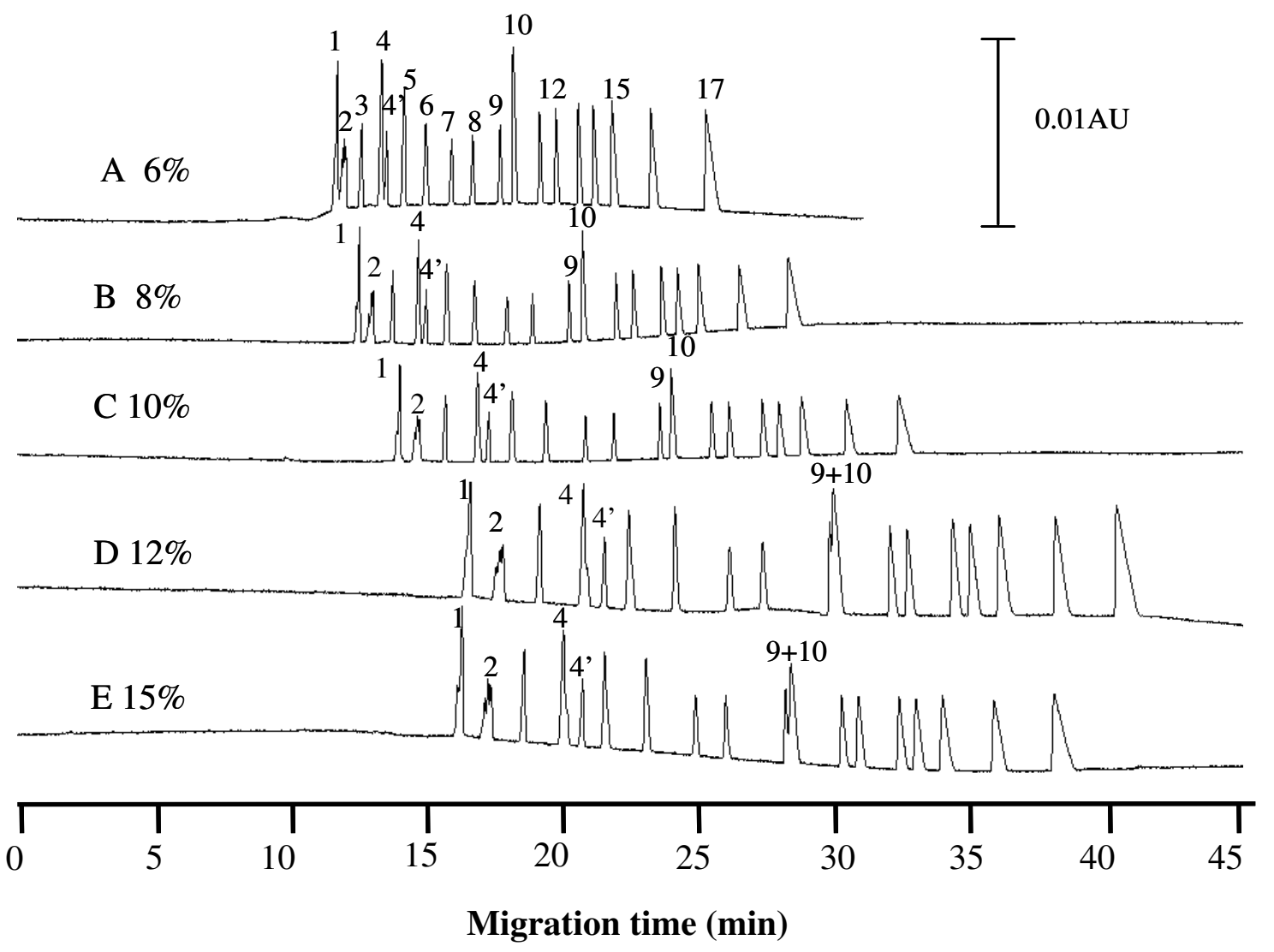

Figure 3-5 Electrophoregrams of 50 bp dsDNA separation with different lipid hydrations at $25^{\circ} \mathrm{C}$ in the $100 \mathrm{~V} / \mathrm{cm}$ electric field. 


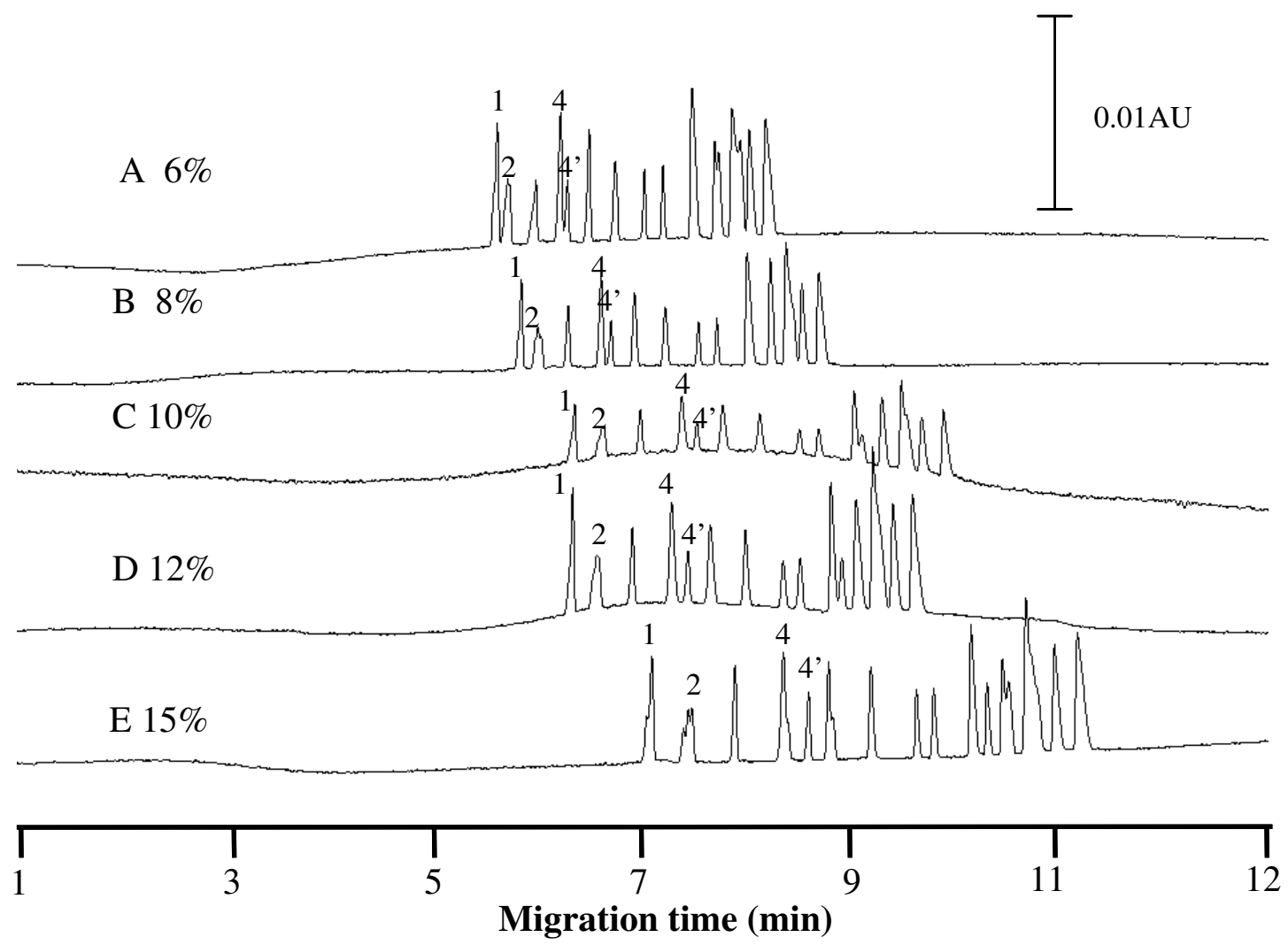

Figure 3-6 Electrophoregrams of $50 \mathrm{bp}$ dsDNA separation with different lipid hydrations at $25^{\circ} \mathrm{C}$ in the $300 \mathrm{~V} / \mathrm{cm}$ electric field. 


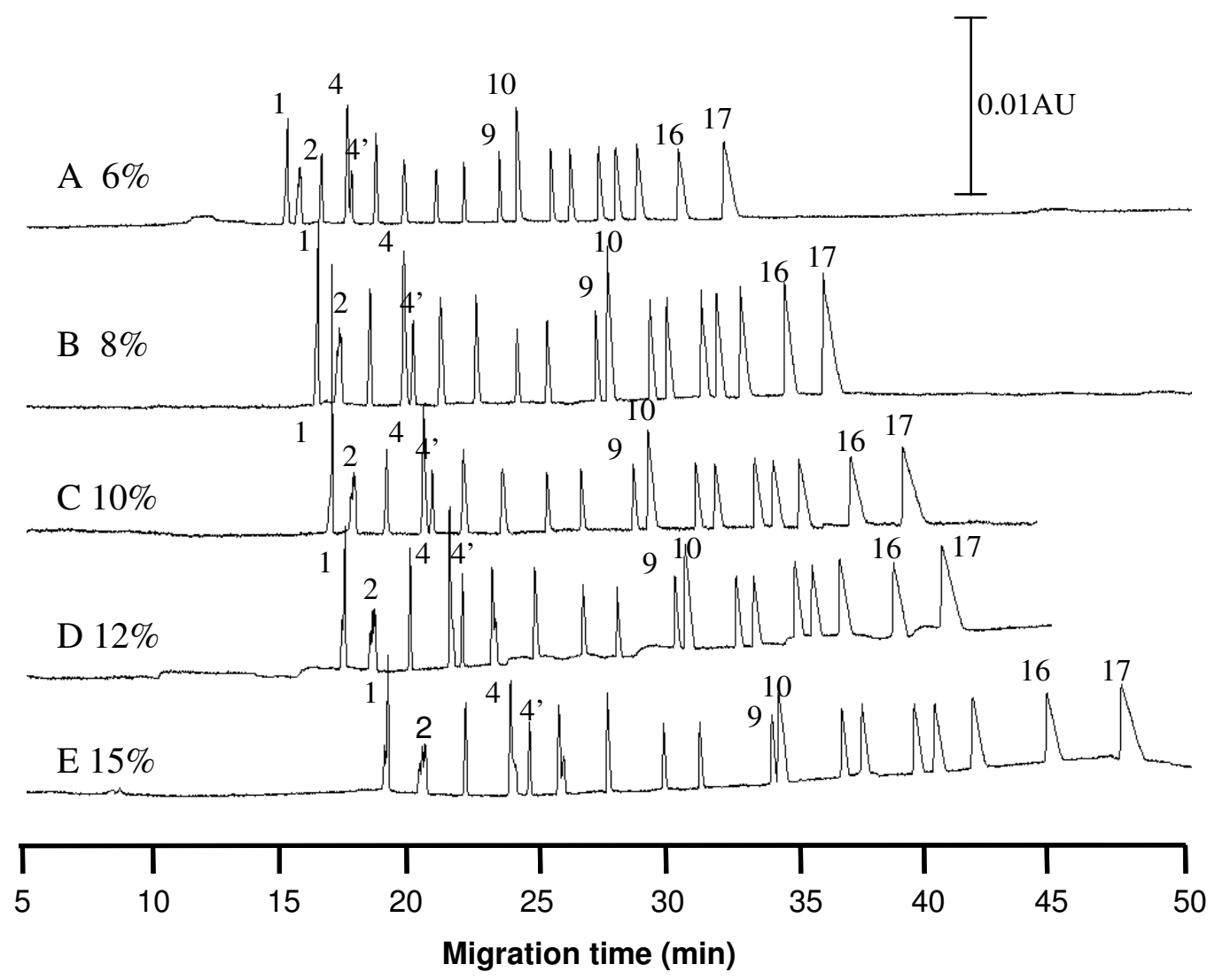

Figure 3-7 Electrophoregrams of $50 \mathrm{bp}$ dsDNA separation with different lipid hydrations at $33{ }^{\circ} \mathrm{C}$ in the $100 \mathrm{~V} / \mathrm{cm}$ electric field. 


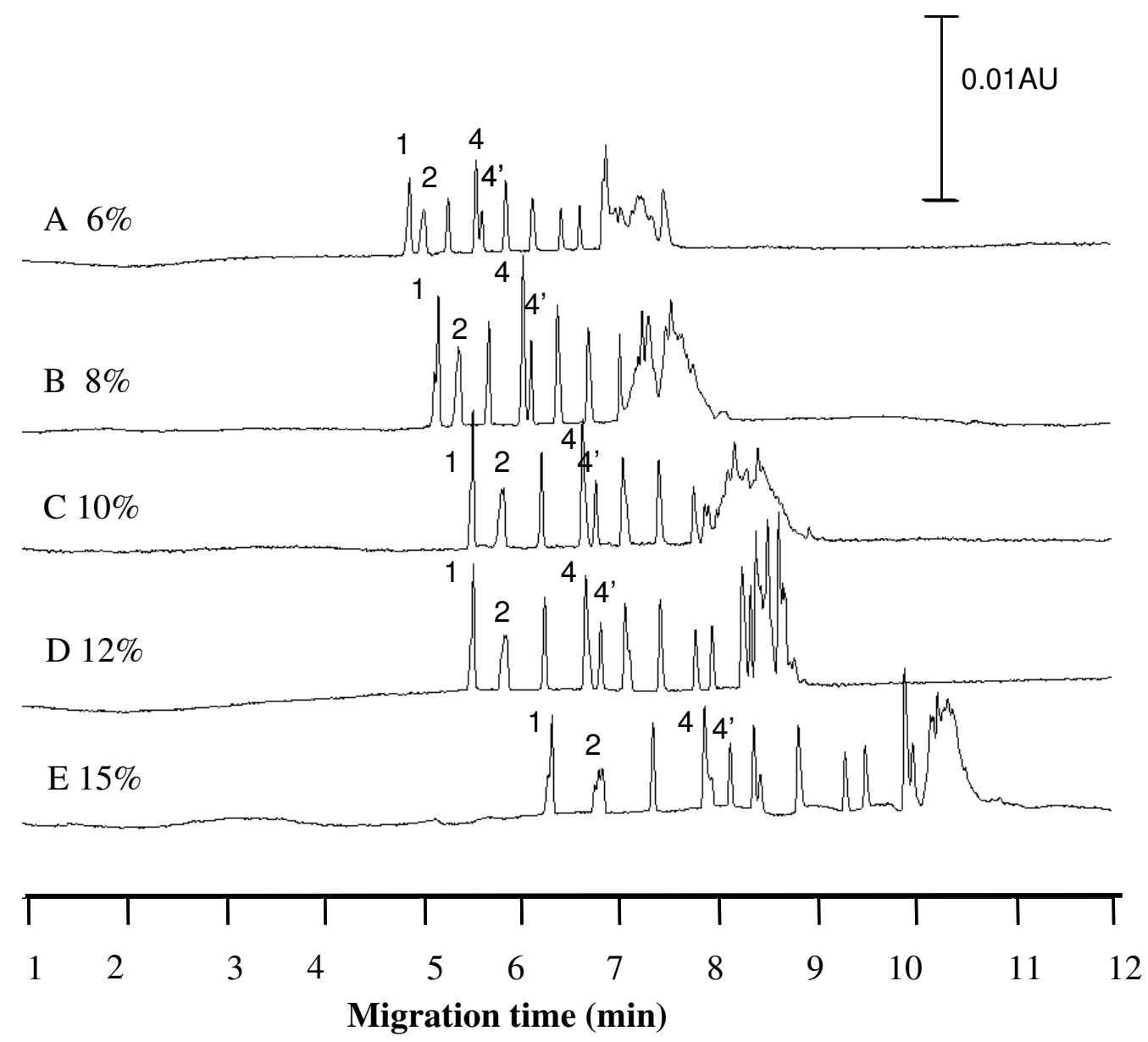

Figure 3-8 Electrophoregrams of $50 \mathrm{bp}$ dsDNA separation with different lipid Hydrations at $33{ }^{\circ} \mathrm{C}$ in the $300 \mathrm{~V} / \mathrm{cm}$ electric field. 


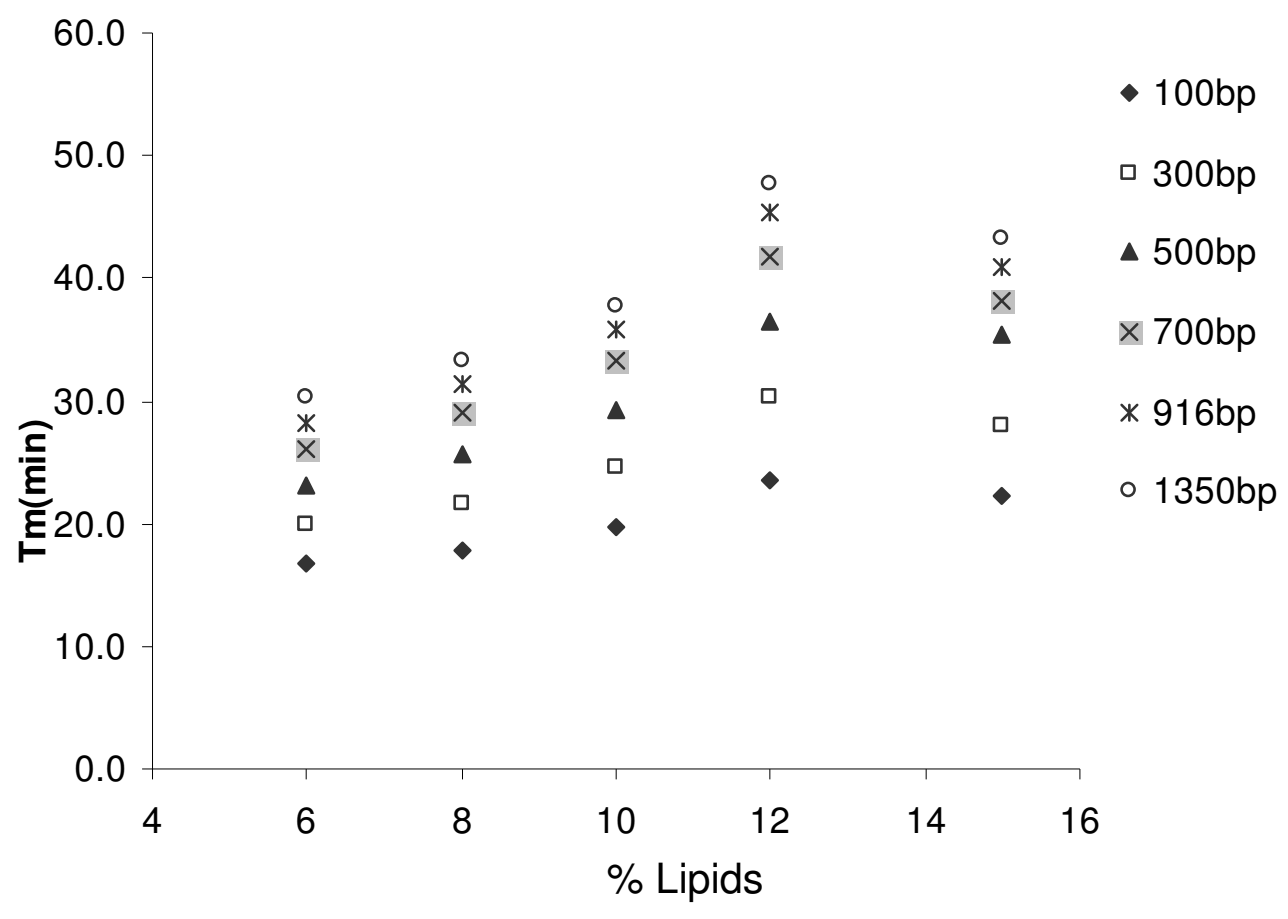

Figure 3-9. A Effect of hydration on migration time of $50 \mathrm{bp}$ dsDNA. The separation was carried out in the $100 \mathrm{~V} / \mathrm{cm}$ electric field at $25^{\circ} \mathrm{C}$. 


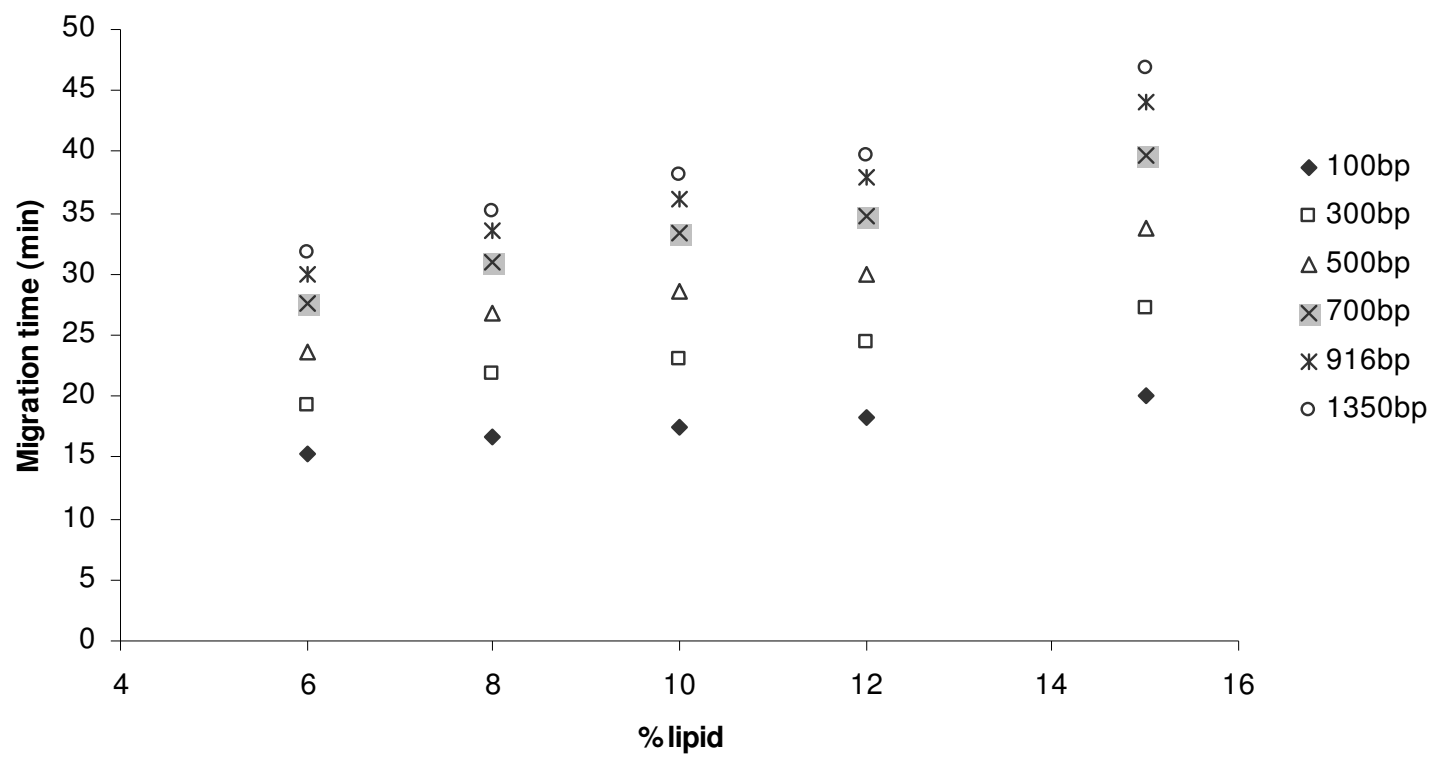

Figure 3-9. B Effect of hydration on migration time of $50 \mathrm{bp}$ dsDNA. The separation was carried out in $100 \mathrm{~V} / \mathrm{cm}$ electric field at $33^{\circ} \mathrm{C}$. 
different apparent pore size. More data points, at other lipid contents such as ones between $12 \%$ and $15 \%$ and greater than $15 \%$, must be collected to substantiate this.

Unresolved peaks were observed for $100 \mathrm{bp}$ fragment in Figure 3-5 to Figure 3-8. This may be due to double stranded DNA that displays secondary structures due to solvent composition and base pair sequence. Peak asymmetry was also notable in some electropherograms. Other groups also reported the observation of asymmetric peaks in capillary gel electrophoresis separation [66-68]. Sun et al demonstrated with a mathematical model, that the interaction between negatively-charged DNA and capillary surface was a primary source for serious band broadening and peak tailing frequently seen in DNA separation [69].

\subsubsection{Effect of temperature on DNA separation}

Temperature is an important factor in controlling separation performance. Temperature affects the viscosity and conductivity, which no doubt affects the separation performance including reproducibility, migration time of analytes and efficiency of separation. Joule heating in electrophoresis system could cause elevated temperature inside of capillary, which affects phospholipid morphology or pore size. Therefore, a temperature control or cooling system is necessary. In this study, temperatures from $20{ }^{\circ} \mathrm{C}$ to $33{ }^{\circ} \mathrm{C}$ were investigated.

Figure 3-10 showed the effect of temperature on migration time. Unlike the behavior of DNA in a regular gel, the migration time of DNA did not decrease linearly at constant electric field. In some cases migration time of these DNA fragments showed little or no fluctuation from $25{ }^{\circ} \mathrm{C}$ to $30^{\circ} \mathrm{C}$ (see Figure 3-10. A). This was particularly evident for small fragments. In other cases (see Figure 3-10. B), there was a maximum migration on each 
curve; below the temperature of this point, the migration time increased with increasing temperature; above this point, the migration of DNA fragments decreased while increasing of temperature. These observations were similar to viscosity profiles of lipids reported earlier but the trends are not as well-defined [70]. The plots in these figures also showed that small fragments migrate faster than bigger fragments. This was consistent with the behavior of DNA in capillary gel electrophoresis.

The electrophoretic separations of DNA in Figures 3-11 and 3-12 cannot be resolved at $20{ }^{\circ} \mathrm{C}$, and were barely resolved at $23{ }^{\circ} \mathrm{C}$. Above $23{ }^{\circ} \mathrm{C}$, the separation performance was improves dramatically. Both small fragments and big fragments were base-line resolved with low electric field at temperatures of $25^{\circ} \mathrm{C}, 27{ }^{\circ} \mathrm{C}, 29^{\circ} \mathrm{C}, 31^{\circ} \mathrm{C}$, and $33{ }^{\circ} \mathrm{C}$. Under high electric field, small fragments still can be separated well, but the analyte resolution decreased for big fragments. This situation was exaggerated at higher temperature. This was demonstrated with data collected at $35{ }^{\circ} \mathrm{C}$ and $40{ }^{\circ} \mathrm{C}$ using an additive of q $2.5-10 \%$. Single-stranded DNA sequencing is often accomplished at much higher temperatures ranging from $50{ }^{\circ} \mathrm{C}$ to $70{ }^{\circ} \mathrm{C}[19,32,71-72]$. The current work focuses on separations at $35{ }^{\circ} \mathrm{C}$ or lower. It may be interesting to study lipids behavior at temperatures higher than $40{ }^{\circ} \mathrm{C}$ for DNA separation. 


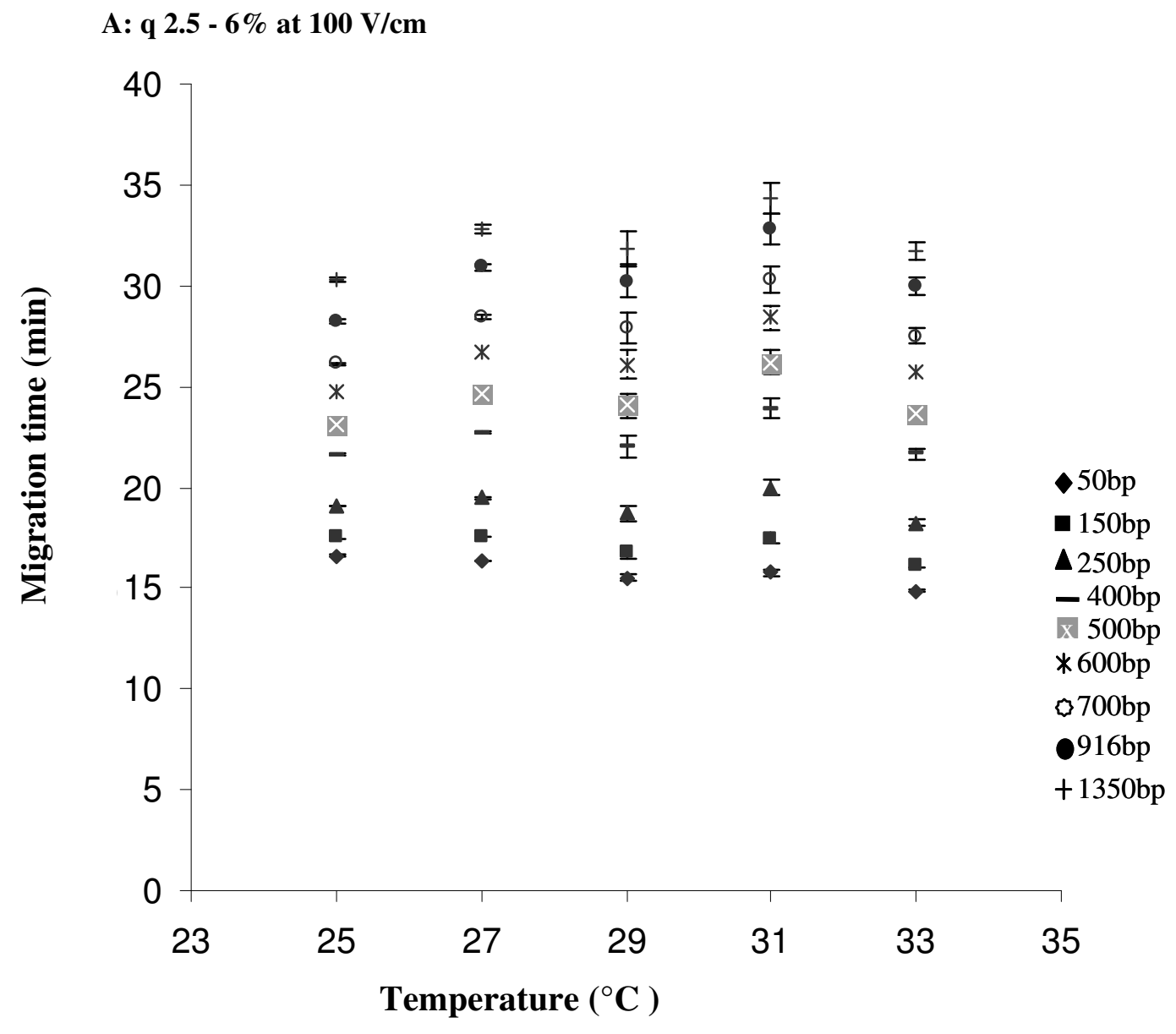

Figure 3-10. A Effect of temperature on migration time of DNA fragments. The capillary was coated with a phospholipid and then filled with phospholipid additives for separation. The effective capillary length was $30.2 \mathrm{~cm}$ and total length was $40 \mathrm{~cm}$. 
B: q $2.5-10 \%$ at $100 \mathrm{~V} / \mathrm{cm}$

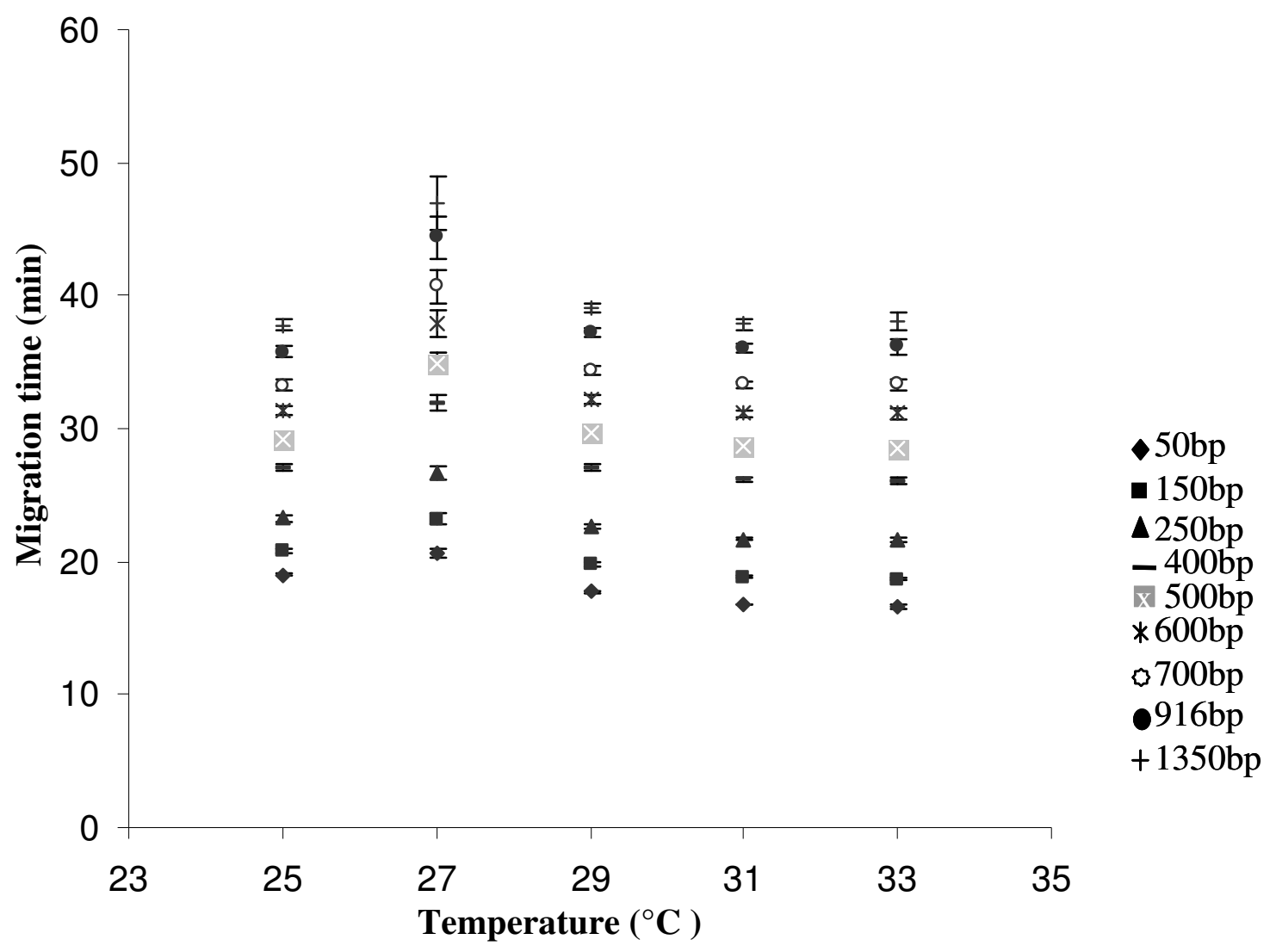

Figure 3-10. B Effect of temperature on migration time of DNA fragments. The capillary was coated with a phospholipid and then filled with phospholipid additives for separation. The effective capillary length was $30.2 \mathrm{~cm}$ and total length was $40 \mathrm{~cm}$. 


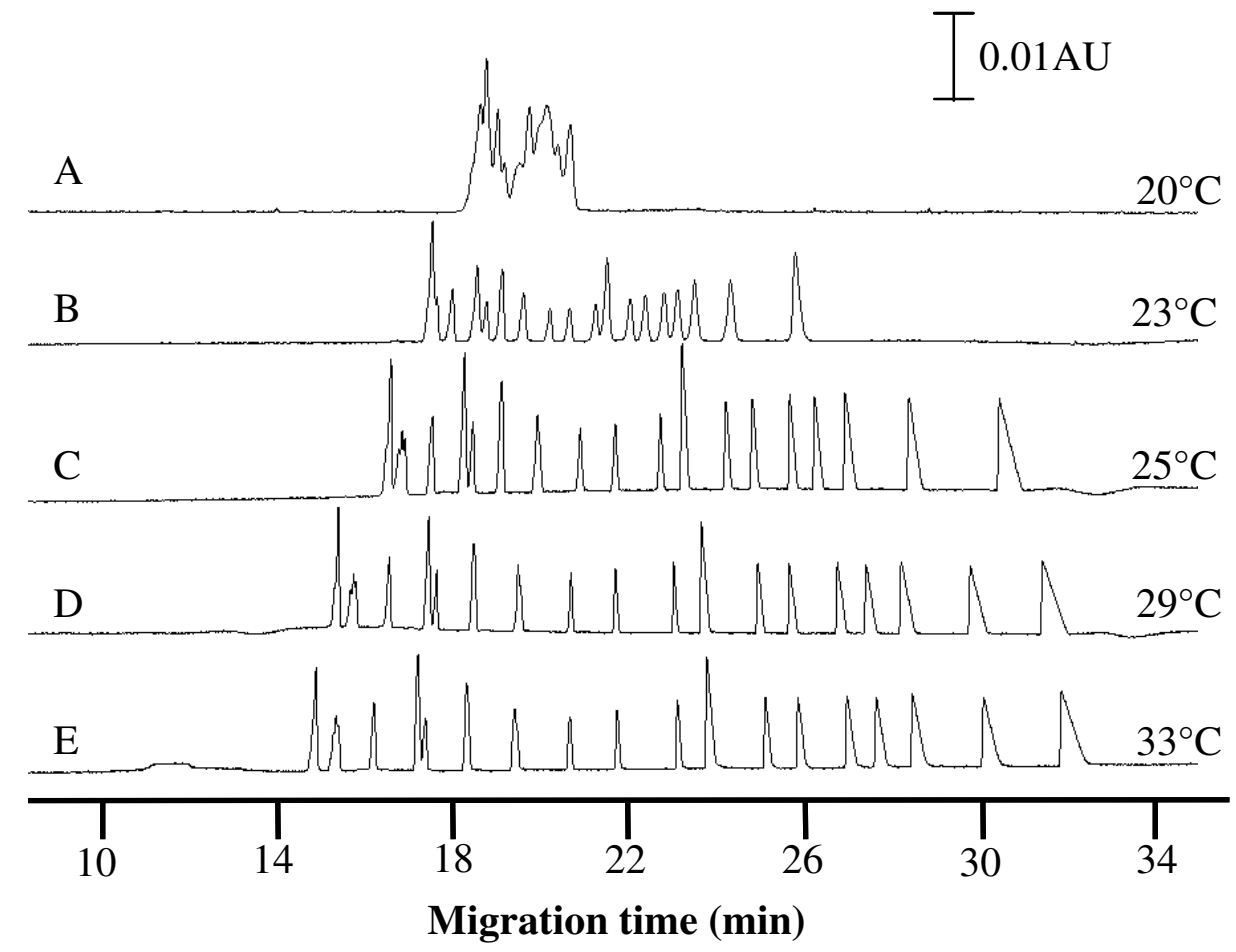

Figure 3-11 Separation of $50 \mathrm{bp}$ dsDNA with q 2.5 - $6 \%$ lipids in $100 \mathrm{~V} / \mathrm{cm}$ electric field at different temperatures. 


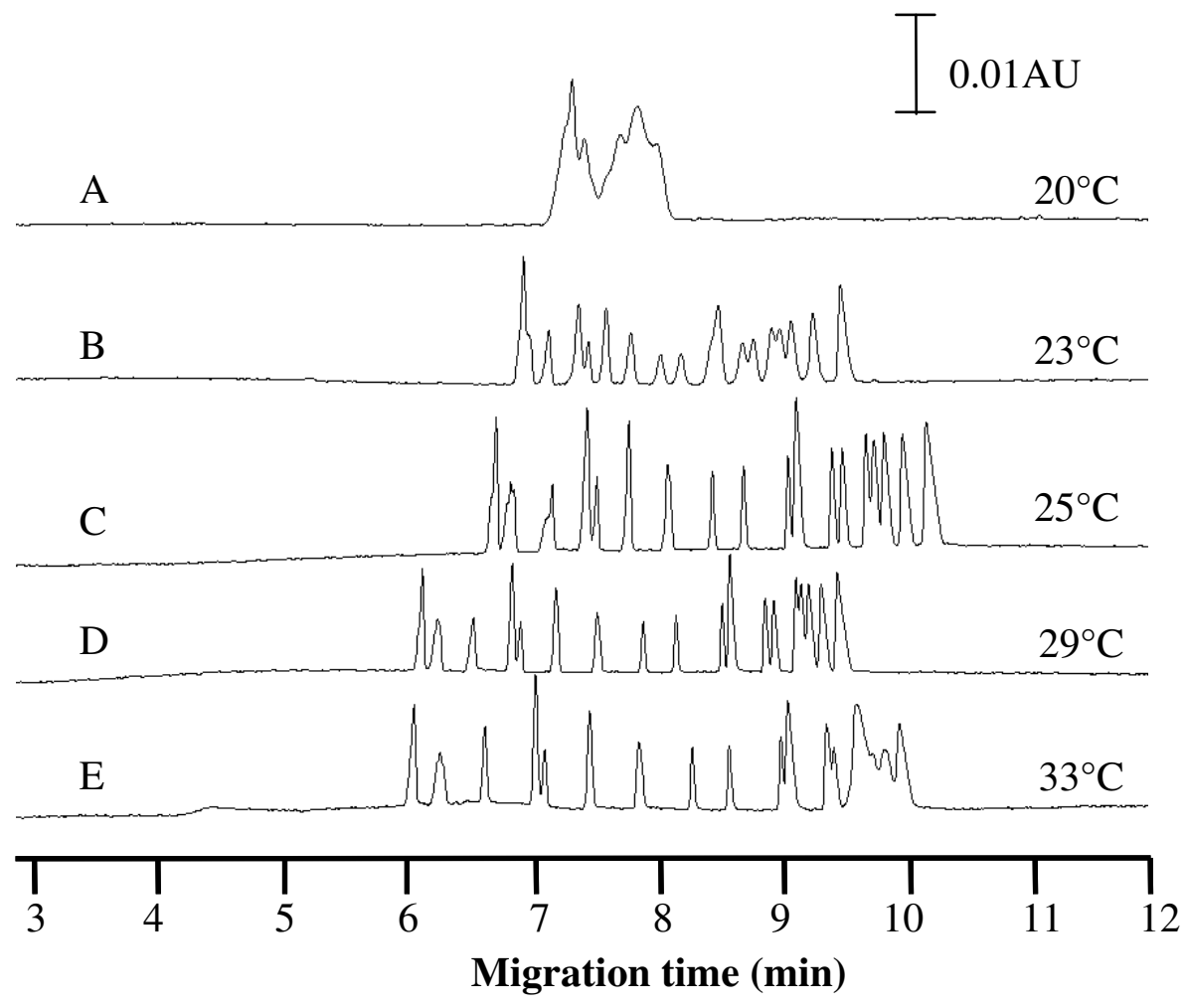

Figure 3-12 Separation of $50 \mathrm{bp}$ dsDNA with q 2.5 - $6 \%$ lipids in $250 \mathrm{~V} / \mathrm{cm}$ electric field at different temperatures. 


\subsubsection{Effect of electrical field on DNA separation}

In traditional gel electrophoresis accomplished with a low electric field (less than 10 $\mathrm{V} / \mathrm{cm}$ ), the mobility of DNA fragments smaller than $1000 \mathrm{bp}$ is constant with variation of electric field strength as small as $1 \mathrm{~V} / \mathrm{cm}$ [73-75]; however, under a high electric field, the mobility is dependent on electric field $[53,76]$. In capillary gel electrophoresis, DNA mobility is dependent electric field strength $[55,57,77]$.

Investigation of DNA migration with phospholipid additives demonstrated a linear increase in migration with increasing electric field regardless of fragment size (see Figure 313). The electric field affected the separation of small fragments and big fragments differently. This was shown in the electrophoregrams in Figures 3-14, 3-15, 3-16, and 3-17. In these separations, fragments up to $400 \mathrm{bp}$ can be resolved well under either high or low electric field regardless lipid hydration and separation temperature; but in most cases, highest resolution values were obtained at electric field smaller than $250 \mathrm{~V} / \mathrm{cm}$. The resolution of big fragments $(\geq 450 \mathrm{bp})$ decreased with electric field. The use of a high hydration lipid such as $15 \%$ lipid at high separation temperature exaggerated this situation (see Figure 3-16 and Figure 3-17).

Assuming that the lipid morphologies were not affected by electric field, there were two possible explanations for the decrease in resolution of big fragments at high electric field. Joule heating from the use of high field could cause band broadening. 
$q 2.5-6 \%$ at $25^{\circ} \mathrm{C}$

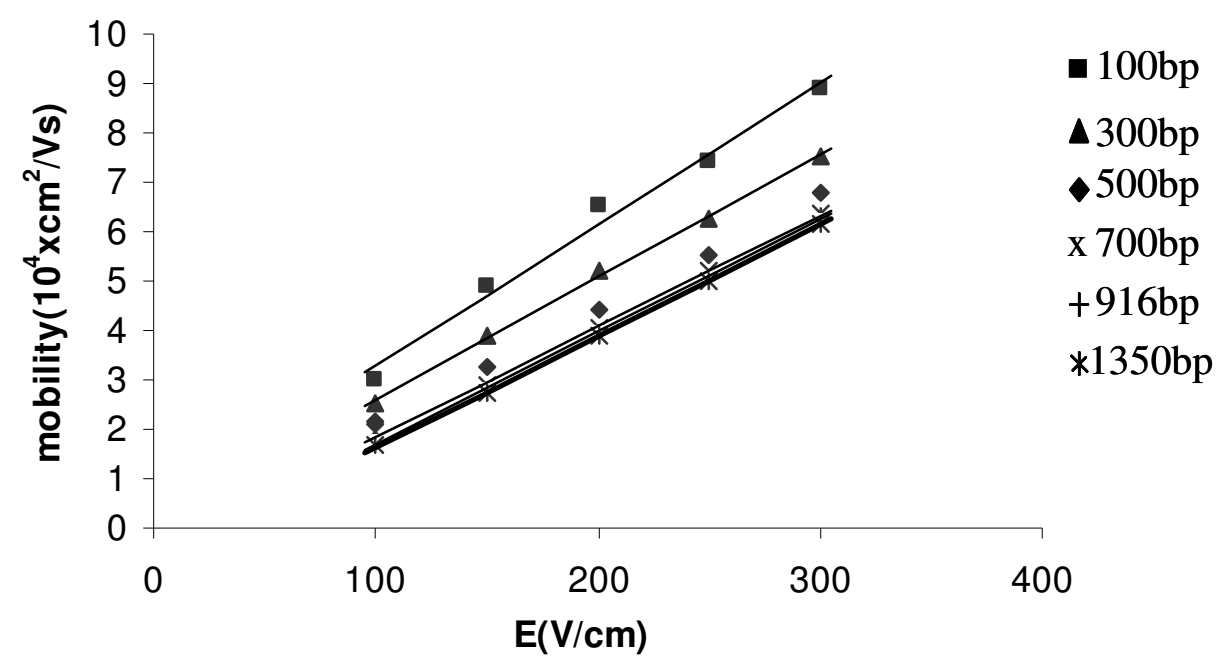

Figure 3-13 Effect of electric field on separation of 50 bp dsDNA. 


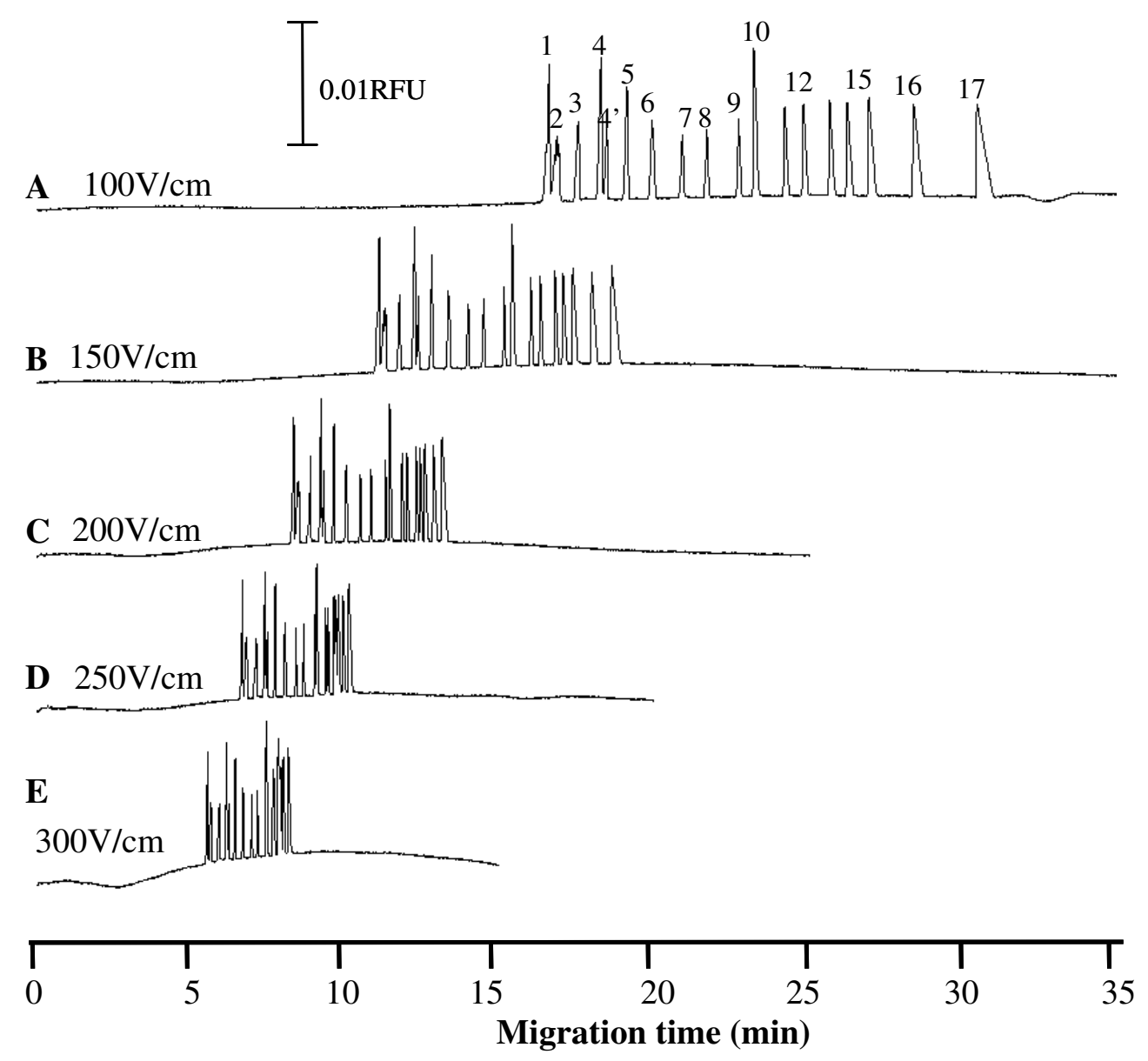

Figure 3-14 Separation of 50 bp dsDNA with q 2.5 - $6 \%$ lipids in the capillary under different electric fields. The separation temperature was $25^{\circ} \mathrm{C}$. 


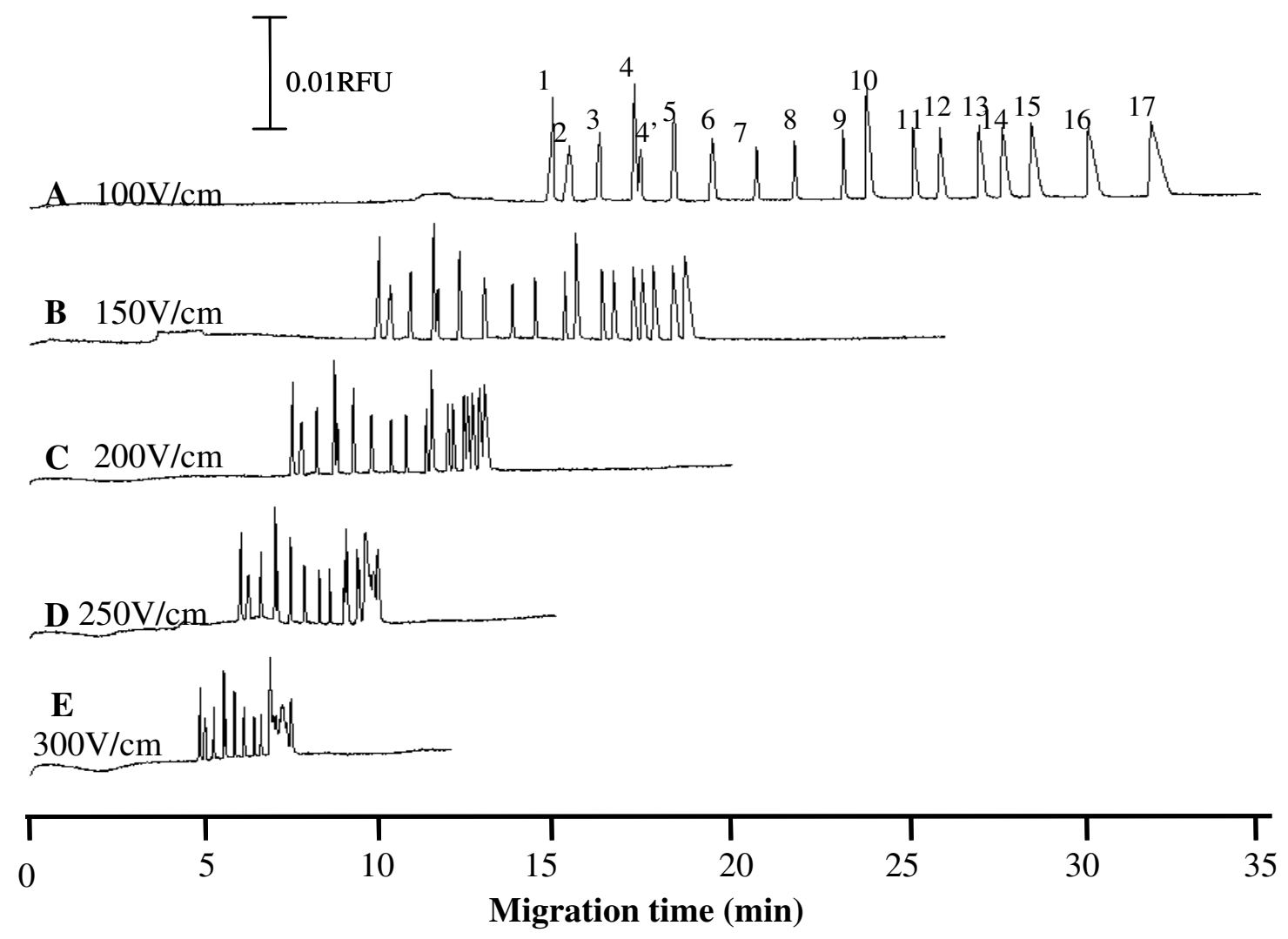

Figure 3-15 Separation of 50 bp dsDNA with q 2.5 - 6\% lipids in the capillary under different electric fields. The separation temperature was $33^{\circ} \mathrm{C}$. 


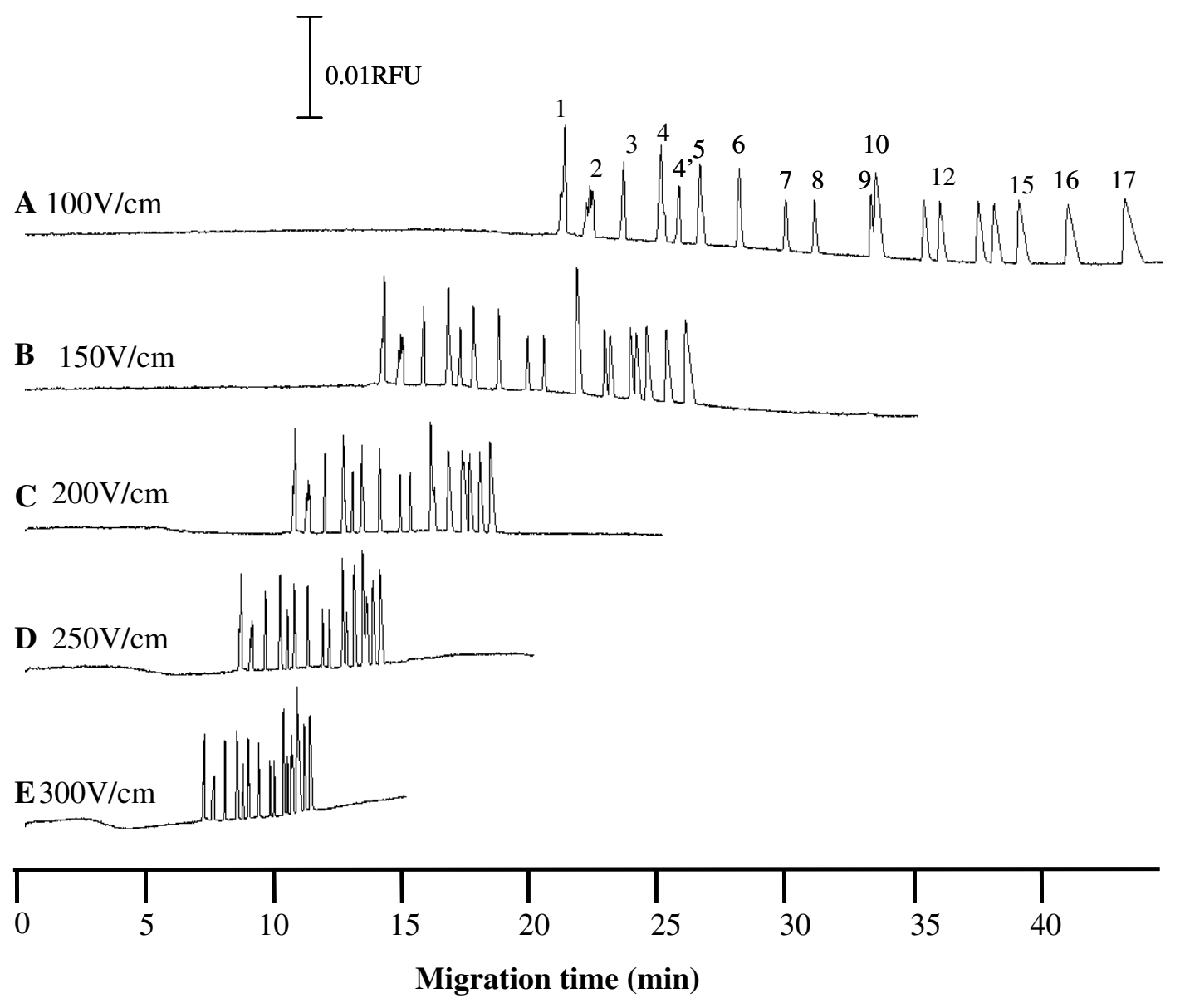

Figure 3-16 Separation of 50 bp dsDNA with q 2.5 - 15\% lipids in the capillary under different electric fields. The separation temperature was $25^{\circ} \mathrm{C}$. 


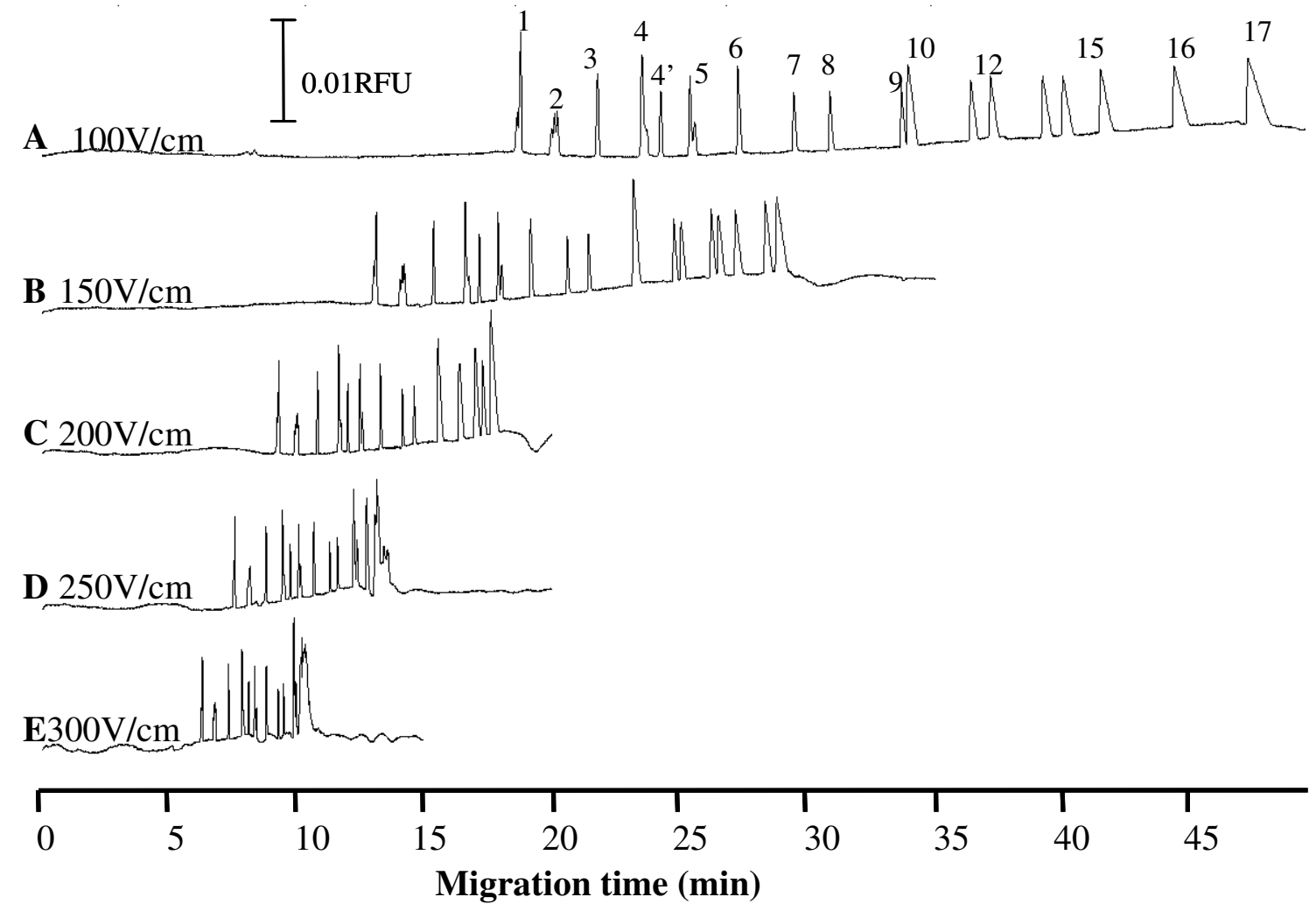

Figure 3-17 Separation of $50 \mathrm{bp}$ dsDNA with q 2.5 - $15 \%$ lipids in the capillary under different electric fields. The separation temperature was $33{ }^{\circ} \mathrm{C}$. 
Studies in Chapter 2 indicated that Joule heating was not significant for electric field strength less than $400 \mathrm{~V} / \mathrm{cm}$. Alternatively, the high electric field may affect the sizedependant mobility of DNA, which decreased the resolution. This behavior was also observed in sieving separations with polymer additives.

\subsubsection{Investigation of separation performance}

The factors investigated included electric field, temperature, and hydrations. The resolution was calculated and tabulated to illustrate quantitatively how these factors affected the separation performance. Among these factors, the electric field dominated the separation performance. As mentioned earlier, an electric field as low as $100 \mathrm{~V} / \mathrm{cm}$ was favorable for the separation of big fragments. However, the resolution was sacrificed for small fragments at this electric field strength.

As mentioned earlier, 50 bp dsDNA can be completely resolved at a temperature above $23{ }^{\circ} \mathrm{C}$. Two pairs of fragments, 50-100 bp, and 916-1350 bp were chosen as representatives to discuss the effect of temperature on separation above $23{ }^{\circ} \mathrm{C}$ in $100 \mathrm{~V} / \mathrm{cm}$ electric field. The data were plotted in Figure 3-18 and 3-19. The error bars drawn on the plots showed that there were some uncertainties with this set of data. However, there were general trends shown by these plots. For the $50-100$ bp pair, the resolution increased with increasing temperature from $25{ }^{\circ} \mathrm{C}$ to $33{ }^{\circ} \mathrm{C}$. However, the resolution for the bigger fragments 916$1350 \mathrm{bp}$ decreased when the temperature was increased at $33{ }^{\circ} \mathrm{C}$. As shown in Table 3-3, the maximum resolution obtained with $15 \%$ lipids was 1.6 fold of the resolution with $6 \%$ for the small fragments. For $916-1350 \mathrm{bp}$, a maximum resolution value obtained at $6 \%$ lipid is 1.3 fold of the maximum value obtained with 


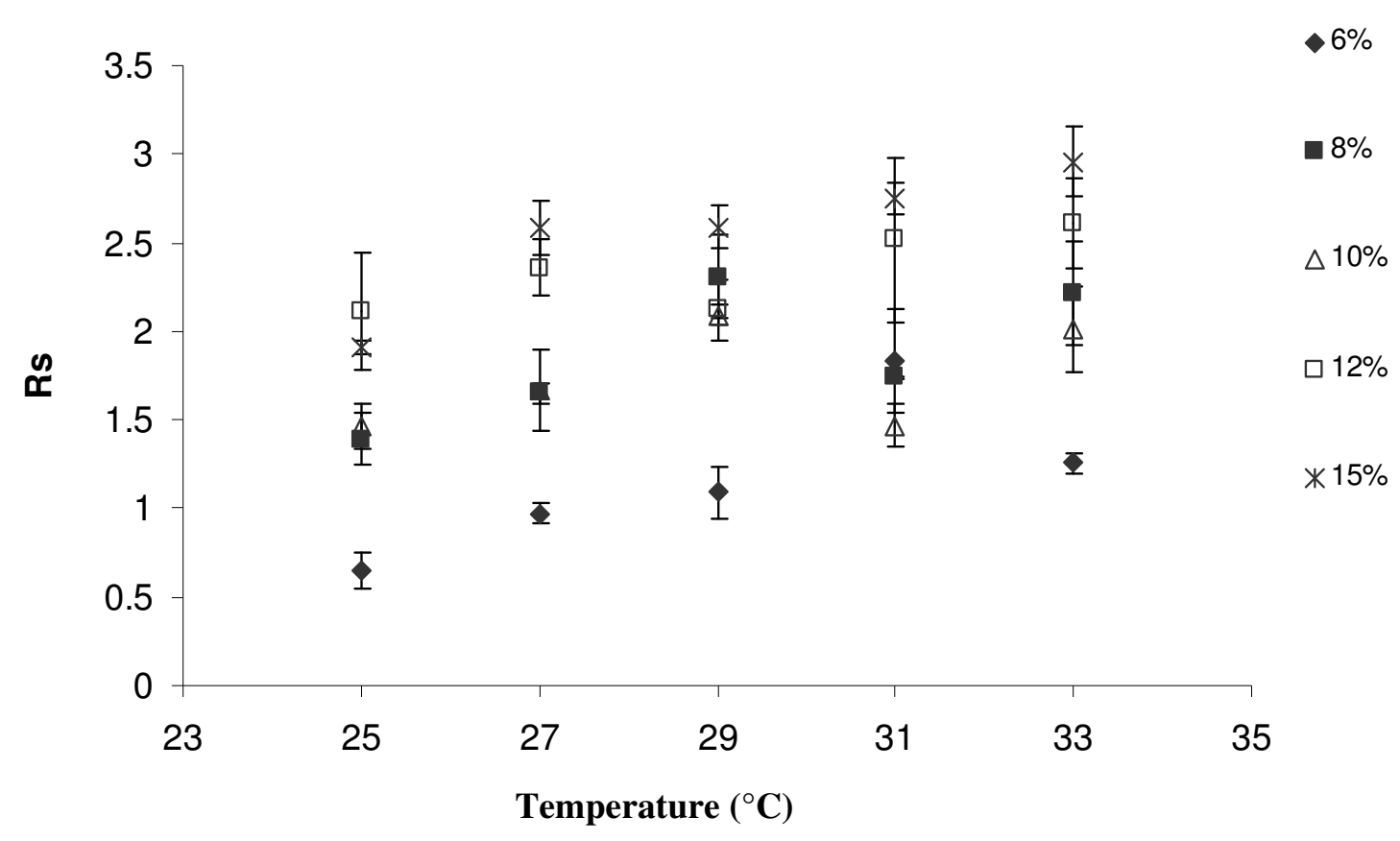

Figure 3-18 Comparison of resolutions (Rs) of $50 \mathrm{bp}$ and $100 \mathrm{bp}$ pair. The separation was carried out with q 2.5 lipids at the $100 \mathrm{~V} / \mathrm{cm}$ electric field. 


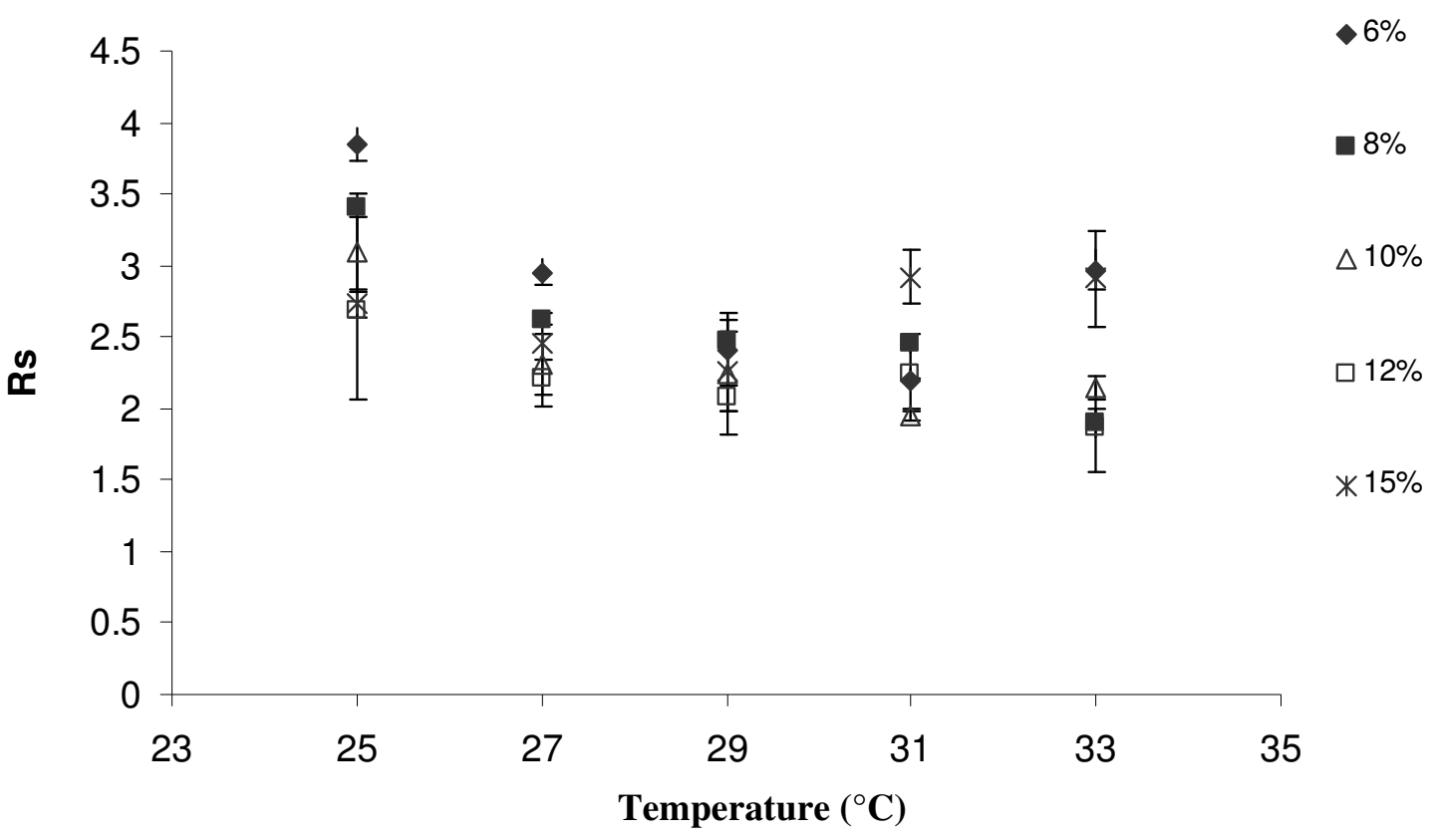

Figure 3-19 Comparison of resolutions (Rs) of 916 and $1350 \mathrm{bp}$. The separation was carried out with q 2.5 lipids at the $100 \mathrm{~V} / \mathrm{cm}$ electric field. 


\begin{tabular}{|c|c|c|c|c|c|c|c|c|c|c|}
\hline \multirow[b]{3}{*}{$\underset{25 c}{A}$} & \multicolumn{2}{|c|}{$6 \%$} & \multicolumn{2}{|c|}{$8 \%$} & \multicolumn{2}{|c|}{$10 \%$} & \multicolumn{2}{|c|}{$12 \%$} & \multicolumn{2}{|c|}{$15 \%$} \\
\hline & Rs & $\mathrm{RSD} \%$ & Rs & RSD\% & Rs & $\mathrm{SD} \%$ & Rs & $\mathrm{SD} \%$ & Rs & $\mathrm{SD} \%$ \\
\hline & 0.652 & 20 & 1.39 & 10 & 1.46 & 9 & 2.11 & 20 & 1.91 & 2 \\
\hline $27 c$ & 0.971 & 6 & 1.65 & 4 & 1.67 & 10 & 2.36 & 7 & 2.58 & 6 \\
\hline $29 c$ & 1.09 & 10 & 2.31 & 10 & 2.09 & 3 & 2.12 & 8 & 2.59 & 5 \\
\hline $31 c$ & 1.83 & 20 & 1.74 & 0.5 & 1.47 & 8 & 2.52 & 20 & 2.75 & 3 \\
\hline $33 c$ & 1.25 & 4 & 2.21 & 10 & 2.01 & 10 & 2.61 & 10 & 2.96 & 7 \\
\hline B & & & & & & & & & & \\
\hline $25 c$ & 3.85 & 3 & 3.40 & 3 & 3.09 & 8 & 2.68 & 20 & 2.73 & 3 \\
\hline $27 c$ & 2.95 & 3 & 2.63 & 2 & 2.31 & 9 & 2.22 & 9 & 2.46 & 5 \\
\hline $29 c$ & 2.41 & 10 & 2.47 & 6 & 2.24 & 20 & 2.09 & 5 & 2.26 & 10 \\
\hline $31 c$ & 2.20 & 9 & 2.45 & 3 & 1.95 & 2 & 2.24 & 1 & 2.91 & 6 \\
\hline $33 c$ & 2.97 & 5 & 1.90 & 5 & 2.14 & 4 & 1.86 & 20 & 2.91 & 10 \\
\hline
\end{tabular}

Table 3-3 Comparison of resolutions (Rs) for two pairs of fragments. A was for $50 \mathrm{bp}$ and $100 \mathrm{bp}$; B is for 916 and $1350 \mathrm{bp}$. The separation was carried out with q 2.5 lipids at the $100 \mathrm{~V} / \mathrm{cm}$ electric field. All data were based on triplet runs. 
$15 \%$ hydration. Other fragments were also investigated and yielded resolution intermediate to the 50-100 and 916-1350 pairs.

In summary, larger fragments were better resolved with a less concentrated lipid solution, while smaller fragments were better resolved with a concentrated lipid solution. This observation was analogous to the that observed with DNA separations in linear polymer $[18,62]$. The effects of temperature on the separation of smaller vs. larger fragments were also analogous to that observed with polymer additives, and suggested that the phospholipid additives formed smaller pores at high temperature. In the DNA separation with polymer solution, the best separation possibly occurred when the mesh size of polymer matrix is comparable to the size of DNA coils [62]. This theory was also applicable for the lipid matrix separations and was utilized to predict the pore size.

\subsubsection{Discussion of separation mechanism}

Understanding the separation mechanism is important for selection of separation conditions. A typical Ferguson plot as shown in Figure 3-20 was built from the data obtained at $33{ }^{\circ} \mathrm{C}$ and $100 \mathrm{~V} / \mathrm{cm}$. The linear relationship between $\log (\mu)$ and concentration of lipids suggested that Ogston sieving was occurring. However, the y-intercept (equal to log of DNA mobility in free solution) of the plot for fragments larger than $250 \mathrm{bp}$ was much smaller with the one for the fragments smaller than $250 \mathrm{bp}$, which implied that the larger fragments behaved differently in lipid solution. Figure 3-21 showed a plot of $\log (\mu)$ versus $\log (1 / \mathrm{N})$ (reptation plot). The plot in this figure revealed that DNA larger than 250 base pairs displayed a linear relationship between $\log (\mu)$ versus $\log (1 / \mathrm{N})$. A typical reptation plot should yield a slope $=1$. However, a value of 0.4 was obtained in our study. This value was much smaller than a typical reptation plot, 


\section{Ferguson plot}

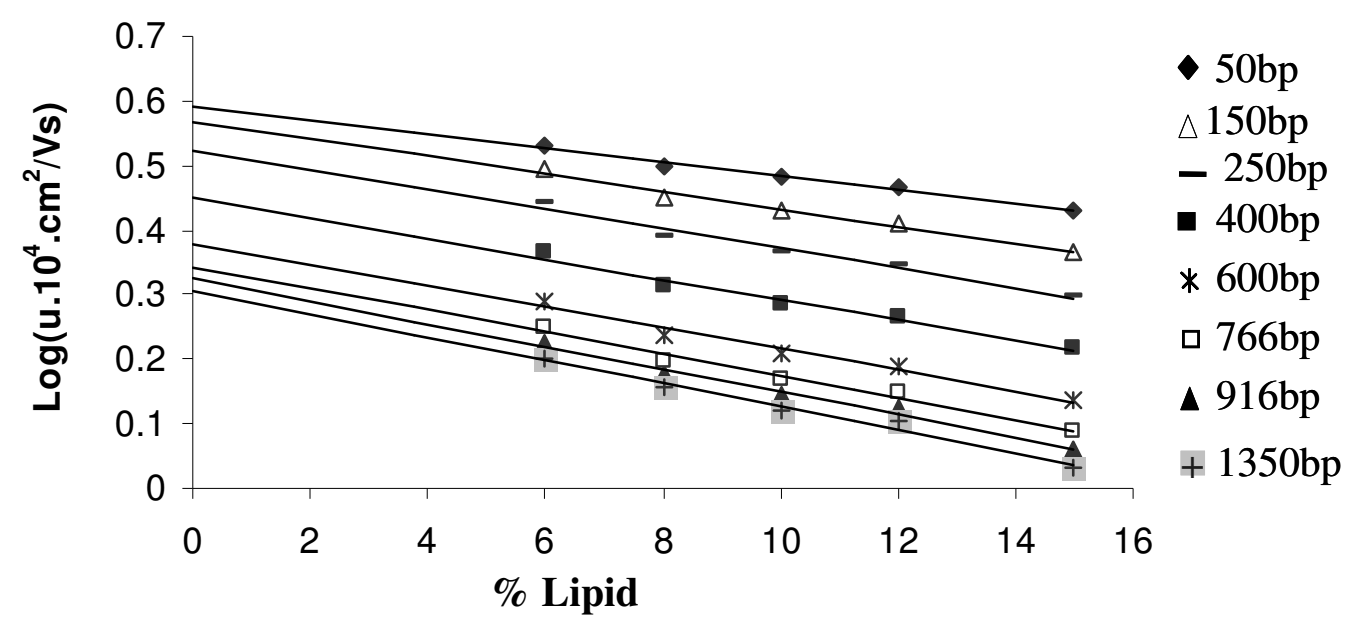

Figure 3-20 A typical Ferguson plot of 50bp dsDNA. The separation was carried out at $33{ }^{\circ} \mathrm{C}$ in the $100 \mathrm{~V} / \mathrm{cm}$ electric field. $\mathrm{N}$ is the number of base pair. 


\section{Ferguson plot}

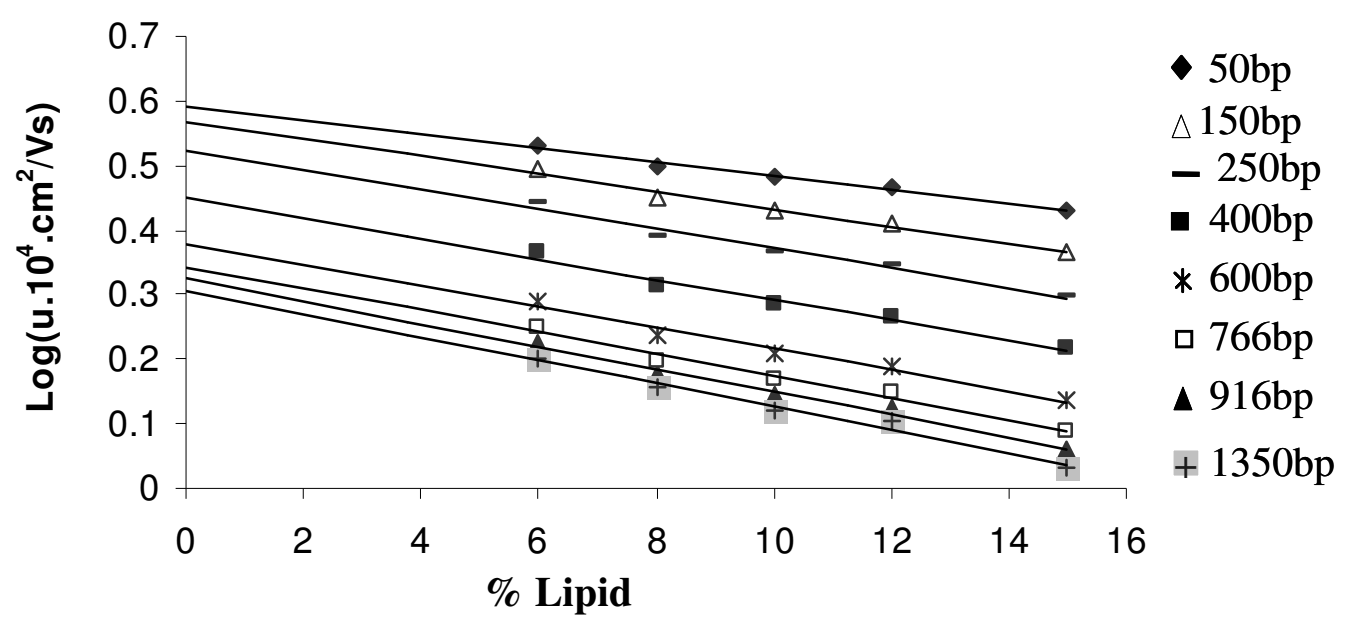

Figure 3-21 Reptation plot for separation of $50 \mathrm{bp}$ dsDNA. The separation was carried out at $33{ }^{\circ} \mathrm{C}$ in the $100 \mathrm{~V} / \mathrm{cm}$ electric field. $\mathrm{N}$ is the number of base pair. 
which meant pure reptation was not possible for big fragments [53]. The biggest fragment, $1350 \mathrm{bp}$ deviated away the reptation line. Biased reptation with fluctuation of $1350 \mathrm{bp}$ fragment could be the reason of deviation because $1350 \mathrm{bp}$ fragment exhibited mobility close to that of the $916 \mathrm{bp}$ fragment.

Valuable information delivered by Ferguson plot was the mean pore size of phospholipid solution. A standard equation as shown below was applied to calculate the average pore size: $\mathrm{R}_{\mathrm{G}}=\left\langle\mathrm{R}_{\mathrm{g}}{ }^{2}\right\rangle^{1 / 2}=\left((p \mathrm{~L} / 3)[1-p / \mathrm{L}+p / \mathrm{L}[\exp (-\mathrm{L} / p)])^{1 / 2}\right.$

Where $p$ is the persistence length and equals to $50 \mathrm{~nm}, \mathrm{~L}$ is the contour length of DNA fragment and equals \# bp $\times 0.34 \mathrm{~nm}$ [78-79]. The slopes of Ferguson plot obtained from our research were close among fragments smaller than $250 \mathrm{bp}$. The fragments larger than $250 \mathrm{bp}$ gave a different slope. Therefore, $250 \mathrm{bp}$ was used for the calculation of pore size. The contour length of $250 \mathrm{bp}$ fragment is $85 \mathrm{~nm}$. By fitting this data into the equation, the mean pore size obtained for the phospholipids used was $\sim 29 \mathrm{~nm}$. This value was close to the reported pore size $(\sim 27 \mathrm{~nm})$ of the polymer solution employed for the separation of a similar DNA ladder [80].

\subsubsection{Conclusion.}

As demonstrated in this study, phospholipids were effective as buffer additives in capillary electrophoresis for the separation of DNA. The results showed some similarities with DNA separation in polymer solutions. The concentrated lipids gave better separation of small DNA fragments, while more dilute lipids were suitable for the separation of bigger fragments. The temperature above $23{ }^{\circ} \mathrm{C}$ showed opposite effect on small and big DNA fragments. An electric field as low as $100 \mathrm{~V} / \mathrm{cm}$ resulted in best resolution than higher 
electric field. Other lipid concentration or q values may also be useful and should be investigated for DNA separation. 


\section{References}

1. Klepárník, K. and Boček, P., DNA diagnostics by capillary electrophoresis. Chemical Reviews, 2007. 107(11): p. 5279-5317.

2. Lerman, L.S. and Frisch, H.L., Why does the electrophoretic mobility of DNA in gels vary with the length of the molecule? Biopolymers, 1982. 21(5): p. 995-997.

3. Schellman, J.A. and Stigter, D., Electrical double layer, zeta potential, and electrophoretic charge of double-stranded DNA. Biopolymers, 1977. 16(7): p. 14151434.

4. Ettre, L.S., The evolution of capillary gel electrophoresis: From proteins to DNA sequencing. LC-GC North America, 2004. 22(9): p. 896-904.

5. Brody, J.R. and Kern, S.E., History and principles of conductive media for standard DNA electrophoresis. Analytical Biochemistry, 2004. 333(1): p. 1-13.

6. Andrews, A.T., Electrophoresis : Theory, techniques, and biochemical and clinical applications. Vol. Clarenden Press ; New York : Oxford University Press. 1986.

7. Rickwood, D. and Hames, B.D., Gel electrophoresis of nucleic acids : A practical approach. Irl press, washington, d.C. 1983.

8. Guttman, A., Gel and polymer-solution mediated separation of biopolymers by capillary electrophoresis. Journal of Chromatographic Science, 2003. 41: p. 449-459.

9. Hjertén, S., Elenbring, K., Kilár, F., Liao, J.-L., Chen, A.J.C., Siebert, C.J., and Zhu, M.-D., Carrier-free zone electrophoresis, displacement electrophoresis and isoelectric focusing in a high-performance electrophoresis apparatus. Journal of Chromatography A, 1987. 403: p. 47-61. 
10. Guttman, A., Cohen, A.S., Heiger, D.N., and Karger, B.L., Analytical and micropreparative ultrahigh resolution of oligonucleotides by polyacrylamide gel high-performance capillary electrophoresis. Analytical Chemistry, 1990. 62(2): p. $137-141$.

11. Motsch, S.R., Kleemiß, M.-H., and Schomburg, G., Production and application of capillaries filled with agarose gel for electrophoresis. Journal of High Resolution Chromatography, 1991. 14(9): p. 629-632.

12. Zhao, D.S., Roy, B., McCormick, M.T., Kuhr, W.G., and Brazill, S.A., Rapid fabrication of a poly(dimethylsiloxane) microfluidic capillary gel electrophoresis system utilizing high precision machining. Lab on a Chip, 2003. 3(2): p. 93-99.

13. Zhu, M., Hansen, D.L., Burd, S., and Gannon, F., Factors affecting free zone electrophoresis and isoelectric focusing in capillary electrophoresis. Journal of Chromatography A, 1989. 480: p. 311-319.

14. Barbier, V. and Viovy, J.-L., Advanced polymers for DNA separation. Current Opinion in Biotechnology, 2003. 14(1): p. 51-57.

15. $\mathrm{Xu}, \mathrm{F}$. and Baba, Y., Polymer solutions and entropic-based systems for doublestranded DNA capillary electrophoresis and microchip electrophoresis. Electrophoresis, 2004. 25(14): p. 2332-2345.

16. Marshall, E. and Pennisi, E., Hubris and the human genome. science, 1998. 280(5366): p. 994.

17. Henry, C., Medicine prize recognizes mri Chemical \& Engineering News 2003. 81(41): p. 12. 
18. Barron, A.E., Sunada, W.M., and Blanch, H.W., The effects of polymer properties on DNA separations by capillary electrophoresis in uncross-linked polymer solutions. Electrophoresis, 1996. 17(4): p. 744-757.

19. Carrilho, E., Ruiz-Martinez, M.C., Berka, J., Smirnov, I., Goetzinger, W., Miller, A.W., Brady, D., and Karger, B.L., Rapid DNA sequencing of more than 1000 bases per run by capillary electrophoresis using replaceable linear polyacrylamide solutions. Analytical Chemistry, 1996. 68(19): p. 3305-3313.

20. Fung, E.N. and Yeung, E.S., High-speed DNA sequencing by using mixed poly(ethylene oxide) solutions in uncoated capillary columns. Analytical Chemistry, 1995. 67(13): p. 1913-1919.

21. Zhang, N. and Yeung, E.S., Genetic typing by capillary electrophoresis with the allelic ladder as an absolute standard. Analytical Chemistry, 1996. 68(17): p. 29272931.

22. Gao, Q. and Yeung, E.S., A matrix for DNA separation: Genotyping and sequencing using poly(vinylpyrrolidone) solution in uncoated capillaries. Analytical Chemistry, 1998. 70(7): p. 1382-1388.

23. Barta, C., Ronai, Z., Sasvari-Szekely, M., and Guttman, A., Rapid single nucleotide polymorphism analysis by primer extension and capillary electrophoresis using polyvinyl pyrrolidone matrix. Electrophoresis, 2001. 22(4): p. 779-782.

24. Menchen, S., Johnson, B., Winnik, M.A., and Xu, B., Flowable networks as DNA sequencing media in capillary columns. Electrophoresis, 1996. 17(9): p. 1451-1459. 
25. Liu, Y. and Kuhr, W.G., Separation of double- and single-stranded DNA restriction fragments: Capillary electrophoresis with polymer solutions under alkaline conditions. Analytical Chemistry, 1999. 71(9): p. 1668-1673.

26. Barron, A.E., Soane, D.S., and Blanch, H.W., Capillary electrophoresis of DNA in uncross-linked polymer solutions. Journal of Chromatography A, 1993. 652(1): p. 316.

27. Baba, Y., Ishimaru, N., Samata, K., and Tsuhako, M., High-resolution separation of DNA restriction fragments by capillary electrophoresis in cellulose derivative solutions. Journal of Chromatography A, 1993. 653(2): p. 329-335.

28. Rill, R.L., Liu, Y., Van Winkle, D.H., and Locke, B.R., Pluronic copolymer liquid crystals: Unique, replaceable media for capillary gel electrophoresis. Journal of Chromatography A, 1998. 817(1-2): p. 287-295.

29. Zhang, J., Fang, Y., Hou, J.Y., Ren, H.J., Jiang, R., Roos, P., and Dovichi, N.J., Use of non-cross-linked polyacrylamide for four-color DNA sequencing by capillary electrophoresis separation of fragments up to 640 bases in length in two hours. Analytical Chemistry, 1995. 67(24): p. 4589-4593.

30. Chiari, M., Micheletti, C., Nesi, M., Fazio, M., and Righetti, P.G., Towards new formulations for polyacrylamide matrices: $<i>n</ i>$-acryloylaminoethoxyethanol, a novel monomer combining high hydrophilicity with extreme hydrolytic stability. Electrophoresis, 1994. 15(1): p. 177-186.

31. Simò-Alfonso, E., Gelfi, C., Sebastiano, R., Citterio, A., and Righetti, P.G., Novel acrylamido monomers with higher hydrophilicity and improved hydrolytic stability: I. 
Synthetic route and product characterization. Electrophoresis, 1996. 17(4): p. 723731.

32. Goetzinger, W., Kotler, L., Carrilho, E., Ruiz-Martinez, M.C., Salas-Solano, O., and Karger, B.L., Characterization of high molecular mass linear polyacrylamide powder prepared by emulsion polymerization as a replaceable polymer matrix for DNA sequencing by capillary electrophoresis. Electrophoresis, 1998. 19(2): p. 242-248.

33. Sassi, A.P., Barron, A., Alonso-Amigo, M.G., Hion, D.Y., Yu, J.S., Soane, D.S., and Hooper, H.H., Electrophoresis of DNA in novel thermoreversible matrices. Electrophoresis, 1996. 17(9): p. 1460-1469.

34. Bashkin, J., Marsh, M., Barker, D., and Johnston, R., DNA sequencing by capillary electrophoresis with a hydroxyethylcellulose sieving buffer. Applied and Theoretical Electrophoresis 1996. 6: p. 23-28.

35. Albarghouthi, M.N. and Barron, A.E., Polymeric matrices for DNA sequencing by capillary electrophoresis. Electrophoresis, 2000. 21(18): p. 4096-4111.

36. Buchholz, B.A., Doherty, E.A.S., Albarghouthi, M.N., Bogdan, F.M., Zahn, J.M., and Barron, A.E., Microchannel DNA sequencing matrices with a thermally controlled “viscosity switch”. Analytical Chemistry, 2000. 73(2): p. 157-164.

37. Liang, D., Song, L., Zhou, S., Zaitsev, V.S., and Chu, B., Poly $(<i>n</ i>-$ isopropylacrylamide)- $<i>g</ i>$-poly(ethyleneoxide) for high resolution and high speed separation of DNA by capillary electrophoresis. Electrophoresis, 1999. 20(14): p. $2856-2863$. 
38. Liang, D., Zhou, S., Song, L., Zaitsev, V.S., and Chu, B., Copolymers of poly $(n-$ isopropylacrylamide) densely grafted with poly(ethylene oxide) as high-performance separation matrix of DNA. Macromolecules, 1999. 32(19): p. 6326-6332.

39. Wu, C., Liu, T., Chu, B., Schneider, D.K., and Graziano, V., Characterization of the peo-ppo-peo triblock copolymer and its application as a separation medium in capillary electrophoresis. Macromolecules, 1997. 30(16): p. 4574-4583.

40. Wei and Yeung, E.S., DNA capillary electrophoresis in entangled dynamic polymers of surfactant molecules. Analytical Chemistry, 2001. 73(8): p. 1776-1783.

41. Grosser, S.T., Savard, J.M., and Schneider, J.W., Identification of pcr products using pna amphiphiles in micellar electrokinetic chromatography. Analytical Chemistry, 2007. 79(24): p. 9513-9519.

42. Huang, M.-F., Kuo, Y.-C., Huang, C.-C., and Chang, H.-T., Separation of long double-stranded DNA by nanoparticle-filled capillary electrophoresis. Analytical Chemistry, 2003. 76(1): p. 192-196.

43. Zheng, J. and Yeung, E.S., Anomalous radial migration of single DNA molecules in capillary electrophoresis. Analytical Chemistry, 2002. 74(17): p. 4536-4547.

44. Han, J. and Craighead, H.G., Characterization and optimization of an entropic trap for DNA separation. Analytical Chemistry, 2001. 74(2): p. 394-401.

45. Mayer, P., Slater, G.W., and Drouin, G., Theory of DNA sequencing using freesolution electrophoresis of protein-DNA complexes. Analytical Chemistry, 1994. 66(10): p. 1777-1780. 
46. Meagher, R.J., Won, J.-I., McCormick, L.C., Nedelcu, S., Bertrand, M.M., Bertram, J.L., Drouin, G., Barron, A.E., and Slater, G.W., End-labeled free-solution electrophoresis of DNA. Electrophoresis, 2005. 26(2): p. 331-350.

47. Meagher, R.J., McCormick, L.C., Haynes, R.D., Won, J.-I., Lin, J.S., Slater, G.W., and Barron, A.E., Free-solution electrophoresis of DNA modified with drag-tags at both ends. Electrophoresis, 2006. 27(9): p. 1702-1712.

48. Ogston, A.G., The spaces in a uniform random suspension of fibres. Transactions of the Faraday Society 1958. 54: p. 1754 - 1757.

49. Ferguson, K.A., Starch-gel electrophoresis; application to the classification of pituitary proteins and polypeptides Metabolism, Clinical and Experimental, 1964. 13(10): p. 985-1002.

50. de Gennes, P.G., Scaling concepts in polymer physics. 1979: cornell university press.

51. Doi, M. and Edwards, S.F., Dynamics of concentrated polymer systems. Part 1.brownian motion in the equilibrium state. Journal of the Chemical Society, Faraday Transactions 2: Molecular and Chemical Physics 1978. 74: p. 1789 - 1801.

52. Grossman, P.D. and Soane, D.S., Experimental and theoretical studies of DNA separations by capillary electrophoresis in entangled polymer solutions. biopolymers, 1991. 31(10): p. 1221-1228.

53. Lumpkin, O.J., Déjardin, P., and Zimm, B.H., Theory of gel electrophoresis of DNA. biopolymers, 1985. 24(8): p. 1573-1593.

54. Duke, T., Viovy, J.-L., and Semenov, A.N., Electrophoretic mobility of DNA in gels. I. New biased reptation theory including fluctuations. biopolymers, 1994. 34(2): p. 239-247. 
55. Ronai, Z., Barta, C., Sasvari-Szekely, M., and Guttman, A., DNA analysis on electrophoretic microchips: Effect of operational variables. Electrophoresis, 2001. 22(2): p. 294-299.

56. Tietz, D., Gottlieb, M.H., Fawcett, J.S., and Chrambach, A., Electrophoresis on uncrosslinked polyacrylamide: Molecular sieving and its potential applications. Electrophoresis, 1986. 7(5): p. 217-220.

57. Heiger, D.N., Cohen, A.S., and Karger, B.L., Separation of DNA restriction fragments by high performance capillary electrophoresis with low and zero crosslinked polyacrylamide using continuous and pulsed electric fields. Journal of Chromatography A, 1990. 516(1): p. 33-48.

58. Smith, S., Aldridge, P., and Callis, J., Observation of individual DNA molecules undergoing gel electrophoresis. science, 1989. 243(4888): p. 203-206.

59. Carlsson, C., Larsson, A., Jonsson, M., and Norden, B., Dancing DNA in capillary solution electrophoresis. Journal of the American Chemical Society, 1995. 117(13): p. 3871-3872.

60. Shi, X., Hammond, R.W., and Morris, M.D., DNA conformational dynamics in polymer solutions above and below the entanglement limit. Analytical Chemistry, 1995. 67(6): p. 1132-1138.

61. Sunada, W.M. and Blanch, H.W., A theory for the electrophoretic separation of DNA in polymer solutions. Electrophoresis, 1998. 19(18): p. 3128-3136.

62. Slater, G.W., Kenward, M., McCormick, L.C., and Gauthier, M.G., The theory of DNA separation by capillary electrophoresis. Current Opinion in Biotechnology, 2003. 14(1): p. 58-64. 
63. Slater, G.W., Guillouzic, S., Gauthier, M.G., Mercier, J.-F., Kenward, M., McCormick, L.C., and Tessier, F., Theory of DNA electrophoresis (sim 1999 2002 1/2). Electrophoresis, 2002. 23(22-23): p. 3791-3816.

64. Luo, R., Archer-Hartmann, S.A., and Holland, L.A., Transformable capillary electrophoresis for oligosaccharide separations using phospholipid additives. Analytical Chemistry, 2010. 82(4): p. 1228-1233.

65. Kan, C.W. and Barron, A.E., A DNA sieving matrix with thermally tunable mesh size. Electrophoresis, 2003. 24(1-2): p. 55-62.

66. Schwinefus, J.J., Band broadening during $d c$ and field inversion capillary electrophoresis of DNA in dilute hydroxyethylcellulose solutions. analyst, 1998. 123: p. $1481-1485$.

67. Kim, Y. and Morris, M.D., Pulsed field capillary electrophoresis of multikilobase length nucleic acids in dilute methyl cellulose solutions. Analytical Chemistry, 1994. 66(19): p. 3081-3085.

68. Madabhushi, R.S., Vainer, M., Dolnik, V., Enad, S., Barker, D.L., Harris, D.W., and Mansfield, E.S., Versatile low-viscosity sieving matrices for nondenaturing DNA separations using capillary array electrophoresis. Electrophoresis, 1997. 18(1): p. 104-111.

69. Sun, Y., Kwok, Y., and Nguyen, N.-T., Modeling and experimental characterization of peak tailing in DNA gel electrophoresis. Microfluidics and Nanofluidics, 2007. 3(3): p. 323-332. 
70. Pappas, T.J. and Holland, L.A., Fluid steering in a microfluidic chip by means of thermally responsive phospholipids. Sensors and Actuators B: Chemical, 2008. 128(2): p. 427-434.

71. Salas-Solano, O., Carrilho, E., Kotler, L., Miller, A.W., Goetzinger, W., Sosic, Z., and Karger, B.L., Routine DNA sequencing of 1000 bases in less than one hour by capillary electrophoresis with replaceable linear polyacrylamide solutions. Analytical Chemistry, 1998. 70(19): p. 3996-4003.

72. Zhou, H., Miller, A.W., Sosic, Z., Buchholz, B., Barron, A.E., Kotler, L., and Karger, B.L., DNA sequencing up to 1300 bases in two hours by capillary electrophoresis with mixed replaceable linear polyacrylamide solutions. Analytical Chemistry, 2000. 72(5): p. 1045-1052.

73. Hervet, H. and Bean, C.P., Electrophoretic mobility of lambda phage hind iii and hae iii DNA fragments in agarose gels: A detailed study. Biopolymers, 1987. 26(5): p. $727-742$.

74. Fisher, M.P. and Dingman, C.W., Role of molecular conformation in determining the electrophoretic properties of polynucleotides in agarose-acrylamide composite gels. Biochemistry, 1971. 10(10): p. 1895-1899.

75. Flint, D.H. and Harrington, R.E., Gel electrophoresis of deoxyribonucleic acid. Biochemistry, 1972. 11(25): p. 4858-4864.

76. Southern, E.M., Measurement of DNA length by gel electrophoresis. Analytical Biochemistry, 1979. 100(2): p. 319-323.

77. Guttman, A. and Cooke, N., Capillary gel affinity electrophoresis of DNA fragments. Analytical Chemistry, 1991. 63(18): p. 2038-2042. 
78. Benoit, H. and Doty, P., Light scattering from non-gaussian chains. The Journal of Physical Chemistry, 1953. 57(9): p. 958-963.

79. Holmes, D.L. and Stellwagen, N.C., Estimation of polyacrylamide gel pore size from ferguson plots of normal and anomalously migrating DNA fragments. I. Gels containing $3 \%$ n, nprime-methylenebisacrylamide. Electrophoresis, 1991. 12(4): p. 253-263.

80. Grossman, P.D. and Soane, D.S., Capillary electrophoresis of DNA in entangled polymer solutions. Journal of Chromatography A, 1991. 559(1-2): p. 257-266. 
Chapter 4: Summary and Future Direction 


\subsubsection{Summary of carbohydrate and DNA separation in chapter 2 and 3}

Phospholipid additives were effective for oligosaccharide separation. The separation performance was characterized for linear and branched glycans with theoretical plate count, resolution, and reproducibility. The q 2.5 - 10\% preparation provided the most reproducible separation at $25{ }^{\circ} \mathrm{C}$ and the highest resolution and theoretical plate count. This was apparent in the separation of FII and AII glycans which were not resolved by free solution CE, but they are well separated with q $2.5-10 \%$.

Phospholipid additives were also an effective separation media for DNA. Capillary electrophoresis separations accomplished with phospholipid additives displayed similar behavior to those obtained with polymer solution. Estimation of pore size by using traditional methods suggested that the phosphlipid morphology has an apparent pore size of $29 \mathrm{~nm}$.

\subsubsection{Future direction}

These findings are exciting and open other areas for research. The investigation of glycans described in Chapter 2 focused on phospholipid hydration of 5\%, 10\%, and $15 \%$. The resolution should be tested at additional hydration values between 5 and $10 \%$ as well as 10 and $15 \%$. In the study discussed in chapter two, the sialic acids on both AGP and fetuin glycans were removed. With the knowledge learned from this chapter, naturally occurring sialoglycans present in both glycoproteins should be separated with phospholipid additives. This will increase the complexity of glycan content from fetuin to 23 sialoglycans, as compared to the three asialoglycan characterized in Chapter 2 [1]. AGP should yield over 20 sialoglycans [2]. Screening these more complicated glycan pools will be more challenging. Glycans from other glycoproteins are also of interest and should be addressed in the future as 
well. The separation of glycoforms of glycoproteins should also be possible. With an unlimited budget, expensive glycan standards could be purchased which would speed up the process of glycan identification. The biocompatibility of phospholipid additives has already been used for the passivation of the capillary surface [3] [4] [5]. Another benefit of phospholipids coatings is that proteins can be introduced into the separation capillary without denaturation. The use of phospholipid additives to facilitate the separation of DNA should be investigated at other values of lipid hydration between $6 \%$ and $15 \%$. Other q values should also be investigated since the $\mathrm{q}$ values determine the size of lipid aggregates and should form different apparent pore size. In polymer separation of DNA, low molecular weight polymers are used for the separation of small DNA and high molecular weight polymers are used for separation of larger DNA [6-7]. Different q values may be better for different lengths of DNA.

Separation of single stranded DNA should also be characterized in future studies. Although some preliminary studies have been conducted, further experiments must be performed. Highly viscous polymer solutions are more favorable for single stranded DNA separation [8-10]. Based on this observation, the most viscous phospholipids preparations should be considered as the first choice for single stranded DNA separation. This might require highly concentrated phospholipid solutions. 


\section{References}

1. Green, E.D., Adelt, G., Baenziger, J.U., Wilson, S., and Van Halbeek, H., The asparagine-linked oligosaccharides on bovine fetuin. Structural analysis of nglycanase-released oligosaccharides by 500-megahertz, $1 \mathrm{~h} \mathrm{nmr} \mathrm{spectroscopy.} \mathrm{Journal}$ of Biological Chemistry, 1988. 263(34): p. 18253-18268.

2. Shiyan, S. and Bovin, N., Carbohydrate composition and immunomodulatory activity of different glycoforms of al-acid glycoprotein. Glycoconjugate Journal, 1997. 14(5): p. 631-638.

3. Wang, C. and Lucy, C.A., Oligomerized phospholipid bilayers as semipermanent coatings in capillary electrophoresis. Analytical Chemistry, 2005. 77(7): p. 20152021.

4. White, C.M., Luo, R., Archer-Hartmann, S.A., and Holland, L.A., Electrophoretic screening of ligands under suppressed eof with an inert phospholipid coating. Electrophoresis, 2007. 28(17): p. 3049-3055.

5. Ross, E.E., Mansfield, E., Huang, Y., and Aspinwall, C.A., In situ fabrication of three-dimensional chemical patterns in fused silica separation capillaries with polymerized phospholipids. Journal of the American Chemical Society, 2005. 127(48): p. $16756-16757$.

6. Grossman, P.D. and Soane, D.S., Capillary electrophoresis of DNA in entangled polymer solutions. Journal of Chromatography A, 1991. 559(1-2): p. 257-266.

7. Bergman, M., Claessens, H., and Cramers, C., Properties of entangled polymer solutions in high-performance capillary electrophoresis. Journal of Microcolumn Separations, 1998. 10(1): p. 19-26. 
8. Gennes, P.-G.d., Scaling concepts in polymer physics. 1979: Ithaca, N.Y. : Cornell University Press.

9. Barron, A.E., Soane, D.S., and Blanch, H.W., Capillary electrophoresis of DNA in uncross-linked polymer solutions. Journal of Chromatography A, 1993. 652(1): p. 316.

10. Barron, A.E., Sunada, W.M., and Blanch, H.W., The effects of polymer properties on DNA separations by capillary electrophoresis in uncross-linked polymer solutions. Electrophoresis, 1996. 17(4): p. 744-757. 


\section{RESUME}

NAME: Luo, Ruijuan

EMAIL: rluo1@mix.wvu.eduＰHONE NUMBER: 304-906-9324

\section{EDUCATION:}

2005-now: Ph.D. candidate, Analytical Chemistry, Holland Research Group,

West Virginia University, WV, USA

2003-2005: M.S. student, Organic Chemistry, Lanzhou University, China

1998-2002: B.S. Chemistry, Lanzhou University, China

\section{$\underline{\text { PUBLICATIONS }}$}

1. Luo, Ruijuan.; Archer-Hartmann, Stephanie A.; Holland, Lisa A. "Transformable Capillary Electrophoresis for Oligosaccharide Separations Using Phospholipid Additives", Analytical. Chemistry. 2010, 82, 1228-1233.

2. Luo, Ruijuan.; Holland, Lisa. A. "Phospholipids Used as New Matrices for DNA Separation on Capillary Electrophoresis”, in manuscript

3. White, Christian. M.; Luo, Ruijuan.; Archer-Hartmann, Stephanie A.; Holland, Lisa A. "Electrophoretic Selection and Screening of Potential Ligands under Suppressed Electroosmotic Flow with an Inert Phospholipid Coating", Electrophoresis, 2007, 28, 3049-3055.

4. Luo, Ruijuan.; Langan, Ted.; Holland, Lisa. A. "Capillary Electrophoresis Distance Learning Program: Guided Discovery on the Principles, Assembly ", Learning Module 3 and 4, December 2006, Analytical Sciences Digital Library ASDL Library.

5. Zhou, Yulu.; Luo, Ruijuan.; Liu, Qiang.; Wu, Longmin. "Photoreduction of N-Nitrosodiphenyl- Amines with Aromatic Amines", 4th National Organic Chemistry Conference, P.R. China, Chin. J. Org. Chem. 2005, 25, suppl, 447.

\section{PRESENTATIONS}


1. Luo, Ruijuan.; Holland, Lisa A. "Capillary Electrophoesis Separation of Carbohydrates". 61th Pittsburgh Conference on Analytical Chemistry and Applied Spectroscopy, Orlando, Florida, March 2010.

2. Luo, Ruijuan.; Holland, Lisa A. "Capillary Electrophoresis Separation of Glycans Derived from Glycoprotein by Using Phospholipid as Sieving Media".

59th Pittsburgh Conference on Analytical Chemistry and Applied Spectroscopy, New Orleans, LA, March 2008

3. Luo, Ruijuan.; Holland, Lisa A. "Capillary Electrophoesis Separation of Carbohydrates". 58th Pittsburgh Conference on Analytical Chemistry and Applied Spectroscopy, Chicago, Illinois, February 2007.

\section{$\underline{\text { HONOR }}$}

ACS membership 